\title{
GERENCIAMENTO DE FROTAS DO TRANSPORTE RODOVIÁRIO DE CARGAS UTILIZANDO SISTEMAS DE RASTREAMENTO POR SATÉLITE
}

\author{
LiLian Cristina Anefalos
}

Dissertação apresentada à Escola Superior de

Agricultura "Luiz de Queiroz", Universidade de São Paulo, para obtenção do título de Mestre em Ciências, Área de Concentração: Economia Aplicada.

P I R A C I C A B A

Estado de São Paulo - Brasil

Maio - 1999 


\title{
GERENCIAMENTO DE FROTAS DO TRANSPORTE RODOVIÁRIO DE CARGAS UTILIZANDO SISTEMAS DE RASTREAMENTO POR SATÉLITE
}

\author{
LiLian Cristina Anefalos
}

Dissertação apresentada à Escola Superior de

Agricultura "Luiz de Queiroz", Universidade de São Paulo, para obtenção do título de Mestre em Ciências, Área de Concentração: Economia Aplicada.

P I R A C I C A B A

Estado de São Paulo - Brasil

Maio - 1999 


\title{
GERENCIAMENTO DE FROTAS DO TRANSPORTE RODOVIÁRIO DE CARGAS UTILIZANDO SISTEMAS DE RASTREAMENTO POR SATÉLITE
}

\author{
LiLian CRistina Anefalos
}

Engenheiro Agrônomo

Orientador: Prof. Dr. JOSÉ VICENTE CAIXETA FILHO

\author{
Dissertação apresentada à Escola Superior de \\ Agricultura "Luiz de Queiroz", Universidade de \\ São Paulo, para obtenção do título de Mestre em \\ Ciências, Área de Concentração: Economia \\ Aplicada \\ P I R A C I C A B A \\ Estado de São Paulo - Brasil \\ Maio - 1999
}


Dados Internacionais de Catalogação na Publicação (CIP)

DIVISÃO DE BIBLIOTECA E DOCUMENTAÇÃO - Campus “Luiz de Queiroz"/USP

Anefalos, Lilian Cristina

Gerenciamento de frotas do transporte rodoviário de cargas utilizando sistemas de rastreamento por satélite / Lilian Cristina Anefalos. - - Piracicaba, 1999.

134 p. : il.

Dissertação (mestrado) - - Escola Superior de Agricultura Luiz de Queiroz, 1999.

Bibliografia.

1. Economia de transportes 2. Rastreamento 3. Satélite 4. Segurança do trabalho 5 . Sensoriamento remoto 6 . Tecnologia da informação 7 . Transporte rodoviário de carga I. Título

CDD 388.1

"Permitida a cópia total ou parcial deste documento, desde que citada a fonte - O Autor" 
Aos meus pais Homero e Laila e à minha filha Yasmin 


\section{AGRADECIMENTOS}

À CAPES, à ESALQ e ao IEA, pelo apoio institucional e financeiro em todas as etapas deste estudo.

Ao Prof. Dr. José Vicente Caixeta Filho, por sua orientação e dedicação, que foram decisivas para o bom andamento desta dissertação e para o meu aprimoramento profissional.

Ao Prof. Rodolfo Hoffman, à Prof ${ }^{\mathrm{a}}$ Zilda Paes de Barros Mattos e ao Pesquisador Científico José Roberto Vicente, por terem contribuído para o enriquecimento teórico desta pesquisa.

Ao assessor técnico da NTC Neuto Gonçalves dos Reis, ao Pesquisador Científico Francisco Alberto Pino e ao Prof. Hilton Thadeu Z. Couto, por terem colaborado na fase de formulação do questionário e delineamento da amostra.

Ao Prof. Heitor T. Kato, à doutoranda Suely de Fátima Ramos Silveira e aos Pesquisadores Científicos Ana Maria Montragio P. Camargo e Mário A. Margarido, por suas valiosas sugestões e pelo apoio em etapas importantes desta dissertação.

Aos funcionários do IEA (em especial da biblioteca e do xérox) e também do Departamento de Administração, Economia e Sociologia Rural, pela grande colaboração desde o início desta pesquisa.

Às empresas fornecedoras de sistemas de rastreamento por satélite, por auxiliarem no esclarecimento de informações sobre o objeto deste estudo.

Às transportadoras que foram entrevistadas, pela atenção durante a entrevista e pelas informações transmitidas, cujo conteúdo foi vital para o desenvolvimento desta pesquisa.

A todas as pessoas que, de alguma forma, contribuíram nas várias etapas deste trabalho.

Enfim, a todos os amigos e familiares, pelo carinho e incentivo em todas as fases desta jornada. 


\section{SUMÁRIO}

Página

LISTA DE FIGURAS _............................................................................... vii

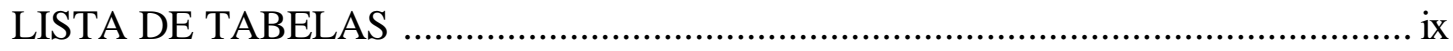

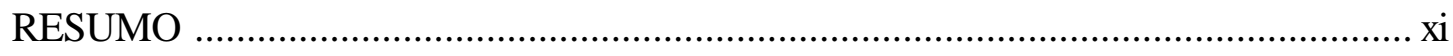

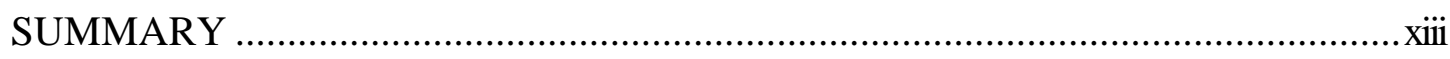

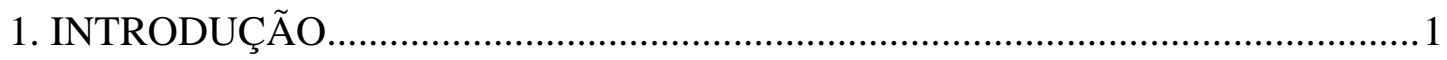

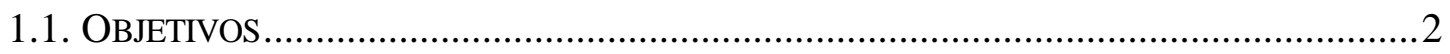

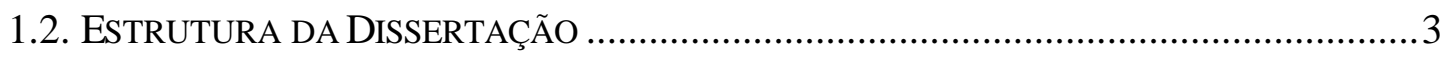

2. SISTEMAS DE RASTREAMENTO POR SATÉLITE .......................................

2.1. SituAÇÃO ATUAL E PERSPECTIVAS FUtURAS DO USO DOS SISTEMAS DE

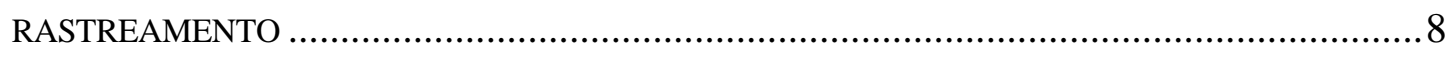

2.1.1. Características da utilização nos EUA, Europa e Japão .............................. 8

2.1.2. Características da Utilização no Brasil..........................................................

2.2. ANÁLISE ECONÔMICA DE INVESTIMENTOS EM SISTEMAS DE RASTREAMENTO.......13

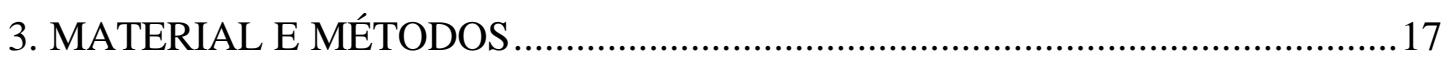

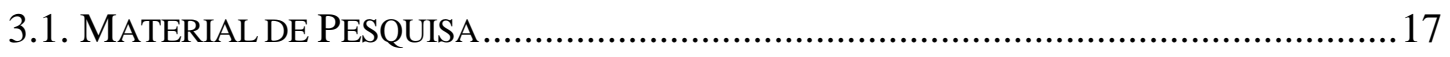

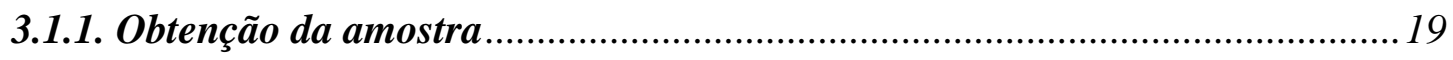

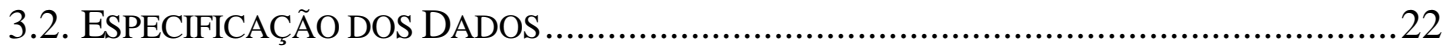

3.3. MÉtodos e TÉCNICAS PRopostos PARA o ESTUdo .........................................23

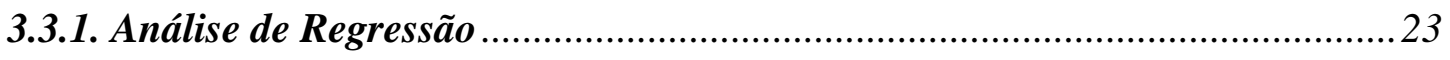

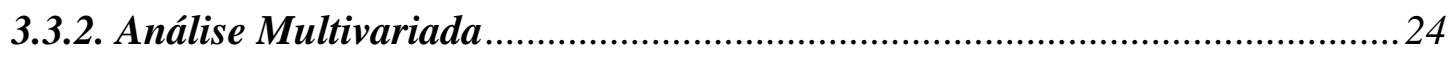

3.3.2.1. Análise de Correspondência ...................................................................25

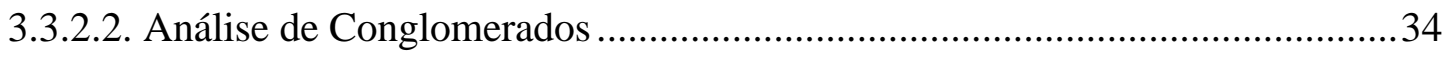

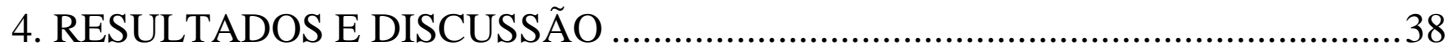

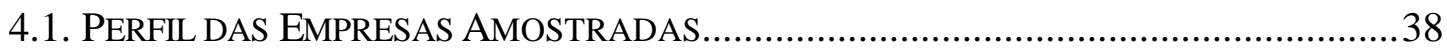

4.2. Produtos mais Transportados e Regiões de Entrega Mais IMPORTANTes COM E SEM o USO dos Sistemas de RASTREAMENTO 
4.3. TiPOS DE Sistemas MAIS UTILIZAdOS NO MERCADO.

4.3.1. Relação entre a porcentagem de caminhões rastreados e o tempo de uso nas transportadoras 45

4.4. VARIÁVEIS UTILIZADAS PELAS EMPRESAS PARA DECIDIR SOBRE A AQUISIÇÃO DOS SISTEMAS DE RASTREAMENTO

4.5. PRINCIPAIS IMPACTOS FINANCEIROS (POSITIVOS OU NEGATIVOS) OCASIONAdOS PELO EMPREGO DOS SISTEMAS DE RASTREAMENTO NAS EMPRESAS ...........................50

4.5.1. Estudo dos Principais Impactos Financeiros através das Análises de Correspondência e de Conglomerados 53

4.6. PRINCIPAIS AÇÕES TOMADAS PELAS EMPRESAS PARA SUA MELHOR ADEQUAÇÃo À UTILIZAÇÃO DOS RASTREADORES

4.6.1. Estudo das Principais Ações Tomadas pelas Empresas através das Análises de Correspondência e de Conglomerados.

4.7. MAIORES BenEFícios ObTidos PELAS TRANSPORTADORAS COM O USO DOS SISTEMAS DE RASTREAMENTO

4.7.1. Estudo dos Principais Benefícios Obtidos pelas Transportadoras através das Análises de Correspondência e de Conglomerados. 73

4.8. ANÁlise CONJUNTA dOS PRINCIPAIS IMPACTOS FinANCEIROS, AÇÕES TOMADAS E Benefícios Obtidos pelas Transportadoras através da ANÁlise DE CONGLOMERADOS . .79

5. CONCLUSÕES .83

Anexo A - Análise de Correspondência da Questão 3 ................................................87

Anexo B - Análise de Correspondência da Questão 5 ...............................................90

Anexo C - Análise de Correspondência da Questão 6 ...............................................92

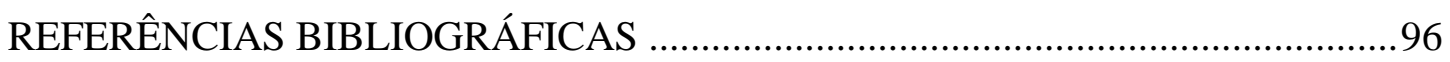

Apêndice 1 - Questionário para Empresas Usuárias dos Sistemas de Rastreamento 103 Apêndice 2 - Histograma dos 25 Primeiros Autovalores da Questão 3 109 Apêndice 3 - Coordenadas e Contribuições Relativas para cada uma das Modalidades das Variáveis Ativas e Suplementares da Questão 3 110 
Apêndice 4 - Coordenadas e Contribuições Relativas para cada uma das Empresas da Questão 3

Apêndice 5 - Primeiro Plano Fatorial Relacionando as Variáveis da Questão 3

Apêndice 6 - Segundo Plano Fatorial Relacionando as Variáveis da Questão 3 ......114

Apêndice 7 - Terceiro Plano Fatorial Relacionando as Variáveis da Questão 3 .......115

Apêndice 8 - Histograma dos 25 Primeiros Autovalores da Questão 5

Apêndice 9 - Coordenadas e Contribuições Relativas para cada uma das Modalidades das Variáveis Ativas e Suplementares da Questão 5

Apêndice 10 - Coordenadas e Contribuições Relativas para cada uma das Empresas

da Questão 5

Apêndice 11 - Primeiro Plano Fatorial Relacionando as Variáveis da Questão 5 ....120

Apêndice 12 - Segundo Plano Fatorial Relacionando as Variáveis da Questão 5 ....121

Apêndice 13 - Terceiro Plano Fatorial Relacionando as Variáveis da Questão 5 .....122

Apêndice 14 - Histograma dos 25 Primeiros Autovalores da Questão 6

Apêndice 15- Coordenadas e Contribuições Relativas para cada uma das Modalidades das Variáveis Ativas e Suplementares da Questão 6.

Apêndice 16 - Coordenadas e Contribuições Relativas para cada uma das Empresas da Questão 6

Apêndice 17 - Primeiro Plano Fatorial Relacionando as Variáveis da Questão 6 ....128

Apêndice 18 - Segundo Plano Fatorial Relacionando as Variáveis da Questão 6 ....129

Apêndice 19 - Terceiro Plano Fatorial Relacionando as Variáveis da Questão 6 ......130

Apêndice 20 - Quarto Plano Fatorial Relacionando as Variáveis da Questão 6 ......131

Apêndice 21 - Quinto Plano Fatorial Relacionando as Variáveis da Questão 6 .......132

Apêndice 22 - Sexto Plano Fatorial Relacionando as Variáveis da Questão 6 .........133

Apêndice 23 - Número de Classes Obtidas pelo Método de Ward .... 


\section{LISTA DE FIGURAS}

Página

1 Funcionamento de sistemas de rastreamento por satélite (adaptado de Lopez, 1996)...5

2 Principais Motivos para Não Utilização de Sistemas de Rastreamento por Satélite em Transportadoras Rodoviárias de Carga, Cidade de São Paulo, 1997. ......................... 19

3 Representação dos pontos linha num referencial de colunas (a) e dos pontos coluna num referencial de linhas (b), a partir da Tabela T (Crivisqui, 1993, p.40)..............28

4 Representação da Nuvem de Pontos-Perfis em Relação ao Ponto $m$ (Crivisqui \&

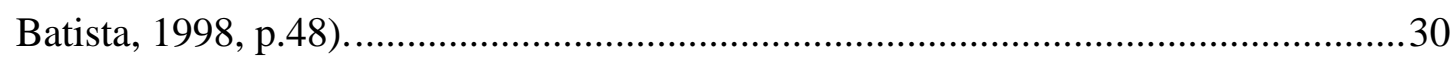

5 Representação do Ponto-Perfil $i$ e do eixo fatorial $\alpha$ num plano (Crivisqui, 1993,

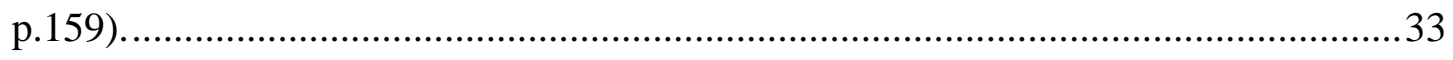

6 Tempo de Existência (anos) das Empresas Entrevistadas, Cidade de São Paulo, 199798. 39

7 Relação entre o Tempo do Funcionário na Empresa, no Cargo e Sua Formação

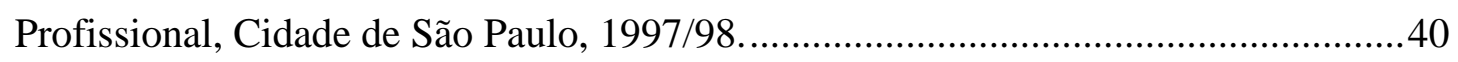

8 Relação entre Tempo de Uso dos Sistemas de Rastreamento e Porcentagem de Caminhões Rastreados, Cidade de São Paulo, 1997-98.........................................48

9 Impactos nas Empresas em Relação ao Uso dos Sistemas de Rastreamento por Satélite, Cidade de São Paulo, 1997-98 ..................................................................51

10 Participação das Principais Ações Tomadas pelas Empresas durante o Processo de Adequação aos Sistemas de Rastreamento, Cidade de São Paulo, 1997-98. ..............62

11 Grau de Satisfação das Empresas em Relação aos Benefícios Obtidos dos Sistemas de Rastreamento por Satélite, Cidade de São Paulo, 1997-98. .71 


\section{LISTA DE TABELAS}

Página

1 Fórmulas de Algumas Estatísticas Descritivas relativas às Distribuições Normal, Binomial e Multinomial.

2 Estrutura de uma Tabela de Contingência (Tabela T) com I modalidades da variável $L$ e $J$ modalidades da variável $C$.

3 Fórmulas dos Perfis em Linha e em Coluna obtidos a partir de Tabelas de Contingência e de Freqüências Relativas.

4 Produtos Transportados Sem Rastreamento por Empresas Usuárias de Sistemas de Rastreamento, Cidade de São Paulo, 1997-98.

5 Produtos Transportados Com Rastreamento por Empresas Usuárias de Sistemas de Rastreamento, Cidade de São Paulo, 1997-98

6 Nível de Utilização e Tempo de Uso dos Sistemas de Rastreamento por Satélite nas Empresas.

7 Análise de Variância: Porcentagem de Caminhões Rastreados em Função do Tempo de Uso e do Tipo de Sistema, Cidade de São Paulo, 1997-98

8 Estatísticas Complementares da Análise de Variância: Porcentagem de Caminhões Rastreados em Função do Tempo de Uso e do Tipo de Sistema, Cidade de São Paulo, 1997-98.

9 Estimativas dos Parâmetros para Porcentagem de Caminhões Rastreados em Relação ao Tempo de Uso e ao Tipo de Sistema, Cidade de São Paulo, 1997-98.

10 Variáveis Responsáveis pela Decisão das Empresas na Aquisição de Sistemas de Rastreamento por Satélite.

11 Abrangência dos Principais Impactos Positivos Obtidos em Relação aos Sistemas de Rastreamento por Satélite nas Empresas.

12 Classificação Hierárquica em Relação aos 3 Primeiros Eixos Fatoriais da Questão 3.

13 Descrição dos Grupos (Classes) formados pela Análise de Conglomerados da Questão 3. 
14 Classificação Hierárquica em Relação aos 3 Primeiros Eixos Fatoriais da Questão 5. .

15 Descrição dos Grupos (Classes) formados pela Análise de Conglomerados da

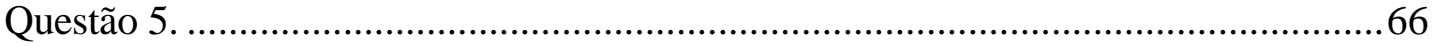

16 Principais Benefícios Observados em Relação aos Sistemas de Rastreamento por Satélite nas Empresas.

17 Classificação Hierárquica em Relação aos 4 Primeiros Eixos Fatoriais da Questão 6.

18 Descrição dos Grupos (Classes) formados pela Análise de Conglomerados da Questão 6. 75

19 Descrição dos Grupos (Classes) formados pela Análise de Conglomerados das 3 Questões. 


\title{
GERENCIAMENTO DE FROTAS DO TRANSPORTE RODOVIÁRIO DE CARGAS UTILIZANDO SISTEMAS DE RASTREAMENTO POR SATÉLITE
}

\author{
Autora: LILIAN CRISTINA ANEFALOS \\ Orientador: Prof. Dr. JOSÉ VICENTE CAIXETA FILHO
}

\section{RESUMO}

O principal objetivo desta dissertação foi caracterizar o uso dos sistemas de rastreamento por satélite no transporte rodoviário de cargas, na cidade de São Paulo. Tratase de uma tecnologia de ponta pouco estudada no Brasil, apesar de seu potencial de crescimento e importância econômica para o setor de transportes.

Foram feitas entrevistas a partir de uma amostra aleatória de 26 transportadoras, mediante a aplicação de um questionário, para que se pudesse avaliar melhor o impacto desses sistemas nas transportadoras, em termos das principais ações tomadas pelas empresas para sua melhor adequação ao sistema, e em relação aos maiores benefícios obtidos pelas transportadoras com o uso dessa tecnologia. Além da análise descritiva dos dados, as variáveis qualitativas foram exploradas com maior profundidade por meio de análise multivariada, que incluiu análise de correspondência e de conglomerados, para agrupar empresas com comportamentos semelhantes em relação ao uso dos sistemas de rastreamento.

De maneira geral, os sistemas que utilizavam apenas satélites dominaram o mercado, apesar de seus preços serem mais elevados em relação a sistemas que associavam rádio e satélite. Em ambos os casos havia preferência pelo rastreamento de cargas de alto valor agregado (medicamentos, produtos eletrônicos, cosméticos, produtos químicos, produtos agrícolas processados).

Apesar dessa tecnologia ter sido recomendada tanto para logística como para segurança das cargas, seu emprego na cidade de São Paulo proliferou principalmente para o gerenciamento de risco, em função do aumento dos sinistros. Por outro lado, verificou-se 
que há necessidade de mudanças de ordem cultural, social e tecnológica nas transportadoras para que haja maior percepção dos benefícios do uso do sistema ao longo do tempo, uma vez que há muitos recursos que só poderão ser explorados se houver alteração na dinâmica interna das empresas e maior integração com outros setores produtivos. 


\title{
FLEET MANAGEMENT OF THE FREIGHT HIGHWAY TRANSPORTATION USING SATELLITE TRACKING SYSTEMS
}

\author{
Author: LILIAN CRISTINA ANEFALOS \\ Adviser: Prof. Dr. JOSÉ VICENTE CAIXETA FILHO
}

\section{SUMMARY}

The main objective of this dissertation was to analyze the use of the satellite tracking systems in freight highway transportation in São Paulo city. This edge technology has not been well studied in Brazil, in spite of its potential growth and increasing economic importance to the transportation sector.

A questionnaire was applied to 26 randomly chosen trucking companies to better evaluate the impacts of these systems on the firms, in terms of their reaction and adjustment to the systems and their ability to benefit from the use of such technology. The qualitative data were analyzed through descriptive and multivariate analyses, including correspondence and cluster analyses, so as to group companies with similar behavior concerning the use of tracking systems.

In general, the use of satellite systems predominated, though they had higher prices than the radio/satellite systems. However, in both types of systems there was a preference to track high aggregate value freights, such as medicines, electronic products, chemical products and processed agricultural products.

Although this technology was recommended for logistics and freight security reasons, its use in São Paulo city has mainly proliferated in the area of risk management, as a consequence of the increase in the number of robberies. On the other hand, it was verified that cultural, social and technological changes are needed for trucking companies to better capture the benefits of the use of the system. Many of them can be exploited only in the presence of changes in the internal dynamics of firms and observing a higher integration with other productive sectors. 


\section{INTRODUÇÃO}

$\mathrm{O}$ acesso à informação tem sido um aspecto de fundamental importância para a estrutura organizacional das instituições. Nesse sentido, a utilização de informações online mais precisas tem diferenciado a tomada de decisão tanto por empresas públicas como privadas.

Para ampliar o emprego de novas tecnologias nessa era da informação, segundo Tigre, Rovere e Fagundes (1995), as indústrias de informática e de telecomunicações têm se associado para possibilitar a criação, transmissão, acumulação e processamento de dados, gerando as chamadas tecnologias da informação (TI).

Um dos setores chaves da economia brasileira que tem se empenhado em investir em TI é o transporte rodoviário de cargas, visando um melhor abastecimento de várias regiões do país e do Mercado Comum do Cone Sul (Mercosul, composto por Argentina, Brasil, Paraguai e Uruguai; Chile e Bolívia ainda estão em negociações), através do cumprimento de prazos mais reduzidos e de entrega de vários tipos de cargas, melhor embaladas e conservadas, como é o caso dos produtos agropecuários.

Essa tendência vem ao encontro de importantes considerações feitas por Silva (1995, p.28), a partir de uma análise das tecnologias da informação na agricultura e de seus impactos no Brasil. Este autor afirmou que "os investimentos em ciência básica e criação de infra-estrutura tecnológica são, mais uma vez, fundamentais. Obviamente não se trata de abrir estradas para expandir a fronteira agrícola ou de construir silos ou armazéns; estamos falando de infra-estrutura de telecomunicações - telefonia, rádio, satélites; e de armazenamento de dados...".

Dentre os projetos de TI de maior relevância nesse setor, destacam-se os de gerenciamento de frotas por sistemas de rastreamento por satélite que, ao aliarem 
aplicações logísticas modernas e de segurança, têm se revelado instrumentos de grande valia no dia-a-dia das empresas de transporte.

Apesar dessa nova tecnologia envolver, geralmente, grandes volumes de capital para sua implantação, houve poucos avanços concretos no dimensionamento do seu verdadeiro papel dentro das empresas. Há necessidade de estudos focados em um melhor entendimento da importância e do potencial de crescimento desses sistemas por satélite para o setor de transportes.

\subsection{OBJETIVOS}

O objetivo geral desta dissertação é caracterizar o uso dos sistemas de rastreamento por satélite em empresas da área de transporte rodoviário de cargas que possuam matriz ou filial na cidade de São Paulo. A restrição geográfica deve-se à importância econômica paulistana, aliada à alta concentração de transportadoras de carga naquela região. Especificamente, pretende-se, a partir de uma amostra de empresas que utilizam os sistemas de rastreamento:

- descrever as principais estratégias utilizadas pelas empresas para gerenciar suas frotas por meio dos rastreadores;

- avaliar a influência dos vários tipos de sistemas de rastreamento nas empresas usuárias.

Para que esses objetivos sejam atingidos satisfatoriamente, as seguintes questões foram feitas junto às empresas amostradas:

- Qual o perfil das empresas usuárias dos sistemas?

- Quais as cargas mais transportadas?

- Quais são as principais regiões de entrega com e sem o uso dos sistemas de rastreamento?

- Quais são os tipos de sistemas mais usados no mercado?

- Quais os tipos de análise usadas para decidir sobre a aquisição do sistema? 
- Quais são os impactos (positivos ou negativos) nas empresas, decorrentes do emprego dos sistemas de rastreamento?

- Quais são as principais ações tomadas pelas empresas para sua melhor adequação à utilização dessa nova tecnologia?

- Quais são os maiores benefícios obtidos pelas transportadoras com o uso dos rastreadores?

\subsection{ESTRUTURA DA DISSERTAÇÃO}

Esta dissertação está dividida em cinco capítulos:

1. este, o primeiro, refere-se à introdução e aos objetivos e aponta para algumas metas a serem atingidas;

2. o segundo trata dos conceitos e da influência de sistemas de rastreamento por satélite sobre as empresas, caracterizando os que estão atualmente disponíveis nos mercados mundial e brasileiro;

3. o terceiro diz respeito ao material e método que serão utilizados;

4. o quarto trata dos resultados e discussão;

5. o quinto apresenta as conclusões desta dissertação. 


\section{SISTEMAS DE RASTREAMENTO POR SATÉLITE}

De acordo com Reis (1997), os sistemas de rastreamento por satélite possuem três funções básicas: (a) comunicação entre a estação de controle e os veículos; (b) localização on-line de veículos; (c) controle da frota em relação a: nível de combustível, velocidade do veículo, temperatura do compartimento de cargas, fechamento de portas, presença de caronas, entre outros.

De maneira geral, para que um veículo parado ou em movimento (como por exemplo, caminhões, trens, navios, entre outros) seja rastreado por satélite, é preciso que haja, inicialmente, a coleta de sua posição através do Sistema de Posicionamento por Satélite (GPS, Global Position System). Em seguida, suas coordenadas devem ser transmitidas para um satélite de comunicação e só depois transferidas para uma estação terrena, para que esta envie as informações sobre o objeto ao usuário (Lopez, 1996). Há, também, a possibilidade de utilizar-se uma estação intermediária (entre a estação terrena e o usuário), que tem a finalidade de gerenciar os dados obtidos, através de software específico, antes de serem retransmitidos ao usuário (Figura 1).

O GPS é um sistema de navegação que foi desenvolvido pelo Departamento de Defesa dos EUA para fins militares. É composto por uma constelação de 24 satélites, que percorrem a órbita da terra em 12 horas (Dana, 1998). Tem a finalidade de: localizar pontos para determinar suas posições em três dimensões na superfície terrestre ou

próximo a ela, através de coordenadas do aparelho receptor (observador); determinar a velocidade, por exemplo, de um veículo em movimento; obter informações mais exatas sobre o tempo de percurso (Andrade \& Blitzkow, 1990; Lopez, 1996). 


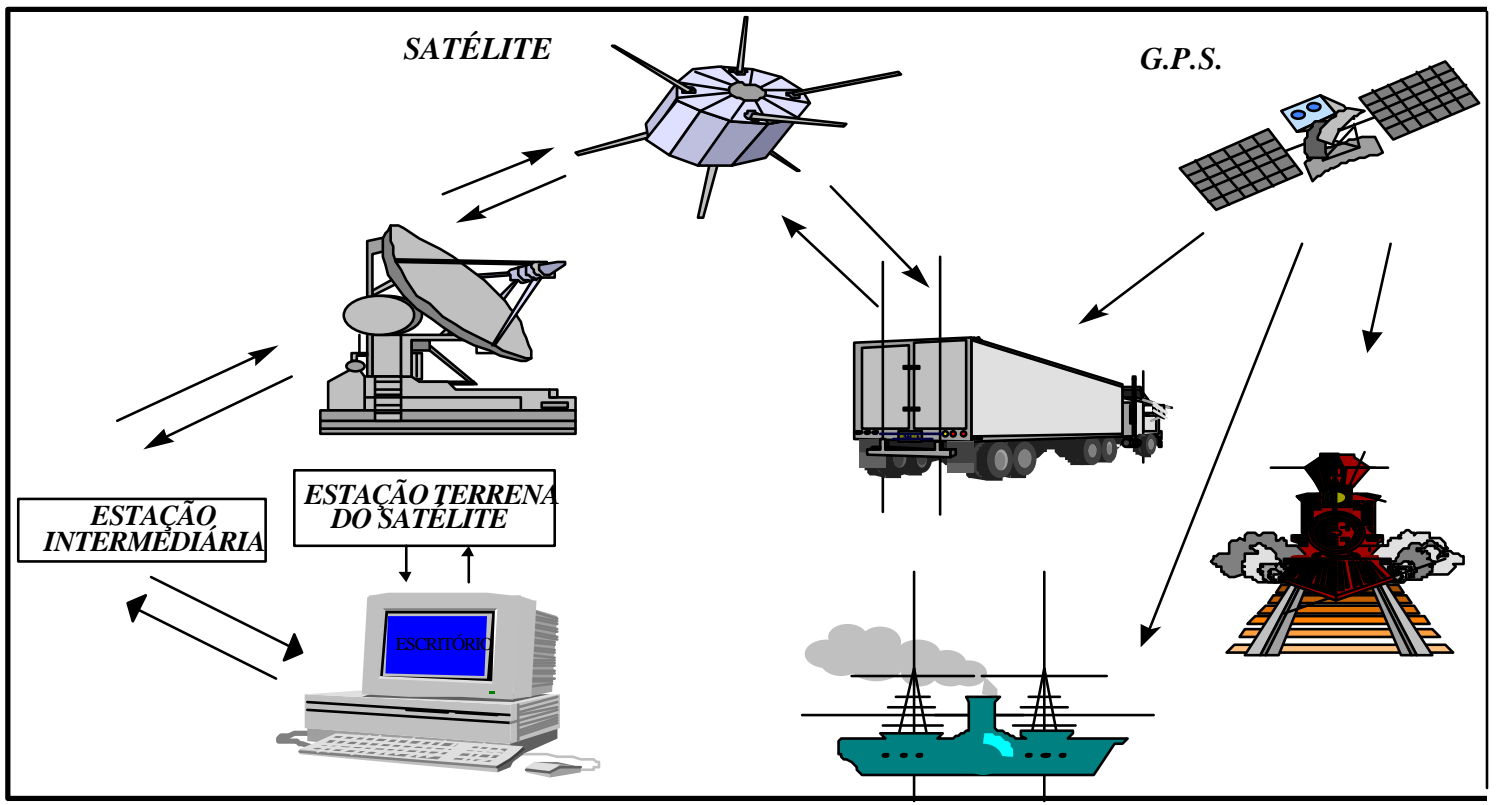

Figura 1 - Funcionamento de sistemas de rastreamento por satélite (adaptado de Lopez, 1996).

De acordo com Chityakov et al. (1996), o GLONASS é um sistema de satélites semelhante ao GPS, usado para obter dados de navegação na Rússia. Além disso, o Instituto de Radionavegação e de Tempo da Rússia (RIRT) está desenvolvendo um serviço para navegação que combina as correções diferenciais do GPS e do GLONASS (respectivamente, DGPS e DGLONASS), denominado Differential Global Navegation Satellite System (DGNSS). Esse novo sistema funciona através da integração entre o DGPS e o DGLONASS, devido principalmente às similaridades de suas estruturas e de seus sinais, cujas correções são atualizadas, respectivamente, a cada 15 e 90 segundos.

Segundo o Anuário do Transporte Rodoviário de Carga (1996), o Inmarsart (International Maritime Satellite) tem sido um dos satélites de comunicação mais utilizados para rastreamento em relação aos demais já existentes. Foi criado pela Organização Marítima Internacional, subordinada às Nações Unidas, em 16 de julho de 1979, e tem base em Londres (Program, 1998). De acordo com Reis (1997), ele tem cobertura global e é gerenciado por um grupo de 78 países (entre eles, Holanda, Estados 
Unidos, Reino Unido, França, Alemanha e Brasil), com tendência de aumento de sua demanda nos próximos anos. O Brasil ocupa a posição de $12^{\circ}$ maior signatário desse sistema. Além disso, no Brasil há outro satélite também muito utilizado, o Brasilsat, que abrange todo o território nacional, e tem apresentado melhores sinais no leste e no sul do País (Reis, 1997).

Para que o usuário obtenha os dados precisa utilizar um computador, uma linha telefônica ou de transmissão de dados e um modem para que a comunicação possa ser estabelecida. No veículo deve ser instalado um kit básico composto de antena, terminal de mensagens, transmissor e receptor de sinais (transceiver).

Além disso, utilizam-se várias estações de referência em terra, em vez de apenas uma no sistema antigo, para correções diferenciais, permitindo uma maior confiabilidade na medida das distâncias e abrangendo uma área muito maior (Franco \& Pessoa, 1995). Porém, devido à utilização de apenas uma estação de coordenada conhecida, com a ampliação dessa área pode ocorrer decorrelação espacial, ou seja, degradação das medições, ocasionando erros de posicionamento. Aravés dos sistemas Wide Area DGPS (WADGPS) há uma minimização do número de estações de referência, geograficamente distribuídas e com coordenadas de alta precisão (Aquino, 1996).

Assim, é de suma importância que os sistemas de rastreamento por satélite garantam a qualidade das informações. Nesse sentido, tem havido grande preocupação com aumento da precisão das distâncias entre as estações e os usuários, principalmente em atividades que necessitam de posicionamento em tempo real, podendo-se citar as relativas à navegação, ao transporte e aos sistemas de informação geográfica ${ }^{1}$ (Pessoa, 1996).

Langley (1997) adverte para a vulnerabilidade do GPS a algumas interferências que podem prejudicar ou inviabilizar a captação dos seus sinais, tais como: proximidade a outro veículo (com outros sinais de comunicação) ou a uma fábrica ou laboratório, interior de construções, no caso de uso terrestre. Em sistemas de navegação podem

${ }^{1}$ Os sistemas de informação geográfica (SIG ou GIS - Geographic Information Systems) manipulam dados espaciais de diversas fontes como mapas, imagens, cadastros, e têm permitido um melhor conhecimento das regiões em todo o mundo, além de estudos mais refinados sobre recursos ambientais e aspectos meteorológicos (Alves, 1990). 
ocorrer problemas de recepção causados por estações locais de TV ou ondas curtas mais próximas.

Os EUA, no entanto, têm apresentado sérias restrições para a proliferação mundial dessa nova tecnologia, pois têm utilizado intensamente o GPS na segurança nacional, como um componente imprescindível para a redução de riscos, através do conhecimento das posições de todos os tipos de equipamentos militares, tanto em terra, mar e ar e de armas teleguiadas (Pace et al., 1996).

Para favorecer o crescimento do GPS em aplicações domésticas e no exterior, os potenciais colaboradores norte-americanos e de outros países, tais como Japão, países da Europa e Rússia, têm pressionado os EUA a permitir o aumento da precisão das posições em grandes áreas.

Nesse sentido, segundo Pace et al. (1996), à medida que o GPS está se popularizando no mundo e o interesse dos usuários em explorar as inúmeras aplicações dessa nova tecnologia está se elevando, os EUA estão se encaminhando para uma encruzilhada: ou promovem o GPS como um padrão mundial, através de acordos internacionais, mantendo os benefícios de suas relações diplomáticas; ou permitem que outros países desenvolvam outros satélites alternativos (com objetivos nem sempre equivalentes aos dos EUA), mas garantindo ainda a segurança nacional dos EUA em relação ao aprimoramento da tecnologia empregada no GPS.

Apesar das diferenças internacionais quanto à implementação da tecnologia GPS, já existem algumas aplicações em alguns setores, dentro das restrições espaciais impostas pelos EUA. Entre eles, o de transportes possui importância ímpar, pois tem necessitado de controle em tempo real de suas operações, para que não ocorram irregularidades ou para que facilite o dia-a-dia dos usuários dos veículos. Sua utilização se estende desde serviços de transportadoras, para o posicionamento, o monitoramento e a segurança das frotas de caminhões, até locadoras de carros. 


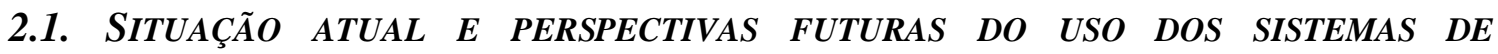 RASTREAMENTO}

A partir do GPS, de acordo com Show (1997), têm sido desenvolvidos sistemas conhecidos como Intelligent Transportation Systems (ITS), que têm por principal objetivo gerenciar mais eficazmente os sistemas de transporte, fornecendo como subsídios relatórios de tráfego em tempo real, guia de rotas, serviços de emergência, melhoria da segurança, entre outros. Na Universidade de Nevada há desenvolvimento de projetos de ITS para aluguel de carros, mediante o controle da localização dos veículos em movimento (Chisholm, 1996).

O United States GPS Industry Council (USGIC), citado por Aquino (1995), revelou, com base em dados de 1995, que até o ano 2000 o mercado de GPS terá crescido em mais de US\$ 8 bilhões, com tendências de queda nos preços de hardware GPS em aproximadamente $30 \%$ por ano, e com maior adequação do software às necessidades dos usuários finais.

Desta forma, espera-se que haja maior endência de personalização dos serviços e aplicações em diversas áreas, dada a relevância do GPS como filtro importante de informações, e que a sua demanda se eleve cada vez mais na América até o início do século 21, inclusive no Brasil, que aparece como um potencial consumidor dessa nova tecnologia. Deve-se ressaltar a importância do papel do Governo por fornecer infraestrutura e regulamentação necessárias para que as empresas utilizem as informações provenientes dos satélites do GPS e administrem os mais diversos tipos de ITS (Show, 1997).

\subsubsection{Características da utilização nos EUA, Europa e Japão}

Atualmente, segundo Show (1997), o uso do GPS é mais significativo no Japão (mais de 1 milhão de equipamentos em funcionamento), Europa (50 mil unidades) e Estados Unidos (6 mil sistemas de navegação). De acordo com Penha (1998), há por volta de 300 mil veículos nos Estados Unidos e Europa providos de sistemas de 
rastreamento por satélite. Conforme dados da Telecom Publishing Group, nos EUA os sistemas de rastreamento são utilizados por mais de 50\% das empresas transportadoras (Tecnologia, 1995).

Há vários sistemas americanos que oferecem facilidades no rastreamento de veículos, tais como: NSCAT (da Newcomb Communications), SAT (da SAT Coorporation), Roadtrac ${ }^{2}$, entre outros. O sistema Roadtrac oferecia, em 1996, o menor preço de mercado. Seu custo de instalação era de US\$ $1.395,00$ por veículo e o custo mensal de serviços era de US\$28,00 (Roadtrac, 1996). Nesse ano havia em torno de 60 opções de provedores de serviços e equipamentos nos Estados Unidos, de acordo com Westbrook (1996).

Dentre as vantagens obtidas com o uso do GPS, Westbrook (1996) destaca que os receptores do satélite podem ser adquiridos nos EUA por menos de US\$ 500,00 e não possuem limite de capacidade, tal como ocorre com os celulares. Outro ponto positivo é que os sinais dos satélites GPS podem ser utilizados livremente por qualquer usuário. No entanto, para que seja utilizado como uma tecnologia completa de comunicação, que inclui modem e rádio para comunicação, o seu custo pode aumentar para US\$3.000,00 por veículo. Há expectativas de que haverá redução do custo total do sistema para menos de US\$ 500,00 nos próximos anos.

\subsubsection{Características da Utilização no Brasil}

Havia dez opções de sistemas de rastreamento no Brasil, até meados de 1997. A saber:

- Cargosat (distribuído pela Prosat Comunicações, cujas antenas e transceptores são fabricados pela Radio Holland, na Holanda);

- Combat (distribuído pela Combat Tecnologia em Segurança Ltda, fabricado pela Cimarron, na Califórnia);

2 Maiores detalhes sobre esses sistemas estão disponíveis, respectivamente, nos seguinte sites: http://www.newcomb.com, http://www.sat.com, http://www.roadtrac.com. 
- Controlsat, antigo Rodosat (fabricado e distribuído pela Schahin Cury, exceto transceiver e antena do rádio);

- Logiq (distribuído pela Avibrás Telecomunicações, fabricado pela Simac - do grupo DAF, Holanda);

- Motorola Motomap (distribuído pela Braslaser Comunicações, fabricado pela Motorola israelense);

- Omnisat (distribuído pela Autotrac Com. e Telecomunicações, fabricado pela Qualcomm, EUA);

- Radiotrack (fabricado e distribuído pela Radiototal, cujo rádio é da marca Radiocom);

- Satcom (distribuído pela Geo Ecosat, fabricado pela Nortel-Daimler Benz e DasaGrundig);

- Teletracker, antigo Geotrak (distribuído pela Vence Engenharia e Empreendimentos S/C Ltda, cujos equipamentos são de origem canadense, exceto rádio);

- Trucksat (fabricado e distribuído pela Trucksat Systems, exceto transceiver e antena do veículo).

A principal diferença entre esses sistemas, segundo Lopez (1996), está na presença ou não de estação intermediária, para estabelecer a ligação entre a estação terrena e o usuário, através de software de comunicação. As posições dos veículos, coletadas por meio do GPS, são transmitidas para um satélite, que as transfere para uma estação terrena, retransmitindo-as para uma estação intermediária opcional (utilizada nos sistemas Omnisat, Controlsat e Trucksat) e finalmente para o usuário. A relação entre o usuário e o seu veículo segue o caminho inverso do descrito anteriormente (Figura 1).

Em relação aos satélites de comunicação utilizados nos sistemas de rastreamento para o transporte rodoviário de cargas no Brasil, deve-se salientar que os sistemas Cargosat, Logiq, Controlsat, Satcom e Trucksat usam o satélite Inmarsat C; o sistema Omnisat utiliza o Brasilsat B2. Futuramente também estará disponível outro satélite, o Globosat (Reis, 1997). 
Em alguns casos, de acordo com Reis (1997), os satélites Brasilsat e Inmarsat podem ser substituídos por rádios convencionais ou troncalizados, permitindo a transmissão de dados e a comunicação por voz entre a central e o veículo através de antenas repetidoras. Apesar dessa alternativa possuir menor investimento, a sua cobertura se restringe a raios de $50 \mathrm{~km}$ de torres de retransmissão. Essa alternativa é utilizada pelos sistemas Braslaser/Motorola, Combat, Radiotrack e Teletracker.

Assim como nos demais países, no Brasil também tem ocorrido uma tendência de queda nos preços do equipamento em função do aumento da concorrência das empresas fornecedoras dessa nova tecnologia. Decorrências desse fato são as mudanças nos equipamentos de comunicação, tais como, diminuição no tamanho da antena e do número de transceptores para realizar a comunicação entre os satélites, que têm auxiliado na redução do preço dos rastreadores para o usuário final (Penha, 1998).

Apesar de suas inúmeras vantagens, ainda não houve efetiva proliferação do uso desses sistemas de rastreamento no Brasil, principalmente devido ao seu alto custo, cujo preço básico por veículo varia entre R \$ 3 e 7 mil. De acordo com Lopez (1996) e Reis (1997), havia por volta de 200 empresas usuárias desses sistemas no Brasil até 1996. Assim, pode-se inferir que as transportadoras fazem uma pré-seleção dos tipos de produtos realmente rastreados, de maior interesse pelas companhias, principalmente em função da abrangência dos tipos de rastreadores (40\% dos sistemas atuam em nível nacional; $40 \%$ em nível regional - cidades de Campinas, São Paulo e Rio de Janeiro; $20 \%$ na América do Sul).

Deve-se também ressaltar que em 1994 houve uma tentativa de promover uma rápida expansão do uso dos sistemas de rastreamento através da proposta do projeto de lei complementar 198/94, que previa, dentre as diversas medidas apresentadas, a obrigatoriedade da instalação de um rastreador em cada caminhão da frota das empresas transportadoras de carga até o prazo máximo de um ano, a partir da vigência da lei, a fim de prevenir, fiscalizar e reprimir o furto e roubo de veículos e cargas; se essa determinação não fosse cumprida, seria aplicada uma multa de aproximadamente R 4 mil por veículo. No entanto, houve muita divergência de opiniões sobre esse projeto, 
principalmente por infringir o artigo 144 da Constituição Federal, que estabelece que a segurança pública é dever do Estado (Geiling, 1995).

Segundo Lopez (1996), o aumento da segurança e sua interface com os roteirizadores $^{3}$ têm se constituído em grandes incentivos para as empresas adquirirem essa tecnologia. Aliado a isso, Penha (1998) vislumbra dois segmentos bem fortes que estão se formando: o gerenciamento de risco, com foco voltado às cargas mais visadas pelos assaltantes, e a logística, específica para aqueles que necessitam de acompanhamento freqüente das condições físicas da carga e do tempo de trajeto da frota.

Outro ponto importante em relação aos rastreadores é que os dados obtidos através dos mesmos também podem ser utilizados pelo usuário via software de gerenciamento de dados, troca eletrônica de documentos (EDI - Electronic Data

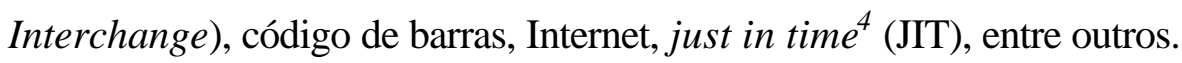

Penha (1998) divulgou algumas previsões otimistas para a quantidade de terminais de sistemas de rastreamento que seriam instalados em 1998 (6750 no total), que sinalizavam para um aumento de 36\% quando comparado ao ano anterior (4314 equipamentos em uso em 1997, baseado nos 7 sistemas de rastreamento atuantes naquele ano).

Em relação aos sistemas disponíveis no mercado, o Omnisat tem reduzido lentamente sua participação em relação ao total de equipamentos instalados nas transportadoras, pois a partir de 1995 outras empresas iniciaram a comercialização de outros tipos de rastreadores por satélite. Em 1997, o sistema Omnisat representou metade dos equipamentos instalados no Brasil.

Em contraposição, segundo Penha (1998), outros sistemas estão se expandindo, destacando-se entre eles, Controlsat, Combat e Teletracker, com as seguintes

\footnotetext{
${ }^{3}$ Segundo Oliveira (1996), a corretora de seguros Pamcary, especializada na prevenção e no combate ao roubo de cargas, controla duzentas mil viagens de caminhões de transporte, em média, por mês, com este sistema.

${ }^{4}$ Segundo Graves, Kan e Zipkin (1993), JIT refere-se basicamente à redução do tempo e do volume dos estoques; conforme Ballou (1993), este controle rígido se dá principalmente pela disponibilidade de informação qualitativa e quantitativa, reduzindo a incerteza ao longo do sistema logístico e beneficiando compradores e fornecedores.
} 
participações no mercado em 1997 (em relação ao total de equipamentos instalados nos veículos): $26 \%, 11 \%$ e $6 \%$.

Há ainda uma evolução tímida no número de clientes efetivos de sistemas de rastreamento, em função de uma série de fatos, tais como: são muito recentes no mercado (Radiotrack, Satcom) ou mesmo enfrentam dificuldades de inserção no mercado (Cargosat), alguns ainda estão sendo testados pelas transportadoras nas chamadas fases de "pré-vendas". Além disso, segundo Penha (1998), o sistema Logiq saiu do mercado em 1998; o Trucksat foi desativado em meados de 1997.

Para que haja maior aprimoramento dos sistemas de rastreamento, há a necessidade de se entender mais sobre os custos, benefícios e limitações dessa nova tecnologia, uma vez que hoje existem 8 empresas fornecedoras desses sistemas (em 1994 havia apenas uma empresa; em 1997 havia 10) - com perspectivas de acirramento da concorrência entre elas e, consequentemente, maior proliferação de seu uso entre as transportadoras de carga.

Portanto, é importante que se avalie o nível de utilização dos sistemas de rastreamento por satélite nas empresas, pois com a sua difusão dentro do setor de transportadoras essa nova tecnologia pode contribuir diretamente para delinear os rumos da comercialização de produtos, principalmente por estar interferindo diariamente na rotina das empresas.

\subsection{ANÁLISE ECONÔMICA DE INVESTIMENTOS EM SISTEMAS DE RASTREAMENTO}

Tradicionalmente, há cinco indicadores financeiros principais para a avaliação de projetos: payback period (apresenta o número de períodos necessários para que haja retorno do capital investido no projeto), valor presente líquido (corresponde à soma algébrica dos valores do fluxo de caixa de um projeto, estimado a uma taxa de desconto correspondente ao custo de oportunidade do capital), taxa interna de retorno (é uma demonstração da rentabilidade do projeto, ou seja, é a taxa de desconto que iguala o valor presente dos benefícios de um projeto ao valor presente dos seus custos) e relação 
custo/benefício (consiste na relação entre o valor presente dos custos e o valor presente dos benefícios).

Dentre esses métodos, o valor presente líquido é considerado como o mais rigoroso e sem falhas técnicas, desde que devidamente especificado e quantificado nos projetos; a relação custo/benefício, apesar de apresentar os maiores problemas, é ainda muito utilizada, principalmente em investimentos para atender às necessidades sociais (Contador, 1981; Buarque, 1991; Woiler \& Mathias, 1992).

Custódio (1983) enfatizou que um ou mais métodos podem ser adotados na avaliação de sistemas, dependendo das suas características e da finalidade da análise, relacionando entre os mais importantes: valor econômico da informação (com base na Teoria Estatística da Decisão), custo/eficácia (modelo centrado no julgamento do tomador de decisão), percepção de valor (baseada no valor que os usuários atribuem ao sistema) e custo/benefício.

A análise custo/benefício, de acordo com Norton ${ }^{5}$ (1986), citado por Apostolopoulos \& Pramataris (1997), e Hares \& Royle (1994), constitui-se num modelo microeconômico que se limita apenas à análise de projetos de curta duração, com a presença de poucos benefícios intangíveis, e de baixo risco e, portanto, não seria adequada para avaliar os investimentos em tecnologia de informação (TI), cujo desenvolvimento não pode ser considerado como um outro investimento de capital, devido à sua interação com toda a estrutura organizacional das empresas. Custódio (1983) enfatizou que há muitas críticas à inserção intuitiva de alguns benefícios na análise custo/benefício dos sistemas de informação (como por exemplo, uso dos sistemas para a melhoria na tomada de decisão).

Witte (1994) propôs um método para padronizar a análise econômica de investimentos em TI, a fim de proporcionar melhores parâmetros para a tomada de decisão das empresas. Foram utilizados apenas fatores historicamente bem estimados (compra e contrato do hardware, licença do software, redes e telecomunicações, desenvolvimento de software interno, redução de funcionários, medição de custos dos projetos de $\mathrm{TI}$ ) e foram desconsiderados os mais problemáticos (eficácia do usuário 
final, aumento do rendimento, eficácia da equipe de programação, benefícios intangíveis, entre outros).

Outra forma para se medir o valor da TI foi proposta por Hares \& Royle (1994), através da avaliação do investimento (AI), na qual estão inseridas técnicas para identificação e avaliação de projetos (entre elas, destacam-se: estimativa custo/benefício, payback period, análise de sensibilidade, etc.) e para a avaliação do investimento (tal como: fatores críticos de sucesso, entre outras).

Apostolopoulos \& Pramataris (1997) propuseram uma estrutura para avaliação de investimentos em telecomunicações baseada em três critérios: econômico (análise custo/beneficio), técnico (exigências do nível de satisfação) e benefícios intangíveis.

Os benefícios intangíveis, segundo Apostolopoulos \& Pramataris (1997) e Violino (1997), podem ser considerados como os elementos mais importantes da TI, pois esse tipo de investimento implica em mudanças em toda a estrutura organizacional, difíceis de serem medidas em termos absolutos. Entre eles, podem-se citar: alta satisfação do usuário e nível de serviço, melhoria da estrutura organizacional, maior qualidade do produto, melhoria das comunicações interna/externa, ganhos de vantagem competitiva, melhoria das relações com fornecedores.

Segundo Hamilton (1993), dentre os benefícios intangíveis no emprego da tecnologia Automatic Vehicle Location (AVL), por satélite, nos EUA, destacam-se: melhoria da comunicação do motorista; redução do tempo de espera do motorista através da minimização das chamadas de comunicação por voz; melhoria do serviço ao cliente; apoio de ferramenta valiosa de vendas e de marketing; aumento na eficiência das entregas.

Em relação ao Brasil, Reis (1997) relaciona os seguintes benefícios intangíveis, advindos dos sistemas de rastreamento por satélite: melhoria do serviço ao cliente; aumento da eficiência operacional do veículo; menor ociosidade do veículo; melhor aproveitamento da capacidade do veículo; melhor controle da jornada do motorista; aumento da segurança do veículo e do motorista; socorro mais rápido em caso de acidentes; menor perda de tempo durante as revisões e manutenções.

\footnotetext{
${ }^{5}$ Norton, D. A case study: Hercules incorporated. Stage by Stage, v.6, n. 5, p.11-17, 1986.
} 
Além disso, a Autotrac (1996) argumenta que há outros benefícios relevantes (entre eles, redução dos sinistros e roubos, redução das despesas com telefonemas na estrada e redução das despesas com socorro e salvamento, aumento na qualidade dos serviços aos clientes, refletidos em menores preços e maior eficiência), que garantem retornos do investimento em 12 meses, em média, e compensação dos investimentos em equipamentos de rastreamento por satélite.

Assim, para entender melhor a importância e o potencial de crescimento dos sistemas de rastreamento por satélite no transporte rodoviário de cargas, este estudo abordará aspectos relativos ao perfil das empresas usuárias desses sistemas, aos tipos de produtos transportados, aos tipos de sistemas mais usados no mercado e procurará detectar quais são as principais ações tomadas pelas empresas para melhor se adequarem a essa nova tecnologia, os maiores impactos ocasionados pelo seu emprego nas empresas e os maiores benefícios obtidos pelas transportadoras com o uso dos rastreadores. 


\section{MATERIAL E MÉTODOS}

Neste capítulo será apresentado o material utilizado na pesquisa, descrevendo de maneira sucinta o conteúdo dos dados e a maneira como foram obtidos. Além disso, serão propostos métodos e técnicas para explorar melhor as informações levantadas na pesquisa de campo e complementar os objetivos propostos para este estudo.

\subsection{MATERIAL DE PESQUISA}

Para que se possa ter uma melhor visão das relações envolvidas neste estudo, há cinco componentes principais que merecem ser destacados:

- empresas fornecedoras da tecnologia de informação (TI);

- seguradoras, que têm atuado como parceiras das empresas fornecedoras de sistemas de rastreamento;

- transportadoras, empresas usuárias primárias do sistema, ou seja, a que efetivamente o utilizam;

- indústrias, atacadistas, varejistas, ou seja, empresas usuárias secundárias do sistema que, através do uso eficiente do sistema pelas usuárias primárias, receberiam o produto em melhores condições e em tempo hábil;

- consumidor final, que é o usuário final, e por isso acumula os benefícios e imperfeições dos sistemas. Portanto, sua satisfação quanto à qualidade e disponibilidade das cargas transportadas torna-se imprescindível para que essa cadeia seja contínua e aberta a mudanças tecnológicas. 
Esta pesquisa baseou-se nas empresas usuárias primárias (transportadoras) que, teoricamente, têm recebido os principais impactos da adoção dessas novas tecnologias. Destas, foram selecionadas as que fazem parte do transporte rodoviário de cargas, pois este setor possui o maior número de usuários dos sistemas de rastreamento por satélite, de acordo com informações obtidas junto aos principais fornecedores de rastreadores no Brasil.

Para compor o universo de estudo utilizou-se o cadastro do Sistema de Informações de Fretes para Cargas Agrícolas (SIFRECA, projeto da ESALQ/ Departamento de Economia, Administração e Sociologia, que visa a coleta e divulgação de informações sobre fretes rodoviários, ferroviários e hidroviários). Este referencial foi complementado através de informações sobre as transportadoras usuárias provenientes de: artigos de revistas (Reis, 1997; Lopez, 1996) e jornais (Tecnologia, 1995); alguns fornecedores de sistemas; Anuário do Transporte Rodoviário de Carga, 1996; As Maiores do Transporte, 1997.

Foram escolhidas apenas as transportadoras rodoviárias de cargas que possuíam matriz ou filial na cidade de São Paulo, uma vez que o Estado de São Paulo possuía na ocasião da seleção de empresas (em novembro de 1997) em torno de $49 \%$ das transportadoras do Brasil (seguido pelo Estado do Paraná com 13\% e Santa Catarina com $12 \%$ em relação ao total no Brasil). A cidade de São Paulo possuía o maior número de empresas dentro do Estado de São Paulo (em torno de 30\% em relação ao Estado), seguida por Santos, com 7\%, e por Guarulhos, com 6\%.

Para que se pudesse caracterizar esse setor quanto ao uso dos sistemas de rastreamento por satélite, havia a necessidade de que as empresas usuárias desses sistemas, que atuavam no transporte rodoviário de carga, fossem discriminadas. Como apenas algumas empresas fornecedoras dos sistemas de rastreamento disponibilizaram informações com relação aos seus principais clientes no ramo do transporte rodoviário de cargas, foi realizado um levantamento por telefone, a partir de cadastro disponível, para se identificar quais empresas utilizavam ou não rastreamento por satélite em suas atividades. Foram localizadas 755, dentre o total de 1338 empresas que faziam parte do cadastro, e dessas apenas 61 confirmaram usar o sistema. Obteve-se, assim, o universo 
deste estudo, composto por 61 empresas usuárias do rastreamento por satélite, que possuíam matriz ou filial na cidade de São Paulo.

Dentre as empresas não usuárias, 73 delas, escolhidas aleatoriamente, forneceram algumas explicações sobre os motivos que as levaram a não utilizar os sistemas de rastreamento (Figura 2). Em torno de $47 \%$ delas representavam empresas pequenas, com frota própria reduzida ou inexistente (praticamente só composta por terceiros). Outras tecnologias alternativas eram usadas por $16 \%$ das transportadoras, como bip, rádio, escolta e telefone celular. Além disso, os altos custos para implantação dos rastreadores foram apontados por $11 \%$ das empresas como o principal motivo para não utilização de sistemas de rastreamento, enquanto aproximadamente outros $11 \%$ das transportadoras não conheciam tais sistemas.

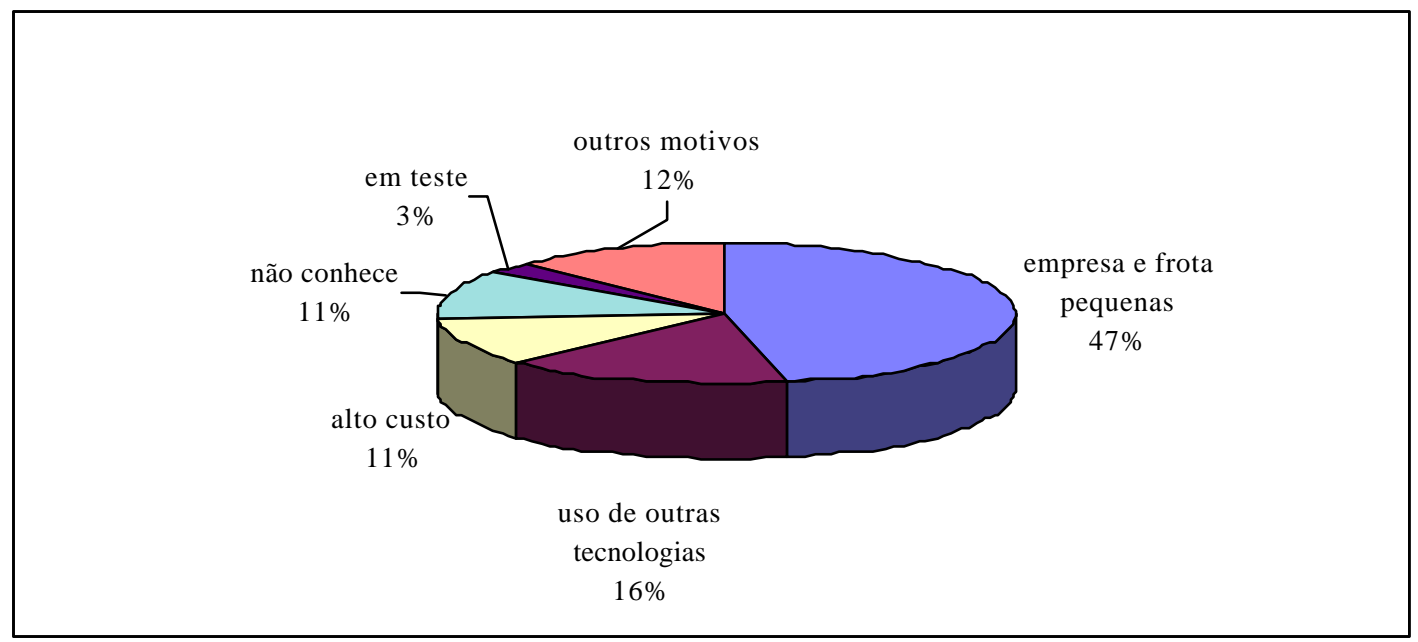

Figura 2 - Principais Motivos para Não Utilização de Sistemas de Rastreamento por Satélite em Transportadoras Rodoviárias de Carga, Cidade de São Paulo, 1997.

\subsubsection{Obtenção da amostra}

Após a formulação do questionário, através do qual procurou-se relacionar as variáveis importantes para dar prosseguimento ao estudo em questão, o seu conteúdo foi testado em três empresas através de entrevistas pessoais aplicadas em novembro de 
1997. Esse levantamento piloto indicou a necessidade de pequenas alterações, que foram incorporadas durante a sua execução. Assim, todas as informações colhidas nesta etapa poderiam ser aproveitadas, se essas empresas fossem sorteadas novamente no levantamento por amostragem.

Em função do resultado altamente satisfatório das entrevistas, optou-se por aplicar pessoalmente o questionário final (Apêndice 1) aos responsáveis por essa área em 36 empresas sorteadas ao acaso. Justifica-se esse procedimento devido a:

- restrição orçamentária, pois um levantamento censitário seria muito dispendioso e não seria a única alternativa válida para se obterem dados com qualidade;

- grande incerteza de obter retorno dos questionários se fossem enviados às transportadoras por correio ou fax, dado que se trata de um setor fechado e receoso em divulgar informações mais detalhadas sobre áreas chaves dentro da empresa.

Deve-se ressaltar que houve esclarecimentos do propósito da pesquisa e do destino das informações coletadas e que foi informado a cada empresa entrevistada que seria mantido o sigilo individual dos dados básicos obtidos deste estudo. Dispendeu-se em média 1,32 horas em cada empresa (para a obtenção de todos os dados necessários para a pesquisa foram necessárias aproximadamente 35 horas, no decorrer de 1 mês de levantamento de campo, com uma variação de 30 a 170 minutos para cada entrevista). No entanto, durante o processo de sorteio das empresas, observou-se que:

- quatro empresas, embora usuárias dos sistemas de rastreamento, não puderam ser entrevistadas, pois os responsáveis por essa área não foram localizados na época da pesquisa;

- duas empresas não foram entrevistadas em função do pouco tempo de uso do sistema (em torno de 1 a 2 semanas), pois alegaram não ter, na ocasião, nenhuma informação sobre a utilização do rastreador na empresa;

- quatro se recusaram a participar da pesquisa, alegando estarem impossibilitadas de divulgar informações confidenciais sobre o uso interno do sistema. 
Desta forma, houve em torno de $28 \%$ de falta de resposta em relação ao total amostrado. Apesar de existirem alguns procedimentos alternativos para a redução desse viés amostral, que é diretamente proporcional à proporção de falta de respostas, Pino \& Caser (1984) enfatizam que deve haver, além da finalidade de se obterem resultados satisfatórios, a preocupação com o aumento da variância e do custo se forem realizadas novas tentativas e utilizados métodos específicos para diminuir a falta de resposta. Assim, optou-se por não reduzir o viés, com base nessas considerações e nas justificativas apresentadas anteriormente.

Deve-se, também, salientar a análise descritiva dos dados, realizada a partir de médias, desvios padrões, variâncias e coeficientes de variação. Suas fórmulas estão relacionadas na Tabela 1. Para isso, foram consideradas $n$ observações na amostra, $p$ sucessos em $n$ ensaios Bernoulli independentes (para o caso de distribuições binomiais), $p_{i}$ sucessos em $n$ ensaios Bernoulli independentes para um resultado $i$, com $i=1,2, \ldots, k$ (para o caso de distribuições multinomiais).

Tabela 1. Fórmulas de Algumas Estatísticas Descritivas relativas às Distribuições Normal, Binomial e Multinomial.

\begin{tabular}{lccc}
\hline \multicolumn{1}{c}{ Estatísticas } & Distribuição Normal & $\begin{array}{c}\text { Distribuição } \\
\text { Binomial }\end{array}$ & $\begin{array}{c}\text { Distribuição } \\
\text { Multinomial }\end{array}$ \\
\hline Média $(\bar{x})$ & $\frac{1}{n} \sum_{i=1}^{n} x_{i}(i=1,2, \ldots, n)$ & $p$ & $p_{i}$ \\
\hline $\begin{array}{l}\text { Estimativa da } \\
\text { variância }\left(s^{2}\right)\end{array}$ & $\frac{1}{n-1} \sum_{i=1}^{n}\left(x_{i}-\bar{x}\right)^{2}$ & $\frac{p(1-p)}{n}$ & $\frac{p_{i}\left(1-p_{i}\right)}{n}$ \\
\hline $\begin{array}{l}\text { Estimativa do } \\
\text { Desvio padrão }(s)\end{array}$ & $\sqrt{s^{2}}$ & {$\left[\frac{p(1-p)}{n}\right]^{\frac{1}{2}}$} & {$\left[\frac{p_{i}\left(1-p_{i}\right)}{n}\right]^{\frac{1}{2}}$} \\
\hline $\begin{array}{l}\text { Estimativa do } \\
\text { coeficiente de } \\
\text { variação }(\mathrm{CV}) \text { - \% }\end{array}$ & $\left(\frac{s}{\bar{x}}\right) 100$ & {$\left[\frac{(1-p)}{n p}\right]^{\frac{1}{2}} 100$} & {$\left[\frac{\left(1-p_{i}\right)}{n p}\right]^{\frac{1}{2}} 100$} \\
\hline
\end{tabular}

Fonte: Evans, Hastings e Peacock (1993) e Kish (1965) 
De acordo com a fórmula do coeficiente de variação para variáveis binomiais ou multinomiais do levantamento amostral (ver Apêndice 1), o seu valor será 6,54\% para proporção igual a 0,90; à medida em que as proporções diminuírem, o coeficiente de variação aumentará com diferenciais cada vez maiores, elevando o erro de amostragem. Este fato está relacionado a amostras de eventos $\operatorname{raros}^{6}$. De maneira geral, os resultados da amostra serão satisfatórios e poderão ser expandidos para toda a população se houver proporção mínima de 0,50 (onde o seu coeficiente de variação será igual a 19,61\% e seu valor variará de 0,30 a 0,70 ) para a variável analisada.

\subsection{ESPECIFICAÇÃO DOS DADOS}

Para caracterizar o uso dos sistemas de rastreamento por satélite em empresas da área de transporte rodoviário de cargas, várias questões foram propostas, conforme apresentadas no questionário utilizado junto às empresas amostradas (Apêndice 1).

Para identificar o perfil das empresas usuárias dos sistemas, foram analisadas as respostas dadas às seguintes questões: 8, 11, 12 e 13, que se referem, respectivamente, a tipo de empresa (matriz ou filial), tipo de frota (própria e/ou terceiros), faixa de faturamento anual, volume total transportado em média por ano e tempo de existência da empresa.

As cargas mais transportadas pelas empresas, com e sem rastreadores, foram obtidas a partir da questão 1. Associadas a elas foram relacionadas as regiões de entrega mais freqüentes ao longo do ano e a localização das filiais das empresas que utilizam ou não os sistemas. Essas informações foram fornecidas, respectivamente, por meio das questões 2 e 9.

Em relação ao nível de utilização dos sistemas de rastreamento, havia algumas variáveis essenciais para comparar sua abrangência em relação ao mercado e às transportadoras (todas relativas à questão 4): porcentagem de caminhões rastreados em relação às frotas própria e total (que inclui caminhões próprios e de terceiros), tempo de

\footnotetext{
${ }^{6}$ Maiores detalhes poderão ser encontrados em Kish (1965) e em Pino, Igue e Amaro (1990).
} 
uso do sistema, nível de satisfação com o sistema. Além disso, o tipo de análise econômica utilizada pelas empresas para adquirirem os rastreadores (questão 7) também foi importante para confrontar os tipos de sistemas disponíveis no mercado.

Para entender melhor o emprego dos sistemas nas transportadoras, três aspectos foram abordados: os impactos ocasionados pelo emprego dos sistemas (questão 3), as principais ações tomadas pelas empresas para sua melhor adequação aos rastreadores (questão 5) e os maiores benefícios obtidos pelas transportadoras com o uso dos sistemas de rastreamento (questão 6).

\subsection{MÉtodos e TÉCNICAS PRopostos PARA O ESTUDO}

Para complementar a análise descritiva dos dados, propôs-se dois tipos de enfoques para que as variáveis pudessem ser exploradas com maior profundidade: o primeiro, centrado nas variáveis quantitativas, através da análise de regressão; o segundo, baseado nas variáveis qualitativas (que eram a maioria), através de análises multivariadas.

\subsubsection{Análise de Regressão}

O principal objetivo de uma análise de regressão é explicar o comportamento de uma variável dependente a partir de, no mínimo, uma variável independente. De maneira geral, essas variáveis podem ser relacionadas como mostra a eq. (1).

$$
y_{i}=\alpha+\beta x_{i}+\varepsilon_{i}
$$

onde:

$y_{i}:$ valor da variável dependente na observação $i, \operatorname{com} i=1, \ldots, n$;

$x_{i}$ : valor da variável independente na observação $i, \operatorname{com} i=1, \ldots, n$; 
$\alpha$ : intercepto; $\beta$ : coeficiente de regressão;

$\varepsilon_{i}$ : erro aleatório.

Suas pressuposições básicas são: não há correlação entre o regressor $\left(x_{i}\right)$ e o erro aleatório $\left(\varepsilon_{i}\right)$; o erro $\left(\varepsilon_{i}\right)$ possui distribuição normal com média zero e variância $\sigma^{2}$; há homocedasticidade, ou seja, a variância de $\varepsilon_{i}$ é e igual a $\sigma^{2}$ e é constante para todo $i^{7}$.

Além disso, a esse modelo pode-se adicionar variáveis binárias como preditoras, também conhecidas como dummy $\left(z_{i}\right)$, que têm a finalidade de possibilitar comparações entre diferentes situações ou grupos de observações. Sua forma geral está expressa na eq. (2):

$$
y_{i}=\alpha+\beta x_{i}+\delta z_{i}+\varepsilon_{i}
$$

onde:

$z_{i}$ : valor da variável independente na observação $i, \operatorname{com} i=1, \ldots, n$;

$\alpha$ : intercepto; $\beta, \delta$ : coeficiente de regressão.

Com esse instrumental estatístico foi analisada a influência do tempo de uso dos sistemas e do tipo de sistema utilizado pela empresa (variável binária que assume valor 0 para sistemas com satélite e rádio e valor 1 para sistemas só com satélites) sobre a porcentagem de caminhões rastreados.

\subsubsection{Análise Multivariada}

Para entender melhor as relações entre basicamente três grupos de variáveis categóricas (maiores impactos ocasionados pelo emprego dos sistemas, questão 3; principais ações tomadas pelas empresas para sua melhor adequação aos rastreadores,

\footnotetext{
${ }^{7}$ Explicações mais detalhadas podem ser encontradas em Greene (1993).
} 
questão 5; maiores benefícios obtidos pelas transportadoras com o uso dos sistemas de rastreamento, questão 6), relevantes para a caracterização dos sistemas de rastreamento, foram utilizadas análises de correspondência e de conglomerados.

\subsubsection{Análise de Correspondência}

De acordo com Hair et al. (1995), a análise de correspondência é uma das técnicas recentemente desenvolvidas para analisar relações não lineares e dados com respostas categóricas (medidas em termos nominais, como por exemplo: pouco, razoável e muito), o que por sinal ocorre com as variáveis analisadas neste estudo (relativas às perguntas 3, 5 e 6 do questionário). Tem por principal objetivo agrupar variáveis altamente correlacionadas, tendo por consequiência a redução do número de variáveis preditoras do modelo (Hair et al., 1995).

Segundo Greenacre (1984) e Benzécri (1992), outros métodos devem ser utilizados, como, por exemplo, análise de regressão, discriminante ou conglomerados, para complementar a análise de correspondência.

Dos pontos de vista matemático e computacional, a análise de correspondência pode ser considerada uma técnica muito simples, porque possui caráter mais geométrico do que estatístico e, portanto, torna-se adequada para o desenvolvimento de mapas de percepção das relações existentes entre as variáveis (Greenacre, 1984; Hair et al., 1995).

Dentre as aplicações desta análise, pode-se relacionar as realizadas por:

- Guttman ${ }^{8}$ (1971), citado por Greenacre (1984), que relacionou as principais preocupações de pessoas adultas de origem israelita;

- Meimaris $^{9}$ (1978), citado por Benzécri (1992), que objetivou mostrar as relações existentes entre a origem sócio-econômica dos estudantes e as carreiras que escolheram;

\footnotetext{
${ }^{8}$ Guttman, L. Measurement as structural theory. Psychometrick, v. 36, p.329-347, 1971.

9 Meimaris, M. Statistique de l'enseignement en Grèce: étude des différents établissements d'enseignement supérieur suivant 1 'origine socioprofessionelle de leurs étudiants. Cahiers de l' Analyse des Données, v.3, n.3, 355-365, 1978.
} 
- Golveia ${ }^{10}$ (1978), citado por Benzécri (1992), que teve a finalidade de comparar a competição entre diferentes indústrias para avaliar o desenvolvimento do mercado durante 5 anos.

De acordo com Crivisqui (1993), a análise de correspondência - que pode ser múltipla, ou seja, envolvendo mais de 2 variáveis - é uma generalização da análise fatorial de correspondência. De maneira geral, permite estudar I indivíduos descritos por $J$ variáveis qualitativas, expressas por modalidades (pode-se relacionar cada pergunta a uma variável e suas respostas às modalidades). Assim, nessa análise é imprescindível a definição desses três componentes (indivíduos, variáveis e suas modalidades) e sua visualização em tabelas de contingência, denominadas Tabelas $T$, que relacionam as variáveis duas a duas, conforme mostra a Tabela 2.

\section{Tabela 2. Estrutura de uma Tabela de Contingência (Tabela T) com I modalidades da variável $L$ e $J$ modalidades da variável $C$.}

\begin{tabular}{|c|c|c|c|c|c|c|}
\hline \multirow{2}{*}{$\begin{array}{c}\text { Variável } L \\
\text { (modalidades) }\end{array}$} & \multicolumn{5}{|c|}{ Variável $C$ (modalidades) } & \multirow[t]{2}{*}{ total } \\
\hline & 1 & $\ldots$ & $j$ & ... & $J$ & \\
\hline 1 & $n_{11}$ & $\ldots$ & $n_{1 j}$ & $\ldots$ & $n_{1 J}$ & $n_{1}$ \\
\hline$\ldots$ & $\ldots$ & $\ldots$ & $\ldots$ & $\ldots$ & $\ldots$ & $\ldots$ \\
\hline$i$ & $n_{i 1}$ & $\ldots$ & $n_{i j}$ & ... & $n_{i J}$ & $n_{i}$ \\
\hline ... & $\ldots$ & $\ldots$ & $\ldots$ & $\ldots$ & $\ldots$ & $\ldots$ \\
\hline$I$ & $n_{I 1}$ & $\ldots$ & $n_{I j}$ & $\ldots$ & $n_{I J}$ & $n_{I}$ \\
\hline total & $n_{.1}$ & $\ldots$ & $n_{. \mathrm{j}}$ & $\ldots$ & $n_{. J}$ & $n$. \\
\hline
\end{tabular}

Fonte: Crivisqui (1993, p.14)

Nesta tabela $n_{i j}$ é o número de indivíduos que possuem a modalidade $i$ da variável $L$ e a modalidade $j$ da variável $C ; n_{i}$. é o $i$-ésimo elemento da margem da tabela, que corresponde ao número de indivíduos que possuem a modalidade $i$ da variável $L ; n_{. j}$ é o j-ésimo elemento da margem da tabela, que corresponde ao número de indivíduos que

\footnotetext{
${ }^{10}$ Golveia, V. Brazil's imports of industrial equipment: their evolution from 1971 to 1975 . CAD, v.3, n.3, p. $307-317,1978$.
} 
possuem a modalidade $j$ da variável $C ; n$.. é a soma de todas as células da tabela, ou seja, corresponde ao total de indivíduos observados.

A partir dessa tabela, Crivisqui \& Batista (1998) acrescentam que se pode obter a tabela de frequiências relativas, denominada Tabela $\mathrm{F}$, obtida pela divisão de cada célula por $n_{. .}$, conforme mostra a eq. (3).

$$
f_{i j}=\frac{n_{i j}}{n}
$$

onde:

$f_{i j}$ : freqüência relativa ao número total de observações do i-ésimo indivíduo (que apresenta a modalidade $j$ da variável $C$ ).

No estudo de análise de correspondência múltipla, de acordo com Escofier \& Pagès (1992), o conjunto de tabelas de contingência é expresso pela Tabela de Burt (que é simétrica), cuja diagonal é constituída pelas freqüências de cada modalidade para cada variável qualitativa.

Cada uma dessas tabelas podem ser visualizadas em espaços de representação, onde as informações de suas linhas e colunas são representadas por meio das seguintes coordenadas: pontos linha, onde cada linha da tabela representa um ponto num gráfico; pontos coluna, onde cada coluna da tabela representa um ponto em outro gráfico (Figura 3). As distâncias entre os pontos linha (ou pontos coluna) são obtidas com base nas informações da tabela de contingência, conforme mostram a eq. (4) e a eq. (5). 


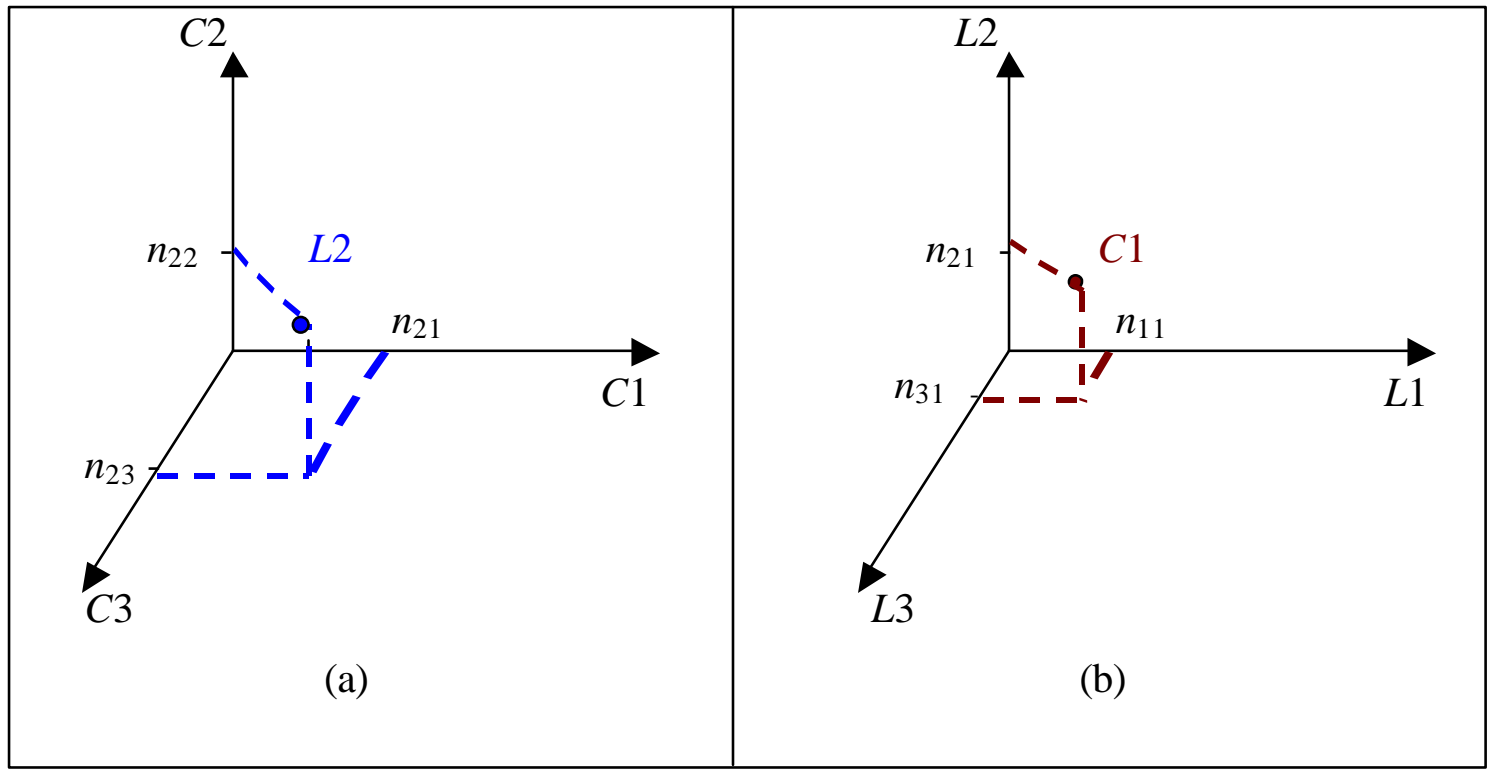

Figura 3 - Representação dos pontos linha num referencial de colunas (a) e dos pontos coluna num referencial de linhas (b), a partir da Tabela T (Crivisqui, 1993, p.40).

$$
d_{\left(i, i^{\prime}\right)}=\sqrt{\sum_{j=1}^{J}\left(n_{i j}-n_{i^{\prime} j}\right)^{2}} \quad \forall i, i^{\prime}
$$

onde:

$d_{(i, i)}$ : distância entre dois elementos linha da tabela;

$n_{i j}$ : elemento da $i$-ésima linha e $j$-ésima coluna;

$n_{i^{\prime} j}$ : elemento da $i^{\prime}$-ésima linha e $j$-ésima coluna.

$$
d_{\left(j, j^{\prime}\right)}=\sqrt{\sum_{i=1}^{I}\left(n_{i j}-n_{i j^{\prime}}\right)^{2}} \quad \forall j, j^{\prime}
$$

onde:

$d_{\left(j, j^{\prime}\right)}:$ distância entre dois elementos linha da tabela; 
$n_{i j}$ : elemento da $i$-ésima linha e $j$-ésima coluna;

$n_{i j}$ : elemento da $i$-ésima linha e $j$ '-ésima coluna.

Para representar melhor os elementos de uma tabela de contingência ou de freqüências relativas, segundo Crivisqui \& Batista (1998), o seu conteúdo é comparado em termos de perfis em linha $\left(f_{i \mid C_{j}}\right.$, que é a proporção da $i$-ésima sub-população que apresenta a modalidade $j$ da variável $C$ ) e de perfis em coluna $\left(f_{j \mid L_{i}}\right.$, que é a proporção da $j$-ésima sub-população que apresenta a modalidade $i$ da variável $L$ ). Para neutralizar as distorções da tabela de contingência, utiliza-se a distância de qui-quadrado (ou distância de Benzécri, trata-se de uma distância euclidiana ponderada) para avaliar dois perfis em linha ou em coluna, conforme mostra a Tabela 3.

Tabela 3. Fórmulas dos Perfis em Linha e em Coluna obtidos a partir de Tabelas de Contingência e de Freqüiências Relativas.

\begin{tabular}{|c|c|c|c|}
\hline \multirow{3}{*}{$\begin{array}{c}\text { Perfis } \\
\text { Em } \\
\text { linha }\end{array}$} & \multicolumn{2}{|r|}{ Tabelas } & \multirow{2}{*}{$\begin{array}{c}\text { Distância de Qui-Quadrado } \\
\text { entre dois perfis }\end{array}$} \\
\hline & de Contingência & de Freqüências relativas & \\
\hline & $\begin{array}{l}f_{i \mid C_{j}}=\frac{n_{i j}}{n_{i .}} \\
\forall i \in I, \forall j \in J\end{array}$ & $\begin{array}{l}f_{i \mid C_{j}}=\frac{f_{i j}}{f_{i .}} \\
\forall i \in I, \forall j \in J\end{array}$ & $\begin{array}{c}d_{\left(i, i^{\prime}\right)}=\sqrt{\sum_{j=1}^{J} \frac{1}{f_{. j}}\left(\frac{f_{i j}}{f_{i .}}-\frac{f_{i^{\prime} j}}{f_{i^{\prime} .}}\right)^{2}} \\
\forall i, i^{\prime} \in I\end{array}$ \\
\hline $\begin{array}{c}\text { Em } \\
\text { coluna }\end{array}$ & $\begin{array}{l}f_{j \mid L_{i}}=\frac{n_{i j}}{n_{j} .} \\
\forall i \in I, \forall j \in J\end{array}$ & $\begin{array}{l}f_{j \mid L_{i}}=\frac{f_{i j}}{f_{. j}} \\
\forall i \in I, \forall j \in J\end{array}$ & $\begin{array}{c}d_{\left(j, j^{\prime}\right)}=\sqrt{\sum_{i=1}^{I} \frac{1}{f_{i .}}\left(\frac{f_{i j}}{f_{. j}}-\frac{f_{i j^{\prime}}}{f_{. j^{\prime}}}\right)^{2}} \\
\forall j, j^{\prime} \in J\end{array}$ \\
\hline
\end{tabular}

Fonte: Crivisqui \& Batista (1998, p.27 e 37)

Para que os pontos-perfis possam ser comparados utiliza-se outra medida, inércia, que associa a cada ponto um peso, à medida que sua posição relativa se altera. Assim, a informação da tabela de frequiências relativas "pode ser lida em termos de 
dispersão dos pontos-massa em relação a um ponto de referência" (Crivisqui, 1993, p.75).

De acordo com Crivisqui \& Batista (1998, p. 48-49), "a inércia (ou dispersão) de uma nuvem de pontos em relação a um ponto $m$ qualquer é igual à soma, para todos os pontos, do produto do peso associado a cada ponto pelo quadrado da distância de cada ponto a $m$ " ( $m$ é um ponto qualquer no espaço, tomado como referência), conforme mostram a eq.(6) e a Figura 4.

$$
I_{m}=\sum_{i=1}^{I} p_{i} d_{(i, m)}^{2} \quad \forall i \in I
$$

onde:

$I_{m}$ : inércia da nuvem de pontos em relação a $m$, sendo que o conjunto de pontos-perfis é representado por $I=\{1,2, \ldots, i\}$;

$p_{i}$ : peso (ou massa) associado a cada ponto $i$;

$d_{(i, m)}:$ distância entre cada ponto $i$ a $m$.

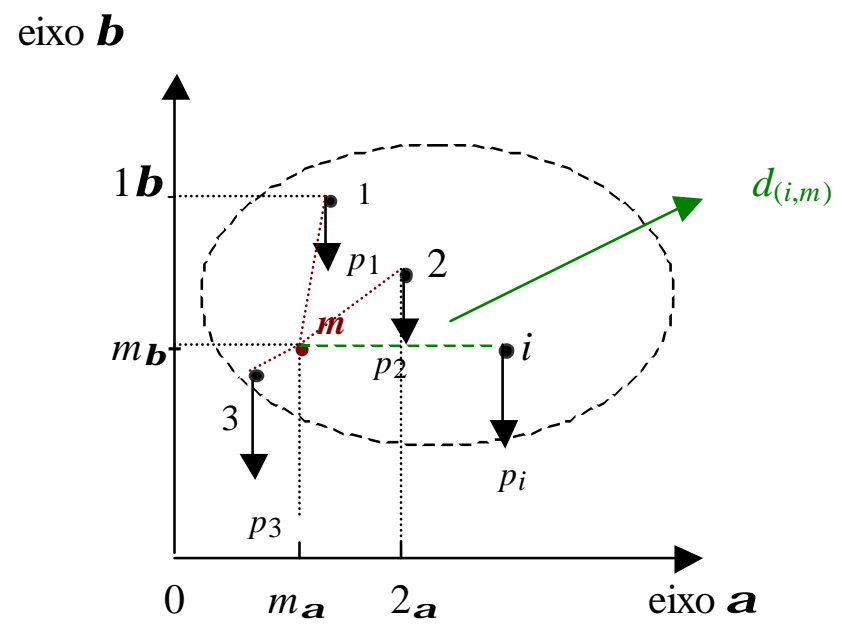

Figura 4 - Representação da Nuvem de Pontos-Perfis em Relação ao Ponto $m$ (Crivisqui \& Batista, 1998, p.48). 
De acordo com Crivisqui \& Batista (1998), a construção das nuvens de pontos em relação ao ponto $G$ (centro de gravidade ou centróide ou vetor médio das coordenadas dos elementos) torna possível a análise da forma dessa nuvem e sua representação gráfica, pois esse ponto possui um valor mínimo de inércia.

Nesse novo sistema de referência, os pontos-perfis são expressos quantitativamente por fatores e são representados nos espaços (ou eixos) fatoriais por coordenadas (Crivisqui, 1993).

Considerando as variáveis quantitativas (fatores), a variância de uma nuvem de pontos pode ser representada por autovalores, a partir da soma das inércias em cada eixo fatorial, ou seja, reproduzem "parte da relação observada entre as variáveis em cada eixo fatorial" (Crivisqui, 1993, p.138), conforme mostra a eq. (7).

$$
s_{\alpha}^{2}=\sum_{i=1}^{I} p_{i}\left[F_{\alpha}(i)\right]^{2} \quad \forall \alpha=1,2, \ldots, p
$$

onde:

$s_{\alpha}^{2}$ : variância do fator $\alpha$, onde $\alpha=1,2, \ldots, p$;

$p_{i}$ : peso associado a cada ponto $i$, onde $i=1,2, \ldots, I$;

$F_{\alpha}(i)$ : coordenada fatorial da $i$-ésima linha da Tabela T sobre o eixo fatorial $\alpha$.

O significado da informação representada no plano fatorial (expresso por dois eixos: 1 e 2, 1 e 3, e assim por diante) é interpretado pelos seguintes componentes: autovalor associado ao eixo $\alpha$, contribuição relativa dos pontos-perfis para a inércia ao longo de um eixo fatorial, contribuição relativa de um fator à distância de um pontoperfil ao centro de gravidade. Tais componentes são descritos mais pormenorizadamente nas próximas seções ${ }^{11}$.

11 Além dos componentes principais (ativos, que fazem parte das tabelas de contingência e são efetivamente utilizados na análise), há ainda aqueles denominados suplementares que, apesar de excluídos dos cálculos dos totais marginais (nas linhas e nas colunas), podem fornecer informações adicionais sobre as relações entre os elementos analisados (Benzécri, 1992). 


\section{- Autovalor associado ao eixo $\alpha$}

Por construção, o autovalor do eixo 1 deve ser maior do que o do eixo 2, e assim, sucessivamente $\left(\lambda_{1} \geq \lambda_{2} \geq \lambda_{3} \geq \lambda_{4} \ldots\right.$... De maneira geral, seus valores auxiliam a definir o número ideal de planos fatoriais, uma vez que devem ser considerados os autovalores que forem maiores ou iguais ao autovalor médio (segundo Benzécri, 1992, abaixo desse valor, geralmente, a porcentagem da inércia diminui de forma regular). Está expresso na eq. (8).

$$
\lambda_{\alpha}=s_{\alpha}^{2}=\sum_{i=1}^{I} p_{i}\left[F_{\alpha}(i)\right]^{2} \quad \forall \alpha=1,2, \ldots, p
$$

onde:

$\lambda_{\alpha}$ : autovalor associado ao eixo $\alpha$, onde $\alpha=1,2, \ldots, p$.

No entanto, esse autor alerta que a interpretação de fatores sucessivos deve ser realizada até que se possa estabelecer algum significado para as associações entre as variáveis.

- Contribuição relativa dos pontos-perfis para a inércia ao longo de um eixo fatorial

A partir de valores altos desse componente, pode-se identificar se houve contribuições balanceadas ou de poucos pontos ao eixo $\alpha$, conforme mostra a eq. (9):

$$
\operatorname{CTR}_{\alpha}(i)=\frac{p_{i}\left[F_{\alpha}(i)\right]^{2}}{\lambda_{\alpha}} \quad \forall i \in N(I)
$$


onde:

$C T R_{\alpha}(i)$ : contribuição relativa do ponto $i$ da inércia do eixo $\alpha$;

$N(I)$ : nuvem de pontos.

- Contribuição relativa de um fator à distância de um ponto-perfil ao centro de gravidade

De acordo com Crivisqui (1993), esta contribuição é interpretada como o quadrado do coeficiente de correlação entre dois pontos linha (ou entre dois pontos coluna). Assim, pode-se dizer que mede a qualidade da representação da distância do ponto $i$ à origem do eixo $\alpha$, pois à medida que essa contribuição relativa aumenta, reflete em melhoria na associação de um ponto perfil $i$ em um eixo fatorial $\alpha$, conforme mostra a eq. (10):

$$
C O R_{\alpha}(i)=\cos ^{2}(\omega)=\frac{\left[F_{\alpha}(i)\right]^{2}}{d^{2}(i, 0)}
$$

onde:

$\operatorname{COR}_{\alpha}(i)$ : contribuição relativa de um fator;

$\cos ^{2}(\omega)$ : quadrado do cosseno do ângulo $\omega$ (vide Figura 5);

$d(i, 0)$ : distância de um ponto-perfil à origem dos eixos fatoriais.

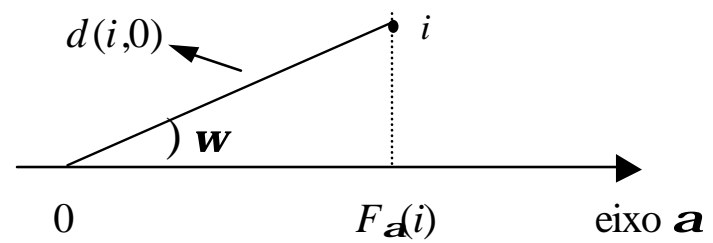

Figura 5 - Representação do Ponto-Perfil $i$ e do eixo fatorial $\alpha$ num plano (Crivisqui, 1993, p.159). 
Nas seções 4.5.1, 4.6.1 e 4.7.1 são apresentados e discutidos os resultados da análise de correspondência aplicada às variáveis das questões 3,5 e 6, respectivamente.

\subsubsection{Análise de Conglomerados}

A análise de conglomerados é uma técnica multivariada que tem por objetivo agrupar indivíduos a partir de similaridades ou distâncias, ou seja, geralmente a proximidade dos itens é indicada por algum tipo de distância e as variáveis são agrupadas com base em coeficientes de correlação ou medidas de associação (Dillon \& Goldstein, 1984; Johnson \& Wichern, 1992).

Segundo os mesmos autores, dentre os coeficientes de similaridade utilizados nesta análise destaca-se a distância euclidiana. Geralmente, prefere-se utilizá-la para análises de agrupamento, pois contém variâncias e covariâncias da amostra em sua fórmula, como mostra a eq. (11):

$$
d(\mathbf{x}, \mathbf{y})=\sqrt{(\mathbf{x}-\mathbf{y})^{\prime} \mathbf{A}(\mathbf{x}-\mathbf{y})}
$$

onde:

$d(\mathbf{x}, \mathbf{y})$ : distância euclidiana entre as observações da amostra contidas nos vetores $\mathbf{x}$ e $\mathbf{y}$

$\mathbf{x}$ : vetor coluna que contém $p$ observações de um item: $\mathbf{x}=\left[x_{1}, x_{2}, \ldots, x_{p}\right]^{\prime}$;

$\mathbf{y}$ : vetor coluna que contém $p$ observações de outro item: $\mathbf{y}=\left[y_{1}, y_{2}, \ldots, y_{p}\right]^{\prime}$;

A: matriz inversa da matriz de variâncias e covariâncias da amostra.

Além da escolha de uma medida de similaridade adequada, o tipo de algoritmo computacional utilizado para a análise também é muito importante. Dentre as técnicas mais conhecidas deve-se citar: hierárquicas, onde os grupos são separados em vários 
níveis, sem que se conheça a priori o número de conglomerados ou a divisão inicial; particionadas (não hierárquicas), onde os grupos são formados por algum critério específico, exigindo-se, portanto, a definição do número de agrupamentos ou da divisão inicial (Sharma, 1996).

Nas técnicas hierárquicas há métodos que auxiliam no agrupamento, destacandose entre eles: aglomerativos (tais como, vizinho mais próximo, centróide, Ward), que agrupam primeiramente os objetos mais semelhantes; hierárquicos divisivos (tal como detecção automática de interação), que dividem, inicialmente, os objetos em dois subgrupos bem distintos (Dillon \& Goldstein, 1984). Os resultados desses métodos são mostrados graficamente na forma de um diagrama de duas dimensões (dendrograma ou árvore de classificação).

Entre os métodos aglomerativos, o do centróide utiliza a distância entre os valores médios das observações das variáveis para obter a distância euclidiana entre dois agrupamentos; no método do vizinho mais próximo, a distância entre conglomerados é definida como a distância entre os elementos mais próximos (Dillon \& Goldstein, 1984; Hair et al., 1995).

O método de Ward baseia-se no agrupamento de indivíduos dentro de conglomerados a partir da soma dos quadrados dos desvios das observações (error sum of squares - ESS), conforme especificada na eq.(12). A cada estágio essa soma é minimizada a partir da combinação de dois agrupamentos do estágio anterior. Outra característica deste método é a união de conglomerados que têm um pequeno número de observações (Hair et al., 1995).

$$
E S S=\sum_{j=1}^{k}\left(\sum_{i=1}^{n_{j}} X_{i j}^{2}-\frac{1}{n_{j}}\left(\sum_{i=1}^{n_{j}} X_{i j}\right)^{2}\right)
$$

onde:

ESS : soma dos quadrados dos desvios das observações;

$X_{i j}$ : valor característico (traço) do indivíduo $i$ no conglomerado $j$; 
$k$ : número total de conglomerados em cada estágio;

$n_{j}:$ número de indivíduos no conglomerado $j$.

Nas técnicas não hierárquicas o método mais utilizado é o $k$-means. Neste algoritmo cada item é agrupado em relação ao centróide mais próximo, ou seja, procurase por uma partição que possua o menor componente de erro $(E)$, definido pela eq. (13), por meio de trocas de indivíduos de um agrupamento para outro até que não ocorram mais reduções no valor de $E$ (Dillon \& Goldstein, 1984).

$$
E[P(n, k)]=\sum_{i=1}^{n} D[i, l(i)]^{2}
$$

onde:

$P(n, k)$ : partição onde cada um dos $n$ indivíduos são alocados em cada um dos $k$ conglomerados;

$l(i)$ : conglomerado que contém o indivíduo $i$;

$D[i, l(i)]:$ distância euclidiana entre o indivíduo $i$ e $l(i)$.

De acordo com Sharma (1996), o desempenho deste método é muito melhor quando se utiliza a divisão inicial dos métodos hierárquicos, mostrando que as técnicas hierárquicas e não hierárquicas deveriam ser consideradas complementares e não alternativas $^{12}$.

De acordo com Crivisqui (1998), pode-se utilizar o algoritmo de classificação hierárquica de Ward para selecionar o número ótimo de classes (grupos), por meio da interpretação do dendrograma, com base nas coordenadas dos planos fatoriais da análise de correspondência. A composição de cada uma das classes poderá ser obtida empregando-se o método não hierárquico $k$-means.

${ }^{12}$ A análise de conglomerados, segundo Sharma (1996), pode ser indicada a algumas situações: identificar cidades similares que poderiam ser usadas para testar produtos; identificar grupos de votantes que têm as mesmas idéias sobre assuntos políticos importantes; entre outras. 
Desta forma, a análise de agrupamentos pode ser aplicada posteriormente à análise de correspondência a cada uma das questões do levantamento de campo (mais especificamente, 3, 5 e 6), para agrupar as empresas (ou os sistemas utilizados por elas) que possuam características semelhantes. 


\section{RESULTADOS E DISCUSSÃO}

A partir da pesquisa realizada com 26 empresas do setor de transporte rodoviário de cargas, cujas matrizes ou filiais se localizavam na cidade de São Paulo, foram ressaltados alguns tópicos importantes, extraídos das informações obtidas das entrevistas. Além disso, as respostas obtidas através dos questionários são organizadas e tratadas estatisticamente.

\subsection{PERFIL DAS EMPRESAS AMOSTRADAS}

O tempo de existência das empresas entrevistadas variou de 3,5 a 70 anos (média de 42 anos). Apenas duas delas atuavam no mercado há menos de 6 anos; o restante possuía no mínimo 10 anos de existência (Figura 6).

Aproximadamente 58\% das empresas eram filiais; o restante, matrizes. Do total, $85 \%$ utilizavam frota própria e de terceiros; as demais empregavam apenas frota própria no transporte de cargas.

Houve uma grande amplitude em relação ao faturamento anual das empresas previsto para o ano de 1997: em torno de 56\% das transportadoras possuíam de US\$ 1 a 99 milhões. Além disso, algumas empresas entrevistadas se auto-classificaram como sendo de médio porte (6 delas) ou de grande porte (3 delas). 


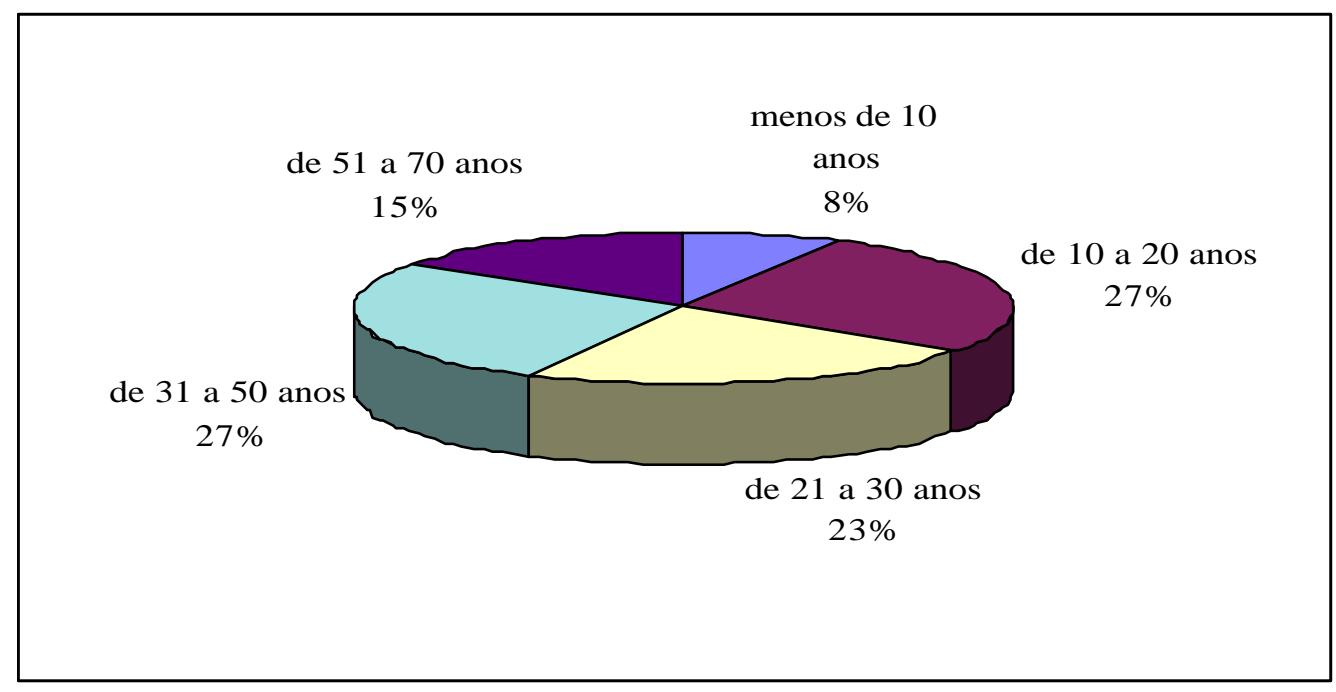

Figura 6 - Tempo de Existência (anos) das Empresas Entrevistadas, Cidade de São Paulo, 1997-98.

Como dado auxiliar para compor o perfil dessas transportadoras, foi obtido o volume total transportado, em média, por ano. No entanto, observou-se que aproximadamente $40 \%$ preferiram não informar o volume transportado. Em relação às empresas que informaram em toneladas por ano, houve diferenças bem significativas entre os volumes relatados, que variaram de 1,8 mil a 20 milhões de toneladas por ano, principalmente em função dos tipos de cargas transportadas pelas empresas. Constatouse, portanto, que a maioria dessas empresas trabalhava com cargas gerais ${ }^{13}$ (ou comuns).

Além disso, para melhor avaliar o perfil da empresa, é interessante conhecer algumas características da pessoa entrevistada. A Figura 7 mostra a relação entre sua formação profissional (estudante de administração de empresas/economia - F1; nível médio - F2; técnico em contabilidade - F3; contador - F4; administrador de empresas F5; analista de sistemas - F6; ciências contábeis - F7; economista - F8; engenheiro de 
produção - F9; estatístico - F10; sistema gerencial - F11), o tempo do funcionário na empresa, tempo no cargo que ocupa, seu cargo na transportadora (assistente/encarregado de frotas- $\mathrm{C} 1$; chefe/supervisor/coordenador operacional - $\mathrm{C} 2$; gerente - $\mathrm{C} 3$; diretor C4; consultor - C5). De maneira geral, os cargos de maior projeção na empresa (gerente, diretor, consultor) eram ocupados por profissionais de nível superior ou estudantes de cursos graduação, independente de seu tempo na empresa (exceto em empresas antigas e funcionário de nível médio com maior tempo na empresa). Por outro lado, a grande maioria de profissionais de nível médio possuía cargos de encarregado de frotas e coordenador operacional.

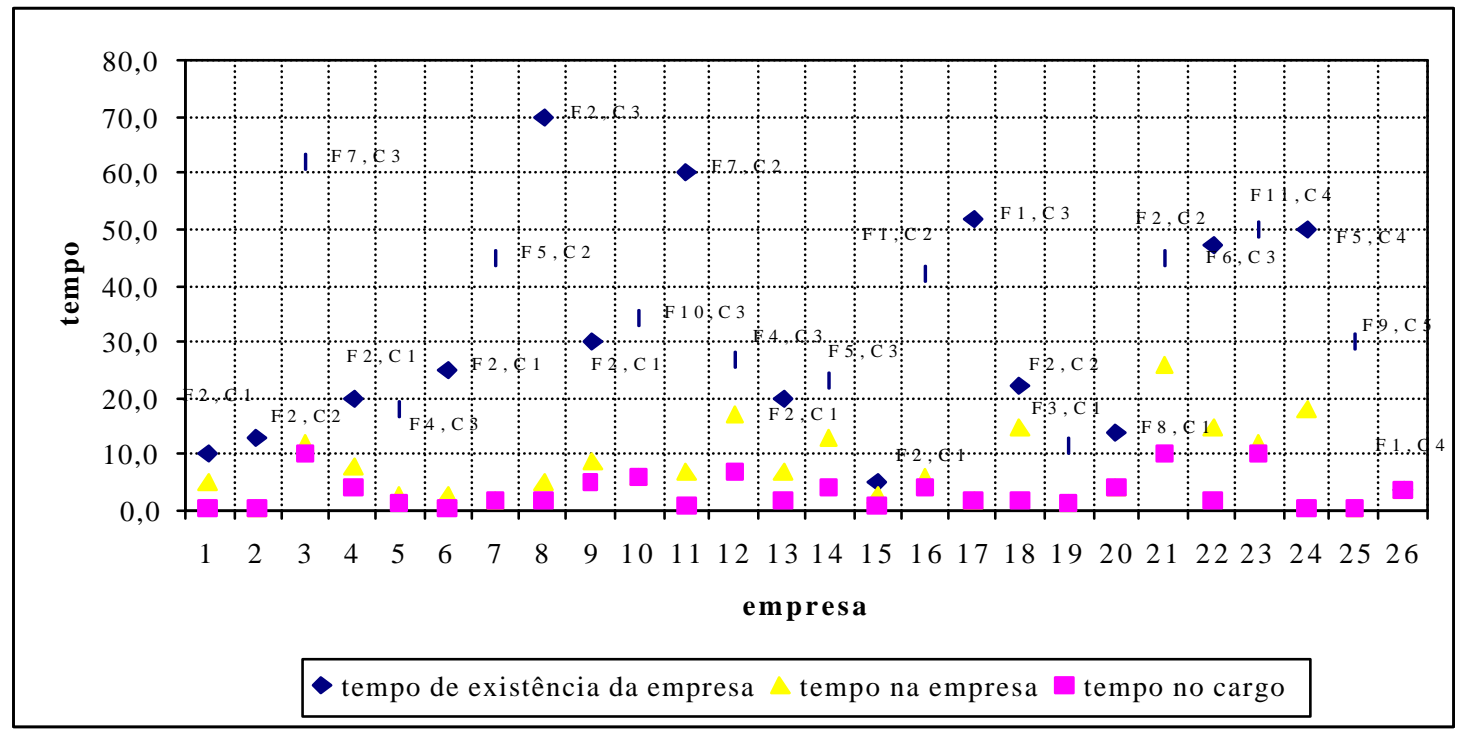

Figura 7 - Relação entre o Tempo do Funcionário na Empresa, no Cargo e Sua Formação Profissional, Cidade de São Paulo, 1997/98.

${ }^{13}$ Cargas gerais dizem respeito a produtos que possuam pesos que variem de 1 a $4.000 \mathrm{~kg}$ e, inclusive, incluem casos de fracionamento da carga (definição apresentada em Manual (1970) e com maiores detalhes em Parreiras \& Mendonça, 1990). 


\subsection{PRodutos mais transportados E REgIÕes de ENTREGa Mais IMPORTANTES COM E SEM O USO DOS SISTEMAS DE RASTREAMENTO}

Em relação ao número de empresas sem o uso dos sistemas de rastreamento, houve destaque para as que transportavam carga geral. Pela Tabela 4 observa-se que as empresas que utilizavam os sistemas Controlsat e Omnisat (os mais utilizados no mercado, conforme relatado na Seção 2.1.2) apresentaram os maiores percentuais em relação ao transporte desse tipo de carga. Além disso, os produtos agrícolas processados, os cosméticos e os produtos químicos foram transportados sem rastreamento por número maior de empresas em relação aos outros tipos de cargas analisadas.

De acordo com a Tabela 5, observa-se claramente que houve maior concentração de caminhões rastreados com cargas de maior valor agregado e, portanto, com maiores riscos de roubo. É importante, também, ressaltar que paralelamente aos segmentos mais tradicionalmente incorporados ao uso de rastreadores (equipamentos eletrônicos, produtos farmacêuticos, cosméticos, vestuários, eletrodomésticos, equipamentos de informática, entre outros), o setor agrícola também teve uma participação significativa na utilização dessa nova tecnologia por satélite, principalmente devido à incorporação de produtos processados, insumos e defensivos químicos, medicamentos para animais (informado por uma empresa), muito utilizados na agricultura em produções de grande escala.

Em relação ao sistema Omnisat, nota-se que predominaram as cargas de maior valor agregado (equipamentos eletrônicos, produtos farmacêuticos, cosméticos, vestuários, eletrodomésticos, equipamentos de informática); no sistema Controlsat houve destaque para os produtos agrícolas processados de maior valor agregado, mencionados no parágrafo anterior. 
Tabela 4. Produtos Transportados Sem Rastreamento por Empresas Usuárias de Sistemas de Rastreamento, Cidade de São Paulo, 1997-98.

\begin{tabular}{|c|c|c|c|c|c|c|c|c|}
\hline \multirow{2}{*}{$\begin{array}{c}\text { Produtos } \\
\text { transportados } \\
\text { sem } \\
\text { rastreamento }\end{array}$} & \multicolumn{8}{|c|}{ Número de Empresas } \\
\hline & Total & Combat & $\begin{array}{l}\text { Control- } \\
\text { sat }\end{array}$ & Logiq & $\begin{array}{c}\text { Moto- } \\
\text { rola }\end{array}$ & $\begin{array}{c}\text { Multi- } \\
\text { sat }\end{array}$ & $\begin{array}{c}\text { Omni- } \\
\text { sat }\end{array}$ & $\begin{array}{c}\text { Tele- } \\
\text { tracker }\end{array}$ \\
\hline $\begin{array}{l}\text { Equipamentos } \\
\text { eletrônicos }\end{array}$ & 3 & - & 1 & - & - & - & 2 & - \\
\hline $\begin{array}{l}\text { Produtos farma- } \\
\text { cêuticos }\end{array}$ & 3 & - & 1 & - & - & - & 2 & - \\
\hline Cosméticos & 4 & - & 1 & - & - & 1 & 2 & - \\
\hline $\begin{array}{l}\text { Eletrodomésti- } \\
\text { cos }\end{array}$ & 2 & - & 1 & - & - & 1 & - & - \\
\hline Vestuários & 2 & - & 2 & - & - & - & - & - \\
\hline $\begin{array}{l}\text { Produtos side- } \\
\text { rúrgicos }\end{array}$ & 2 & - & 1 & - & - & - & 1 & - \\
\hline $\begin{array}{r}\text { Produtos quí- } \\
\text { micos }\end{array}$ & 4 & - & 3 & - & - & - & 1 & - \\
\hline $\begin{array}{l}\text { Produtos agríc. } \\
\text { in natura }\end{array}$ & 3 & - & 1 & - & - & - & 2 & - \\
\hline $\begin{array}{l}\text { Produtos agric. } \\
\text { Processados }\end{array}$ & 6 & - & 2 & - & - & - & 4 & - \\
\hline Madeira & 2 & - & - & - & - & - & 2 & - \\
\hline Móveis novos & 2 & - & - & - & - & - & 2 & - \\
\hline $\begin{array}{l}\text { Combustíveis e } \\
\text { lubrificantes }\end{array}$ & 2 & - & 1 & 1 & - & - & - & - \\
\hline Carga geral & 17 & 1 & 6 & - & 1 & 1 & 7 & 1 \\
\hline Calçados & 2 & - & 1 & - & - & - & 1 & - \\
\hline Outros & 3 & - & 1 & 1 & - & - & 1 & - \\
\hline
\end{tabular}

Fonte: Dados da pesquisa 
Tabela 5. Produtos Transportados Com Rastreamento por Empresas Usuárias de Sistemas de Rastreamento, Cidade de São Paulo, 1997-98.

\begin{tabular}{|c|c|c|c|c|c|c|c|c|}
\hline \multirow{2}{*}{$\begin{array}{c}\text { Produtos } \\
\text { transportados } \\
\text { com } \\
\text { rastreamento } \\
\end{array}$} & \multicolumn{8}{|c|}{ Número de Empresas } \\
\hline & Total & Combat & $\begin{array}{c}\text { Control- } \\
\text { sat }\end{array}$ & Logiq & $\begin{array}{c}\text { Moto- } \\
\text { rola }\end{array}$ & $\begin{array}{c}\text { Multi- } \\
\text { sat }\end{array}$ & $\begin{array}{c}\text { Omni- } \\
\text { sat }\end{array}$ & $\begin{array}{c}\text { Tele- } \\
\text { tracker }\end{array}$ \\
\hline $\begin{array}{r}\text { Equipamentos } \\
\text { eletrônicos }\end{array}$ & 16 & 2 & 3 & 1 & - & - & 8 & 2 \\
\hline $\begin{array}{r}\text { Produtos } \\
\text { farmacêuticos }\end{array}$ & 15 & 1 & 3 & - & - & - & 9 & 2 \\
\hline Cosméticos & 13 & - & 3 & - & 1 & 1 & 6 & 2 \\
\hline Eletrodomésticos & 10 & 1 & 2 & - & - & 1 & 4 & 2 \\
\hline Vestuários & 16 & 1 & 4 & 1 & 2 & - & 6 & 2 \\
\hline $\begin{array}{r}\text { Produtos quí- } \\
\text { micos }\end{array}$ & 12 & 1 & 6 & 1 & 1 & - & 2 & 1 \\
\hline $\begin{array}{l}\text { Produtos agric. in } \\
\text { natura }\end{array}$ & 2 & - & 2 & - & - & - & - & - \\
\hline $\begin{array}{r}\text { Produtos agríc. } \\
\text { Processados }\end{array}$ & 11 & - & 4 & - & 1 & 1 & 4 & 1 \\
\hline Móveis novos & 3 & 1 & 1 & - & - & - & 1 & - \\
\hline $\begin{array}{l}\text { Combustíveis e } \\
\text { lubrificantes }\end{array}$ & 1 & - & 1 & - & - & - & - & - \\
\hline Carga geral & 11 & 1 & 3 & - & 1 & 1 & 4 & 1 \\
\hline $\begin{array}{l}\text { Equipamentos de } \\
\text { informática }\end{array}$ & 4 & 1 & - & - & - & - & 3 & - \\
\hline Autopeças & 5 & - & - & 1 & - & 1 & 3 & - \\
\hline Pneus e borrachas & 7 & 1 & 1 & - & - & - & 4 & 1 \\
\hline Material bélico & 1 & - & - & - & - & - & 1 & - \\
\hline $\begin{array}{l}\text { Medicamentos } \\
\text { para animais }\end{array}$ & 1 & - & - & - & - & - & 1 & - \\
\hline Calçados & 7 & - & 3 & - & - & - & 2 & 2 \\
\hline Outros & 7 & - & 3 & - & - & - & 3 & 1 \\
\hline
\end{tabular}

Fonte: Dados da pesquisa 
De maneira geral, ocorreram entregas de produtos ao longo do ano de $1997 \mathrm{em}$ todas as regiões do país. No entanto, destacaram-se as regiões sudeste e sul em relação às demais regiões. Em relação ao total transportado sem rastreadores, foi observado que apenas uma empresa transportou cargas com destino à Bolívia e ao Paraguai.

Com relação às regiões de entrega, a maioria das filiais localizou-se nas regiões sul e sudeste. Analisando a sua distribuição por estado, $55 \%$ das filiais não utilizavam rastreadores, destacando-se, em ordem decrescente: Paraná, São Paulo, Santa Catarina e Rio Grande do Sul.

Dentre as filiais que utilizavam rastreadores, as que estavam no Estado de São Paulo representaram 29\% do total. Os demais Estados apresentaram porcentagens proporcionalmente bem menores em relação a São Paulo.

\subsection{TIPOS DE SISTEMAS MAIS UTILIZADOS NO MERCADO}

O sistema de rastreamento mais utilizado pelas empresas foi o Omnisat, da Autotrac (48,3\% de uso em relação ao total de empresas); o Controlsat, da Schahin Cury, representou $27,6 \%$ do total. Os demais sistemas tiveram participação bem inferior em relação aos anteriores.

Deve-se ressaltar que 2 empresas utilizaram mais de um sistema (combinando os sistemas Controlsat e Combat ou Teletracker, Omnisat e Controlsat), com o intuito de melhorar o controle de sua frota, do prazo de entrega e dos produtos transportados. Aproximadamente $76 \%$ dos sistemas utilizados tiveram um nível bom de satisfação nas transportadoras, atestando assim uma boa aceitação quanto ao desempenho de todos os sistemas nas empresas entrevistadas.

No entanto, havia grandes diferenças em relação ao tempo de uso dos rastreadores, variando de 4 meses a 5 anos: 31\% das empresas possuíam os sistemas há menos de 1 ano; 59\%, de 1 a 3 anos. Poucas empresas utilizavam os sistemas de 4 a 5 anos.

Ocorreram, também, variações expressivas na porcentagem de caminhões rastreados: de 1,5\% a 100\%, em relação à frota própria; de 0,75\% a 100\%, em relação à 
frota total (que inclui frota própria e de terceiros). De acordo com a Tabela 6, pode-se notar que os sistemas que associavam satélite e rádio (Combat, Teletracker e Motorola) possuíam a maior porcentagem de caminhões rastreados quando comparados aos sistemas baseados totalmente em satélites (Controlsat, Logiq e Omnisat). Deve-se, no entanto, salientar que estes sistemas que utilizam apenas satélites representaram 79,3\% do total das empresas.

Tabela 6. Nível de Utilização e Tempo de Uso dos Sistemas de Rastreamento por Satélite nas Empresas.

\begin{tabular}{|c|c|c|c|c|c|c|c|c|}
\hline \multirow[t]{2}{*}{ Variáveis } & \multicolumn{8}{|c|}{ Média das empresas } \\
\hline & Total & Combat & $\begin{array}{c}\text { Control- } \\
\text { sat } \\
\end{array}$ & Logiq & $\begin{array}{c}\text { Moto- } \\
\text { rola }\end{array}$ & $\begin{array}{c}\text { Multi- } \\
\text { sat }\end{array}$ & $\begin{array}{c}\text { Omni- } \\
\text { sat }\end{array}$ & $\begin{array}{c}\text { Tele- } \\
\text { tracker }\end{array}$ \\
\hline $\begin{array}{l}\text { Tempo de } \\
\text { uso (anos) }\end{array}$ & 1,9 & 2,3 & 1,3 & 4,0 & 0,3 & 0,3 & 2,3 & 1,8 \\
\hline $\begin{array}{l}\text { \% de } \\
\text { Caminhões } \\
\text { rastreados } \\
\text { em relação à } \\
\text { frota própria }\end{array}$ & 54,3 & $100,0^{1}$ & $\begin{array}{c}29,8 \\
(4,7 \mathrm{a} \\
100 \%)\end{array}$ & $40,0^{1}$ & $100,0^{1}$ & $1,5^{1}$ & $\begin{array}{c}63,6 \\
(10 \mathrm{a} \\
100 \%)\end{array}$ & $\begin{array}{c}74,3 \\
(48,6 \mathrm{a} \\
100 \%)\end{array}$ \\
\hline $\begin{array}{l}\text { \% de } \\
\text { Caminhões } \\
\text { rastreados } \\
\text { em relação à } \\
\text { frota total }\end{array}$ & 42,8 & $100,0^{1}$ & $\begin{array}{c}16,3 \\
(3,75 \mathrm{a} \\
25,8 \%)\end{array}$ & $12,5^{1}$ & $100,0^{\top}$ & $0,75^{1}$ & $\begin{array}{c}39,8 \\
(6 \mathrm{a} \\
81,3 \%)\end{array}$ & $100,0^{1}$ \\
\hline
\end{tabular}

Fonte: Dados da pesquisa

${ }^{1}$ Havia apenas 1 observação para compor a média.

\subsubsection{Relação entre a porcentagem de caminhões rastreados e o tempo de uso nas transportadoras}

De maneira geral, pode-se observar que ocorrem diferenças no comportamento das empresas que utilizam dois tipos de sistemas: o primeiro, que usa apenas satélites, cujo preço varia de $\mathrm{R} \$ 6$ a $\mathrm{R} \$ 7$ mil; o segundo, que associa satélite e rádio, com preço que oscila entre R\$ 3-3,5 mil (Penha, 1998). Além disso, pôde-se constatar que a 
porcentagem de caminhões rastreados (em relação à frota própria) foi muito influenciada pelo tempo de uso e pelo tipo de sistema utilizado (satélite, satélite/rádio) pelas transportadoras.

Desta forma, foi analisado o seguinte modelo de regressão linear múltipla, expresso pela eq. (14):

$$
y_{i}=a+b x_{i}+c z_{i}+\varepsilon_{i}
$$

onde:

$y_{i}$ : porcentagem de caminhões rastreados;

$x_{i}$ : tempo de uso dos sistemas (anos);

$z_{i}$ : tipo de sistema utilizado (variável binária: 0 - sistemas com satélite e rádio; 1 sistemas só com satélites);

$a, b, c$ : coeficientes da regressão;

$\varepsilon_{i}$ : erro aleatório.

Foram consideradas 23 observações, pois 1 delas não forneceu informações sobre a porcentagem de caminhões rastreados pela transportadora e as outras 2 relacionavamse a empresas que utilizavam 2 ou 3 sistemas (mesclando sistemas satélite/rádio com satélite), e sua inclusão distorceria a interpretação do modelo. Por meio do pacote computacional SAS, v.6.12 para Windows (SAS Institute Inc., 1988), foram obtidos os resultados, expressos nas Tabelas 7, 8 e 9. A relação entre a porcentagem de caminhões rastreados, os tipos de sistemas e o seu tempo de uso nas empresas foi significativa ao nível de $0,36 \%$, com um coeficiente de determinação de $43 \%$. A estimativa do intercepto e os coeficientes dos tipos de sistema e tempo de uso dos sistemas foram significativos aos níveis de $0,16 \%, 1,46 \%$ e $0,20 \%$, respectivamente. 
Tabela 7. Análise de Variância: Porcentagem de Caminhões Rastreados em Função do Tempo de Uso e do Tipo de Sistema, Cidade de São Paulo, 1997-98.

\begin{tabular}{lccccc}
\hline $\begin{array}{c}\text { Fonte de } \\
\text { Variação }\end{array}$ & $\begin{array}{c}\text { Graus de } \\
\text { Liberdade }\end{array}$ & $\begin{array}{c}\text { Soma dos } \\
\text { Quadrados }\end{array}$ & $\begin{array}{c}\text { Quadrado } \\
\text { Médio }\end{array}$ & Valor de F & Prob>F \\
\hline Modelo & 2 & 12678,03 & 6339,01 & 7,58 & 0,0036 \\
Erro & 20 & 16732,04 & 836,60 & & \\
Total & 22 & 29410,07 & & & \\
\hline
\end{tabular}

Fonte: Dados da pesquisa

Tabela 8. Estatísticas Complementares da Análise de Variância: Porcentagem de Caminhões Rastreados em Função do Tempo de Uso e do Tipo de Sistema, Cidade de São Paulo, 1997-98.

\begin{tabular}{lc}
\hline \multicolumn{1}{c}{ Estatística } & Valor \\
\hline Raiz quadrada do quadrado médio do erro & 28,92 \\
\hline Coeficiente de Determinação $\left(\mathrm{R}^{2}\right)$ & 0,43 \\
\hline $\mathrm{R}^{2}$ ajustado & 0,37 \\
\hline Desvio da média & 54,55 \\
\hline Coeficiente de variação $(\mathrm{CV})$ & 53,03 \\
\hline
\end{tabular}

Fonte: Dados da pesquisa

Tabela 9. Estimativas dos Parâmetros para Porcentagem de Caminhões Rastreados em Relação ao Tempo de Uso e ao Tipo de Sistema, Cidade de São Paulo, 1997-98.

\begin{tabular}{lccccc}
\hline Variável & $\begin{array}{c}\text { Graus de } \\
\text { Liberdade }\end{array}$ & $\begin{array}{c}\text { Estimativa } \\
\text { do } \\
\text { Parâmetro }\end{array}$ & Erro Padrão & $\begin{array}{c}\text { t para } \mathbf{H}_{\mathbf{0}}: \\
\text { Parâmetro=0 }\end{array}$ & Prob>|t| \\
\hline Intercepto & 1 & 56,2 & 15,43 & 3,642 & 0,0016 \\
Tipo de sistema & 1 & $-45,0$ & 16,86 & $-2,674$ & 0,0146 \\
Tempo de uso & 1 & 23,0 & 6,47 & 3,556 & 0,0020 \\
\hline
\end{tabular}

Fonte: Dados da pesquisa 
A Figura 8 mostra que as empresas que utilizavam o sistema satélite/rádio levariam em torno de 1,9 anos para rastrear toda a frota própria. As que optaram pelo sistema por satélite levariam praticamente o dobro do tempo para instalá-lo em todos os caminhões da empresa (em torno de 3,9 anos). Pode-se citar, entre os fatores que poderiam estar influenciando neste comportamento: o preço de cada sistema, conforme especificado no início desta seção; o período de adaptação das empresas em relação ao tipo de sistema utilizado: por satélite (mais complexos) e satélite/rádio (mais simples); a abrangência dos sistemas, uma vez que os sistemas mais caros atuam em nível nacional e os mais baratos restringem-se praticamente à Grande São Paulo (devido à necessidade de existirem torres de retransmissão dos dados nos locais a serem rastreados).

Outro aspecto interessante a ser observado é que após um ano de uso do sistema, em geral, haveria o rastreamento de $80 \%$ dos caminhões nas empresas que optassem por sistemas satélite/rádio e de apenas $34 \%$ dos caminhões nas transportadoras que utilizassem o sistema satélite.

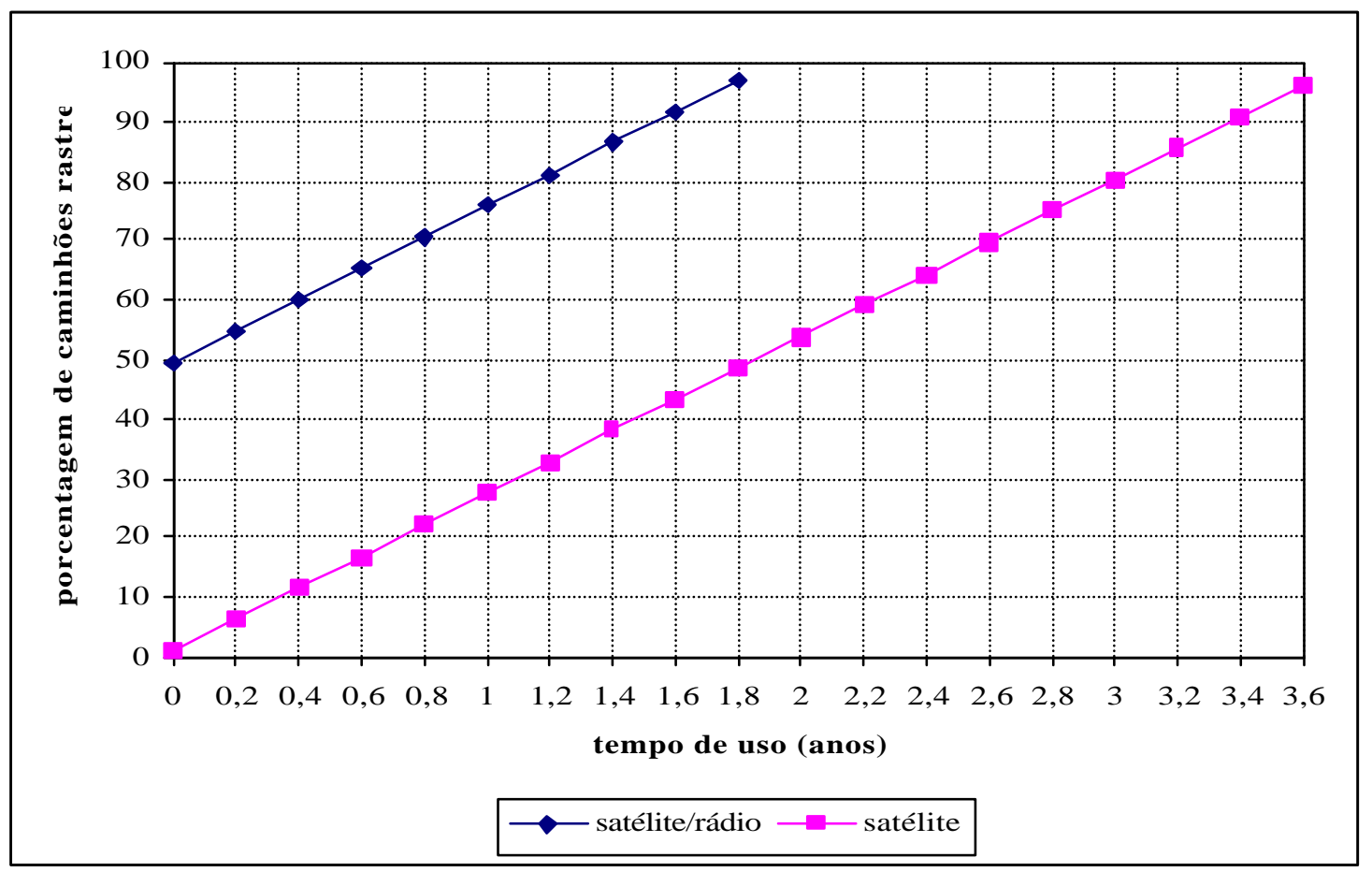

Figura 8 - Relação entre Tempo de Uso dos Sistemas de Rastreamento e Porcentagem de Caminhões Rastreados, Cidade de São Paulo, 1997-98. 


\subsection{VARIÁVEIS UTILIZADAS PELAS EMPRESAS PARA DECIDIR SOBRE AAQUISIÇÃO DOS} SISTEMAS DE RASTREAMENTO

A maioria das empresas considerou suas relações contratuais com outras empresas para que optassem pelos sistemas de rastreamento, a saber: entre transportadoras e seguradoras de carga; entre transportadoras e seus clientes. Vale ressaltar que, para a carga ser transportada, o seu seguro deve ser previamente efetuado. Geralmente, havia uma parceria entre as empresas de seguro e fornecedoras de rastreadores.

Um dos maiores motivos para a aquisição dos sistemas de rastreamento, associado a aproximadamente $46 \%$ das empresas, foi a pressão feita pelas seguradoras (Tabela 10), que demonstravam às transportadoras a necessidade premente de aumentarem a segurança das cargas transportadas e minimizarem os roubos freqüentes das mercadorias mais visadas. Para isso, em muitos casos, as seguradoras indicavam o tipo de rastreador a ser instalado nas transportadoras, especialmente as que tinham parcerias com as fornecedoras do sistema, e propunham alguns incentivos para que as transportadoras implantassem essa nova tecnologia, tais como: redução de preços do seguro e descontos no preço do sistema de rastreamento.

Tabela 10. Variáveis Responsáveis pela Decisão das Empresas na Aquisição de Sistemas de Rastreamento por Satélite.

\begin{tabular}{lc}
\hline $\begin{array}{c}\text { Variáveis na Decisão de } \\
\text { Aquisição }\end{array}$ & $\begin{array}{c}\text { Porcentagem de } \\
\text { Empresas (\%) }\end{array}$ \\
\hline Relação com a seguradora & 46 \\
Relação com o cliente & 8 \\
Análise de custo/benefício & 15 \\
Pesquisa de mercado & 19 \\
Outras & 12 \\
\hline Total & 100 \\
\hline
\end{tabular}

Fonte: Dados da pesquisa 
Por outro lado, alguns clientes de outras transportadoras, também preocupados com os roubos de suas cargas (em torno de $8 \%$ das entrevistadas), exigiram a instalação de rastreadores nos caminhões. Em contrapartida, cobririam os custos de instalação e de manutenção do sistema para viabilizar o rastreamento por satélite no transporte de seus produtos.

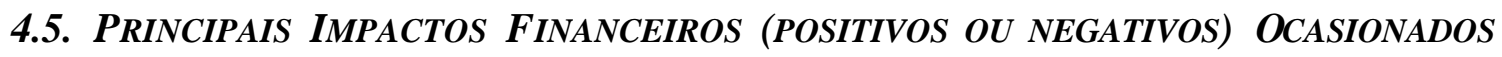 PELO EMPREGO DOS SISTEMAS DE RASTREAMENTO NAS EMPRESAS}

Foram analisados os impactos do uso de sistemas de rastreamento sobre 9 indicadores financeiros (vendas, número de clientes, quantidade vendida, preço final do serviço vendido, custo do serviço vendido, lucro bruto, despesas com vendas, lucro operacional e taxa de retorno ao investimento), conforme mostra a Figura 9.

Os grandes impactos (muito fortes) sofridos por aproximadamente $20 \%$ das empresas relacionaram-se a aumentos em vendas, número de clientes, quantidade vendida, lucro operacional, taxa de retorno ao investimento e redução no custo do serviço vendido.

Relacionando os impactos positivos "muito forte" e "nem forte/nem fraco" às principais variáveis, observa-se na Tabela 11 que as mesmas representaram entre 44,8\% e 58,6\% em relação ao total das transportadoras. De maneira geral, os sistemas mais baratos (que utilizam rádios para transmitir os dados da central ao veículo: Combat, Motorola, Multisat e Teletracker) obtiveram percentual bem maior de impactos positivos nas empresas quando comparados com os sistemas mais caros (que utilizam apenas satélites - Brasilsat ou Inmarsat - Controlsat, Logiq e Omnisat) em relação a esses principais retornos financeiros. Por outro lado, nota-se que as duas empresas entrevistadas que combinaram dois ou mais sistemas, tiveram apenas efeitos positivos em relação aos principais impactos analisados na Tabela 11. 


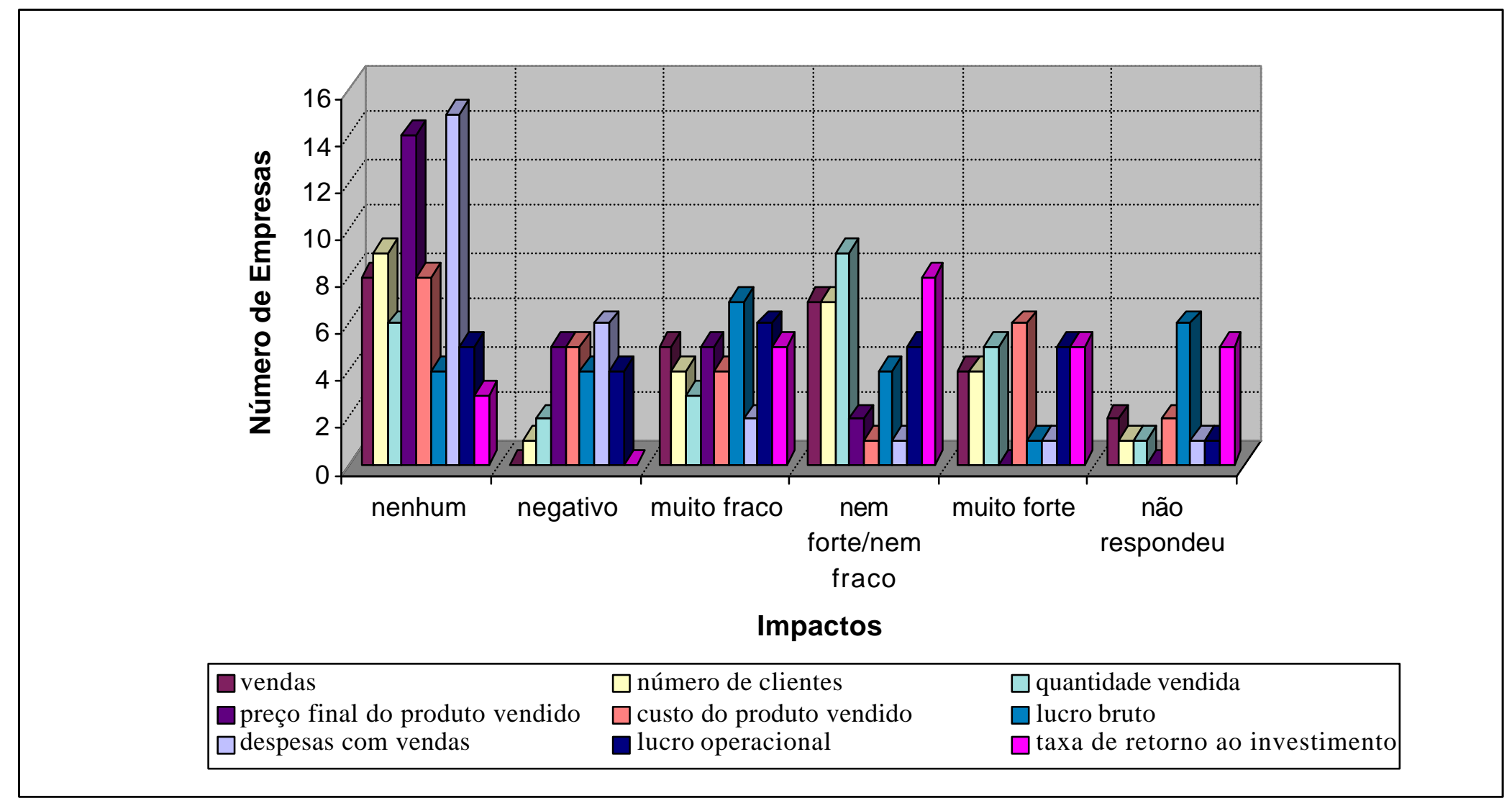

Figura 9 - Impactos nas Empresas em Relação ao Uso dos Sistemas de Rastreamento por Satélite, Cidade de São Paulo, 199798. 
Tabela 11. Abrangência dos Principais Impactos Positivos Obtidos em Relação aos Sistemas de Rastreamento por Satélite nas Empresas.

\begin{tabular}{|c|c|c|c|c|c|}
\hline \multirow[b]{2}{*}{ Tipos de sistemas } & \multicolumn{5}{|c|}{ Porcentagem das empresas com impactos $\operatorname{positivos}^{1}$ em: } \\
\hline & Vendas & $\begin{array}{l}\text { Número de } \\
\text { clientes }\end{array}$ & $\begin{array}{c}\text { Quantidade } \\
\text { vendida }\end{array}$ & $\begin{array}{c}\text { Lucro } \\
\text { operacional }\end{array}$ & $\begin{array}{l}\text { Taxa de retorno } \\
\text { ao investimento }\end{array}$ \\
\hline Combat $^{2}$ & 100,0 & - & 100,0 & 100,0 & 100,0 \\
\hline Controlsat & 50,0 & 33,3 & 66,7 & 33,3 & 50,0 \\
\hline $\operatorname{Logiq}^{2}$ & - & - & - & - & 100,0 \\
\hline Motorola $^{2}$ & - & - & - & 100,0 & 100,0 \\
\hline Multisat $^{2}$ & 100,0 & 100,0 & 100,0 & - & - \\
\hline Omnisat & 23,1 & 38,5 & 38,5 & 30,8 & 30,8 \\
\hline Teletracker $^{2}$ & 100,0 & 100,0 & 100,0 & - & 100,0 \\
\hline 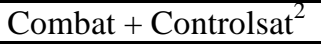 & 100,0 & 100,0 & 100,0 & 100,0 & 100,0 \\
\hline $\begin{array}{l}\text { Controlsat + Omnisat } \\
+ \text { Teletracker }^{2}\end{array}$ & 100,0 & 100,0 & 100,0 & 100,0 & 100,0 \\
\hline Total & 42,3 & 42,3 & 53,8 & 38,5 & 50,0 \\
\hline
\end{tabular}

Fonte: Dados da pesquisa

${ }^{1}$ Referem-se aos impactos muito forte e nem forte/nem fraco.

${ }^{2}$ Há apenas 1 observação para compor a porcentagem.

A análise de custo/beneficio apresenta algumas limitações e problemas quanto ao seu emprego em TI, como discutido na Seção 2.2. Houve, inclusive, propostas de técnicas alternativas para que essas novas tecnologias fossem melhor avaliadas. Apesar de suas restrições, a análise de custo/benefício foi adotada explicitamente pela Autotrac, que detém quase metade do mercado de rastreadores, através da divulgação de folders e publicações, para convencer futuros usuários das inúmeras vantagens do sistema. Além disso, relacionou os principais benefícios intangíveis que seriam obtidos pelas empresas com o uso dos sistemas.

No entanto, apenas 34\% das transportadoras realizaram algum tipo de análise técnica para a escolha do sistema mais adequado. Destas, $15 \%$ utilizaram a análise de custo/benefício; $19 \%$ das empresas fizeram pesquisa de mercado, comparando os sistemas existentes em relação a: diferença de preços, acessórios, confiabilidade, desempenho, tempo de existência no mercado, opiniões de outras usuárias, testes do 
equipamento na empresa, demonstração do software, entre outros. Além disso, aproximadamente $12 \%$ das transportadoras revelaram não ter tido nenhuma preocupação na análise econômica do sistema a ser utilizado na empresa quando o adquiriram.

Em torno de $40 \%$ das transportadoras afirmaram que ocorreram poucos aumentos em vendas, número de clientes, quantidade vendida, lucro bruto, lucro operacional e taxa de retorno ao investimento em função da introdução dos rastreadores.

O preço final do serviço e as despesas com vendas não foram praticamente alterados após o uso dos rastreadores em aproximadamente 60\% das empresas, devido provavelmente à grande competição do mercado e à atuação consolidada do setor de vendas nas empresas, respectivamente.

Aproximadamente $20 \%$ dos entrevistados não souberam informar se o lucro bruto e a taxa de retorno ao investimento tinham ou não sido afetados pelos sistemas de rastreamento.

\subsubsection{Estudo dos Principais Impactos Financeiros através das Análises de Correspondência e de Conglomerados}

Para caracterizar a influência dos principais impactos dos sistemas de rastreamento sobre as transportadoras, comparando suas características predominantes e relacionando as que apresentam comportamentos homogêneos, foi utilizado o módulo de análise de correspondência múltipla (CORMU) do programa computacional SPAD, v. 3.5 (CISIA, 1998), específico para análise de dados categóricos.

Foram analisadas as 9 variáveis ativas (características), já especificadas na seção 4.5, e 3 variáveis suplementares (porcentagem de caminhões rastreados, tempo de uso do sistema e faturamento anual da empresa), para que auxiliassem na interpretação dos fatores por fornecerem informações adicionais sobre as relações entre os elementos analisados, apesar de não influenciarem na dimensão dos autovalores, nas coordenadas e nas contribuições das variáveis ativas. 
Através da projeção dos pontos-perfis em linha (coordenadas) em cada plano fatorial (formado pelas coordenadas de dois eixos), pode-se estabelecer a correspondência entre grupos de modalidades e de sistemas de rastreamento.

Para identificar quantos eixos fatoriais deveriam ser considerados na interpretação dos dados, foram utilizadas informações advindas dos autovalores. No entanto, ao se calcular o autovalor médio (igual a 0,1822), notou-se que existiam 11 autovalores superiores a ele (Apêndice 2), inviabilizando a quantificação dos fatores através desse componente, pois seria recomendado que se analisassem 11 eixos (que comporiam 55 planos fatoriais para analisar apenas 9 variáveis). Por outro lado, observou-se que a porcentagem da inércia diminuía de forma regular após o terceiro eixo fatorial, indicando que seria razoável interpretar apenas os três primeiros eixos fatoriais. De acordo com Benzécri (1992), o mais importante da análise de correspondência é a possibilidade de se obterem fatores interpretáveis, e mesmo quando as porcentagens da inércia são pequenas, resultados confiáveis têm ocorrido com muita frequiência.

A partir das coordenadas dos pontos-perfis (quarta a sexta colunas do Apêndice 3) pôde-se construir os gráficos relacionando os três eixos da seguinte maneira: eixos $1 \mathrm{e}$ 2 (Apêndice 5), eixos 1 e 3 (Apêndice 6) e eixos 2 e 3 (Apêndice 7).

Em relação ao primeiro plano fatorial, utilizou-se os valores das contribuições relativas dos pontos-perfis de cada uma das modalidades das variáveis dessa questão 3 para avaliar a importância relativa dos pontos-perfis em cada um dos eixos 1 e 2 . Os valores mais altos foram destacados (em negrito) nas sétima e oitava colunas do Apêndice 3 e foram representados graficamente por asterisco (*) no Apêndice 5, junto às coordenadas com essas maiores contribuições.

Para garantir a qualidade de representação dos pontos em cada um dos eixos, foi empregada a contribuição relativa de um fator à distância de um ponto-perfil ao centro de gravidade (décima e décima primeira colunas do Apêndice 3) com a finalidade de direcionar até que valor da contribuição relativa dos pontos-perfis seria considerado na análise do primeiro plano fatorial.

Além disso, também foram obtidas as coordenadas e contribuições relativas dos pontos-perfis e de cada fator relativas a cada uma das empresas (Apêndice 4) e 
relacionadas no mesmo plano fatorial. Desta forma, pôde-se distinguir grupos de modalidades e de sistemas a partir de suas maiores contribuições relativas. No Anexo A estão descritos os grupos presentes em cada um dos três planos fatoriais.

Em função do primeiro e segundo planos fatoriais relacionarem melhor as modalidades das variáveis e os sistemas utilizados pelas empresas, concluiu-se que quatro grupos poderiam ser delineados por meio da análise de correspondência.

A partir das coordenadas obtidas nessa análise e com base no agrupamento do conjunto de sistemas de rastreamento, foi realizada uma análise mais aprimorada dos grupos, mediante análise de conglomerados (utilizando o módulo de classificação do programa SPAD, v. 3.5 (CISIA, 1998), para que houvesse uma representação mais clara da localização de cada empresa nos grupos.

A comparação entre os sistemas de rastreamento foi feita com base no conjunto de características observadas por meio do cálculo de distâncias euclidianas entre os pontos-individuais, no hiperespaço de 3 dimensões (referente aos 3 primeiros eixos fatoriais). Para que os sistemas fossem classificados, foi utilizado, primeiramente, o algoritmo de classificação hierárquica ascendente (método de Ward) para selecionar o número ótimo de classes, conforme mostra a Tabela 12.

Assim, o conjunto de pontos-individuais foi dividido com base no total de 4 classes por meio de método não-hierárquico (k-means). A composição final de cada classe (grupo) e as modalidades que mais influenciaram em cada classe estão descritas na Tabela 13, confirmando as análises dos planos fatoriais realizadas através da análise de correspondência. 


\section{Tabela 12. Classificação Hierárquica em Relação aos 3 Primeiros Eixos Fatoriais da Questão 3.}

\begin{tabular}{|c|c|c|c|c|c|}
\hline $\mathrm{N}^{\mathrm{o}}$ & Início & Fim & Peso & Índice & Histograma dos índices \\
\hline 27 & 15 & 20 & 2.00 & 0.00038 & $*$ \\
\hline 28 & 6 & 4 & 2.00 & 0.00138 & \\
\hline 29 & 7 & 21 & 2.00 & 0.00141 & $*$ \\
\hline 30 & 24 & 8 & 2.00 & 0.00194 & \\
\hline 31 & 19 & 26 & 2.00 & 0.00207 & $*$ \\
\hline 32 & 29 & 12 & 3.00 & 0.00219 & \\
\hline 33 & 5 & 14 & 2.00 & 0.00223 & \\
\hline 34 & 18 & 9 & 2.00 & 0.00294 & $*$ \\
\hline 35 & 33 & 11 & 3.00 & 0.00339 & $*$ \\
\hline 36 & 31 & 23 & 3.00 & 0.00465 & \\
\hline 37 & 25 & 27 & 3.00 & 0.00605 & $* *$ \\
\hline 38 & 28 & 30 & 4.00 & 0.00607 & $* *$ \\
\hline 39 & 3 & 17 & 2.00 & 0.00962 & $* *$ \\
\hline 40 & 35 & 2 & 4.00 & 0.01077 & $* *$ \\
\hline 41 & 16 & 10 & 2.00 & 0.01330 & $* * *$ \\
\hline 42 & 34 & 1 & 3.00 & 0.01352 & $* * *$ \\
\hline 43 & 41 & 37 & 5.00 & 0.01814 & $* * * *$ \\
\hline 44 & 38 & 32 & 7.00 & 0.02160 & $* * * *$ \\
\hline 45 & 44 & 42 & 10.00 & 0.03575 & $* * * * * * *$ \\
\hline 46 & 43 & 13 & 6.00 & 0.04053 & $* * * * * * * *$ \\
\hline 47 & 36 & 45 & 13.00 & 0.08013 & $* * * * * * * * * * * * * * *$ \\
\hline 48 & 46 & 39 & 8.00 & 0.08729 & $* * * * * * * * * * * * * * * *$ \\
\hline 49 & 48 & 40 & 12.00 & 0.30296 & ; $* * * * * * * * * * * * * * * * * * * * * * * * * * * * * * * * * * * * * * * * * * * * * * * * * * * * * * * * *$ \\
\hline 50 & 22 & 47 & 14.00 & 0.31410 & ) $* * * * * * * * * * * * * * * * * * * * * * * * * * * * * * * * * * * * * * * * * * * * * * * * * * * * * * * * *$ \\
\hline 51 & 49 & 50 & 26.00 & $0.43920 *$ & 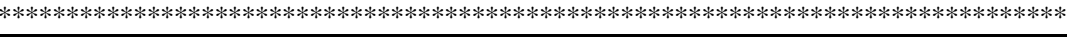 \\
\hline
\end{tabular}

Fonte: Dados da pesquisa

\section{Tabela 13. Descrição dos Grupos (Classes) formados pela Análise de Conglomerados da Questão 3.}

\begin{tabular}{cll}
\hline $\begin{array}{c}\text { Grupos } \\
\text { (classes) }\end{array}$ & \multicolumn{1}{c}{ Empresas $^{1}$} & \multicolumn{2}{c}{ Modalidades (variável/impacto) mais características } \\
\hline 1 & A, C, E, G, I, J, K, L, M, & $\begin{array}{l}\text { Vendas/nenhum; número de clientes/nenhum; quantidade } \\
\text { vendida/nenhum; preço final do serviço vendido/ nenhum; } \\
\text { despesas com vendas/nenhum }\end{array}$ \\
\hline 2 & $\mathrm{U}$ & - \\
\hline 3 & $\mathrm{H}, \mathrm{Q}, \mathrm{W}, \mathrm{Y}$ & $\begin{array}{l}\text { Número de clientes/nem forte, nem fraco; quantidade vendida/nem } \\
\text { forte, nem fraco; lucro bruto/nem forte, nem fraco }\end{array}$ \\
\hline 4 & $\mathrm{~B}, \mathrm{D}, \mathrm{F}, \mathrm{O}, \mathrm{P}, \mathrm{R}, \mathrm{S}, \mathrm{Z}$ & $\begin{array}{l}\text { Número de clientes/muito forte; lucro bruto/sem nota; taxa de } \\
\text { retorno ao investimento /sem nota }\end{array}$ \\
\hline
\end{tabular}

Fonte: Dados da pesquisa

1 Relação das transportadoras quanto ao uso dos sistemas de rastreamento: A (Combat); B a G (Controlsat); H (Controlsat+Combat); I (Logiq); J (Motorola); K (Multisat); L a Z (Omnisat); W (Teletracker); Y (Teletracker+Omnisat+Controlsat). 


\section{Primeiro Grupo}

No primeiro grupo, a grande maioria das empresas possuía um faturamento variando entre US\$ 1 e 99 milhões e usava sistemas apenas por satélite (entre eles, Logiq, Omnisat e Rodosat). Cerca de metade delas usava o sistema entre 4 e 12 meses e a outra metade entre 2 e 3 anos em caminhões da frota própria e em alguns agregados (que são caminhões terceirizados com rotas fixas e, portanto, permitem que as transportadoras invistam neles da mesma forma que em sua frota própria).

Apesar de existirem diferenças no tempo de uso dos rastreadores, em geral havia um pequeno número de caminhões rastreados (entre 5 e 21), o que de certa forma justifica a ausência de repercussão da utilização dos sistemas em alguns impactos financeiros relacionados pela análise de conglomerados (vendas, número de clientes, despesas com vendas, preço final do serviço vendido), descritos no segundo grupo do primeiro plano fatorial da análise de correspondência. Aliado a esse fato, deve-se acrescentar que houve 2 casos em que a implantação dos sistemas mas transportadoras só foi viabilizada porque foi paga por clientes, excluindo-as da existência de quaisquer dos reflexos anteriormente descritos.

Além disso, uma das empresas deste grupo relatou que o rastreamento era uma ferramenta adicional à empresa, justificando assim a ausência de impactos do uso do sistema nas suas despesas com vendas, e que os preços de seus serviços foram reduzidos pelo aumento da competitividade do mercado, não sofrendo qualquer influência do uso dos rastreadores.

\section{Segundo Grupo}

No segundo grupo havia apenas uma empresa, que utilizava o sistema Omnisat por 2 anos em toda a sua frota, especializada no transporte de produtos farmacêuticos a pequenos clientes. Em função da situação econômica dos últimos anos, houve diminuição da sua quantidade vendida, porém com um crescimento regular no valor das vendas e nas despesas com vendas em função do uso dos rastreadores. Essas 
características também foram relacionadas no quarto grupo do primeiro plano fatorial da análise de correspondência (descrito no Anexo A).

\section{Terceiro Grupo}

O terceiro grupo caracterizou-se por empresas que rastreavam todos os caminhões, fossem eles de frota própria, de agregados ou de terceiros (contratados esporadicamente), pois todas tinham muita preocupação com a segurança das cargas transportadas tanto dentro da cidade, para coleta, como nas estradas, para transferências para matrizes e/ou filiais, pois eram de alto valor agregado (não realizavam o "frete podre").

Em geral tratavam-se de empresas que utilizavam sistemas só por satélite ou satélite e satélite/rádio por 3 a 4 anos (apenas uma delas usava o sistema Teletracker, por menos de 1 ano) e que obtiveram impactos positivos no número de clientes, na quantidade vendida e no lucro bruto, conforme especificado no terceiro grupo do primeiro plano fatorial (Anexo A).

No entanto, segundo uma delas, os resultados não foram melhores, pois a empresa não utilizou todos os recursos que o sistema permitiria usar. Outra transportadora, por outro lado, constatou que apesar de ter realizado altos investimentos nos sistemas, houve um aproveitamento de apenas $50 \%$ dos seus recursos, pois a sua adoção integral poderia atrapalhar a segurança da carga transportada (principal objetivo a ser alcançado pela empresa ao adquirir o equipamento), uma vez que isto implicaria, por exemplo, em mudança nas rotas, nem sempre tão seguras quanto as normalmente utilizadas pelas empresas.

\section{Quarto Grupo}

O quarto grupo era formado por transportadoras que adotaram sistemas apenas por satélite (Controlsat, Omnisat) por período de 8 meses a 5 anos, apesar de ter sido ressaltada na análise de correspondência apenas a utilização de sistemas em períodos de 4-5 anos para este grupo. 
Além disso, observou-se que havia uma quantidade de caminhões rastreados bem superior à obtida pela empresas do grupo 1, uma vez que mesmo empresas com menos de 1 ano de uso implantaram o sistema em 20 caminhões próprios em média; em empresas com mais de 1 ano de adoção havia de 41 a 190 caminhões rastreados. Esses elementos confirmaram as expectativas apresentadas pelas empresas em relação aos sistemas, pois muitas delas, apesar de inicialmente terem sido pressionadas pelas seguradoras para adquirir os rastreadores, acreditavam que esse produto poderia ser um grande diferencial para a sua consolidação no mercado frente às concorrentes, por poderem oferecer um serviço diferenciado aos clientes, o que foi confirmado pela ocorrência de impacto positivo no número de clientes com o uso de rastreamento pela maioria das transportadoras. As principais características deste grupo foram descritas no primeiro grupo do primeiro plano fatorial da análise de correspondência (Anexo A).

Por outro lado, naquelas empresas em que houve pequeno aumento no número de clientes, constatou-se que ocorreu elevação na confiança de grandes clientes na empresa em função dos rastreadores, já que se tornaram mais exigentes na seleção das transportadoras para obtenção de serviços de melhor qualidade.

Outra característica presente neste grupo foi a existência de empresas que não souberam responder perguntas relacionadas aos impactos no lucro bruto e na taxa de retorno ao investimento, o que pode ser justificado por estarem utilizando o sistema por pouco tempo (entre 7 e 8 meses) ou mesmo porque o entrevistado estava trabalhando há pouco tempo na empresa e, portanto, em ambos os casos, não teria havido tempo hábil para captar todas as alterações que o uso do sistema poderia ter ocasionado na empresa. 


\subsection{PRINCIPAIS AÇÕES TOMADAS PELAS EMPRESAS PARA SUA MELHOR ADEQUAÇÃO À UTILIZAÇÃO DOS RASTREADORES}

Durante o processo de implantação e implementação dos sistemas de rastreamento nas empresas, algumas ações merecem ser melhor avaliadas, ressaltandose:

- reestruturação da administração ou de toda empresa;

- alocação de capital extra para melhorar seu uso;

- treinamento de funcionários como operadores;

- contratação de novos operadores;

- treinamento de motoristas;

- contratação de novos motoristas;

- compra de novos computadores pessoais;

- $\quad$ substituição de computadores;

- contratação de pessoal para realizar a manutenção dos rastreadores;

- terceirização de serviços para realizar a sua manutenção;

- contratação de analistas/programadores;

- uso de analistas/programadores já existentes na empresa;

- terceirização de serviços de analistas/programadores;

- desenvolvimento interno de software para rastreamento;

- desenvolvimento de software por terceirização de serviços.

Na Figura 10 estão relacionadas as principais ações tomadas pelas empresas e sua abrangência dentro do processo de adequação aos rastreadores. Entre elas houve destaque para o desenvolvimento de software por terceirização de serviços, cuja opção foi feita por praticamente $90 \%$ da empresas entrevistadas. Earl (1996), entretanto, adverte que ao delegar responsabilidades na operação e manutenção de sistemas, alguns riscos poderão ocorrer. Por outro lado, como quase metade dos usuários utilizava o 
sistema Omnisat, isto mostra que, entre outros motivos, as transportadoras procuraram investir no sistema mais antigo do mercado (portanto, mais conhecido e com confiabilidade maior em relação aos concorrentes), e mais voltado ao aperfeiçoamento de equipamentos, software e marketing, na busca de soluções personalizadas dentro das empresas. Os demais sistemas, praticamente, implantavam o software padrão (desenvolvido em outros países) nas transportadoras.

A grande maioria das transportadoras utilizava o kit vendido pelas próprias fornecedoras de rastreadores e somente adaptavam o software à sua estrutura interna (a maioria dos sistemas era de origem estrangeira), não havendo a preocupação em melhor aproveitar os recursos dessa tecnologia através da incorporação de novas funções ao sistema.

Os demais desenvolveram novos módulos em parceria com as fornecedoras, para integrarem os dados advindos dos rastreadores aos demais sistemas utilizados por elas, visando melhorar o controle sobre todas as operações executadas internamente e permitir que os clientes também pudessem interagir em tempo real com a empresa, colhendo informações sobre o tempo de partida ou chegada de suas cargas, seu trajeto, entre outros.

Além disso, a execução do trabalho em equipe (técnicos da fornecedora e da transportadora) para o desenvolvimento de novos módulos do software teve como consequiências diretas alguns acordos entre as partes envolvidas, tais como: isenção de pagamento do programa final por parte da transportadora, incorporação de algumas rotinas ao software por parte da fornecedora de rastreadores, para que fosse vendido a outros clientes como kit básico do sistema de rastreamento. 


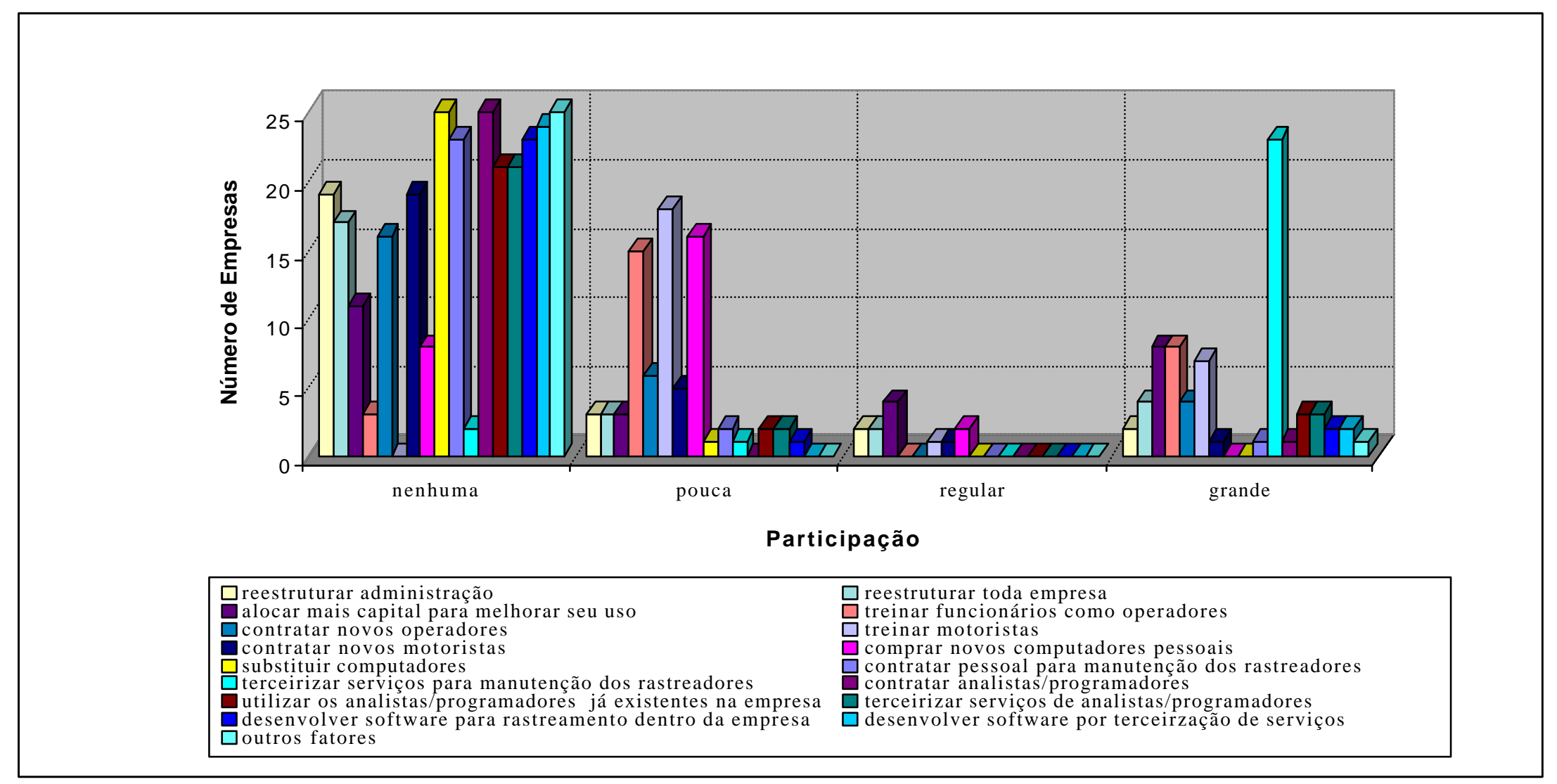

Figura 10 - Participação das Principais Ações Tomadas pelas Empresas durante o Processo de Adequação aos Sistemas de Rastreamento, Cidade de São Paulo, 1997-98. 
Em torno de $65 \%$ das empresas optaram pelo rápido treinamento de funcionários (operadores, motoristas), com o intuito de utilizarem de maneira satisfatória os rastreadores, pois consideraram grande a facilidade de manuseio do sistema. No entanto, Fernandes \& Alves (1992) ressaltam que o treinamento descontínuo de funcionários pode ser apontado como um dos fatores críticos que afetam o sucesso da TI nas empresas. Nesse sentido, foi constatado que algumas transportadoras promoviam palestras periódicas para seus funcionários com o intuito de melhorar a obtenção de informações sobre as cargas que estavam sendo transportadas e o desempenho do rastreamento, tanto em termos logísticos como em segurança. Geralmente, nessas reuniões havia uma interação entre seguradora, fornecedora do sistema e transportadora por meio de relatos de experiências e dicas para o aperfeiçoamento do uso do sistema.

Poucas transportadoras compraram novos computadores pessoais para utilizar o rastreamento por satélite. Em alguns casos, isso ocorreu devido à execução anterior da informatização da empresa, da qual foram aproveitados 1 ou 2 computadores para instalação do software para gerenciamento dos caminhões por satélite.

Em contraposição, as demais ações listadas não foram afetadas pelo processo de adequação das empresas aos rastreadores, demonstrando que a maioria das empresas não pretende investir seu tempo e recursos no aprimoramento dessa nova tecnologia na empresa, aproveitando a estrutura já existente para adaptar esse sistema à rotina da transportadora. No entanto, Custódio (1988) enfatiza a importância de haver interação entre os novos sistemas e as organizações e que, para isso, a empresa deve se moldar a essas tecnologias para que sejam mais eficazes e eficientes. Assim, seria interessante conhecer o nível de eficiência e eficácia dos sistemas de rastreamento nas transportadoras, uma vez que os resultados da pesquisa mostram que se comportam de maneira oposta ao que foi constatado pelo referido autor. 


\subsubsection{Estudo das Principais Ações Tomadas pelas Empresas através das Análises de Correspondência e de Conglomerados}

Foram analisadas as 16 variáveis ativas (características), já especificadas na seção 4.6, e 3 variáveis suplementares (porcentagem de caminhões rastreados, tempo de uso do sistema e faturamento anual da empresa), por meio do programa computacional SPAD, v. 3.5 (CISIA, 1998), para caracterizar a influência das principais ações tomadas pelas empresas em relação à utilização dos sistemas de rastreamento.

Para identificar quantos eixos fatoriais deveriam ser considerados na interpretação dos dados, foram utilizadas informações advindas dos autovalores. No entanto, ao se calcular o autovalor médio (igual a 0,0825), notou-se que existiam 8 autovalores superiores a ele (Apêndice 8). Por outro lado, observou-se que a porcentagem da inércia diminuía de forma regular após o terceiro eixo fatorial, indicando que seria razoável interpretar os três primeiros eixos fatoriais, tal como foi verificado para a questão 3 .

Além disso, também foram obtidas as coordenadas e contribuições relativas dos pontos-perfis e de cada fator relativas a cada uma das modalidades da questão 5 (Apêndice 9) e a cada uma das empresas (Apêndice 10) a fim de distinguir grupos de modalidades e de sistemas a partir de suas maiores contribuições relativas. No Anexo B estão descritos os grupos presentes em cada um dos três planos fatoriais.

Assim, concluiu-se que três grupos poderiam ser delineados por meio da análise de correspondência, pois o segundo e terceiro planos fatoriais relacionaram melhor as modalidades das variáveis e os sistemas utilizados pelas empresas.

A partir das coordenadas obtidas nessa análise e com base no agrupamento do conjunto de sistemas de rastreamento, foi realizada uma análise mais aprimorada dos grupos, mediante análise de conglomerados (utilizando o módulo de classificação do

programa SPAD, v. 3.5 (CISIA, 1998). Foi utilizado, primeiramente, o algoritmo de classificação hierárquica ascendente (método de Ward) para selecionar o número ótimo 
de classes a partir das coordenadas dos 3 primeiros eixos fatoriais discutidos anteriormente, conforme mostra a Tabela 14.

\section{Tabela 14. Classificação Hierárquica em Relação aos 3 Primeiros Eixos Fatoriais da Questão 5.}

\begin{tabular}{|c|c|c|c|c|c|}
\hline \multicolumn{6}{|c|}{$\mathrm{N}^{\circ}$ Início Fim Peso Índice Histograma dos índices } \\
\hline 27 & 23 & 18 & 2,00 & 0,00000 & $*$ \\
\hline 28 & 27 & 17 & 3,00 & 0,00000 & * \\
\hline 29 & 3 & 16 & 2,00 & 0,00020 & * \\
\hline 30 & 9 & 13 & 2,00 & 0,00027 & $*$ \\
\hline 31 & 19 & 15 & 2,00 & 0,00050 & $*$ \\
\hline 32 & 5 & 12 & 2,00 & 0,00052 & * \\
\hline 33 & 31 & 20 & 3,00 & 0,00088 & $*$ \\
\hline 34 & 14 & 25 & 2,00 & 0,00089 & $*$ \\
\hline 35 & 28 & 21 & 4,00 & 0,00126 & $*$ \\
\hline 36 & 4 & 26 & 2,00 & 0,00144 & $*$ \\
\hline 37 & 30 & 10 & 3,00 & 0,00172 & $*$ \\
\hline 38 & 7 & 11 & 2,00 & 0,00313 & $*$ \\
\hline 39 & 29 & 33 & 5,00 & 0,00324 & * \\
\hline 40 & 32 & 6 & 3,00 & 0,00326 & $*$ \\
\hline 41 & 39 & 8 & 6,00 & 0,00406 & $*$ \\
\hline 42 & 34 & 37 & 5,00 & 0,00534 & * \\
\hline 43 & 35 & 41 & 10,00 & 0,00595 & $* *$ \\
\hline 44 & 38 & 1 & 3,00 & 0,01058 & $* *$ \\
\hline 45 & 42 & 24 & 6,00 & 0,01271 & $* * *$ \\
\hline 46 & 36 & 43 & 12,00 & 0,01720 & $* * * *$ \\
\hline 47 & 45 & 44 & 9,00 & 0,04166 & $* * * * * * * *$ \\
\hline 48 & 46 & 40 & 15,00 & 0,06755 & $* * * * * * * * * * * * *$ \\
\hline 49 & 48 & 47 & 24,00 & 0,16748 & $* * * * * * * * * * * * * * * * * * * * * * * * * * * * * * *$ \\
\hline 50 & 2 & 49 & 25,00 & 0,20407 & $* * * * * * * * * * * * * * * * * * * * * * * * * * * * * * * * * * * * *$ \\
\hline 51 & 22 & 50 & 26,00 & $0,44258 * *$ & 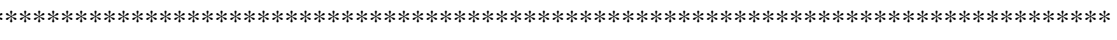 \\
\hline
\end{tabular}

Fonte: Dados da pesquisa

Desta forma, o conjunto de pontos-individuais foi dividido com base no total de 4 classes por meio de método não-hierárquico (k-means). A composição final de cada classe (grupo) e as modalidades que mais influenciaram em cada classe estão descritas na Tabela 15. 
Tabela 15. Descrição dos Grupos (Classes) formados pela Análise de Conglomerados da Questão 5.

\begin{tabular}{cll}
\hline $\begin{array}{c}\text { Grupos } \\
\text { (classes) }\end{array}$ & \multicolumn{1}{c}{ Empresas $^{1}$} & Modalidades (variável/participação) mais características \\
\hline 1 & $\mathrm{~L}, \mathrm{M}, \mathrm{N}, \mathrm{O}, \mathrm{P}, \mathrm{X}, \mathrm{Y}$ & $\begin{array}{l}\text { Treinamento de funcionários da empresa para trabalhar como } \\
\text { operadores/grande; treinamento de motoristas/grande }\end{array}$ \\
\hline 2 & $\begin{array}{l}\mathrm{A}, \mathrm{B}, \mathrm{C}, \mathrm{D}, \mathrm{E}, \mathrm{F}, \mathrm{G}, \mathrm{H}, \mathrm{I}, \mathrm{J}, \mathrm{K}, \mathrm{Q}, \\
\mathrm{R}, \mathrm{S}, \mathrm{T}, \mathrm{V}, \mathrm{Z}\end{array}$ & $\begin{array}{l}\text { Treinamento de funcionários da empresa para trabalhar como } \\
\text { operadores/pouca; treinamento de motoristas/pouca }\end{array}$ \\
\hline 3 & $\mathrm{~W}$ & - \\
\hline 4 & $\mathrm{U}$ & - \\
\hline
\end{tabular}

Fonte: Dados da pesquisa

1 Relação das transportadoras quanto ao uso dos sistemas de rastreamento: A (Combat); B a G (Controlsat); H (Controlsat+Combat); I (Logiq); J (Motorola); K (Multisat); L a Z (Omnisat); W (Teletracker); Y (Teletracker+Omnisat+Controlsat).

\section{Primeiro Grupo}

A maioria das empresas deste grupo possuía um faturamento anual entre US\$ 9 99 milhões e transportavam apenas carga seca fracionada (exceto: produtos perecíveis; móveis não embalados; cigarros; produtos químicos e combustíveis, que por se tratarem de carga perigosa, exigem treinamento especial) e rastreavam apenas cargas de alto valor agregado e de elevado risco de roubo.

Todas as transportadoras utilizavam o sistema Omnisat, sendo que uma delas adotou três sistemas: Controlsat (por 3 anos), Omnisat (por 4 anos) e Teletracker (por 3 anos). Em relação ao sistema Omnisat, as que possuíam poucos caminhões próprios (de 6 a 20), quase todos eram rastreados, independente do tempo de uso; empresas com frota grande (de 200 a 500 caminhões) e que utilizavam o sistema por menos de 1 ano rastreavam em torno de $10 \%$ a $15 \%$ em relação ao total; empresas com grande número de caminhões e com 1,5 a 4 anos, possuíam rastreamento em 50 a $90 \%$ da frota.

Em geral houve participação grande do treinamento de operadores e motoristas para que as empresas se adaptassem aos sistemas, tal como descrito no primeiro grupo do segundo e terceiro planos fatoriais da análise de correspondência. Nesse sentido, as transportadoras que utilizavam apenas o sistema Omnisat (da empresa Autotrac) 
destacaram suas principais estratégias para capacitação dos funcionários para trabalhar como operadores: assistência permanente da fornecedora do sistema aos operadores; treinamento voltado para segurança com contínua reciclagem de conhecimentos; treinamento por 90 dias, realizado por 2 monitores da Autotrac para capacitar os funcionários, criando agentes multiplicadores para repassar a tecnologia dentro da empresa; treinamento inicial feito semanalmente, com fiscalização da seguradora Pamcary para avaliar o desempenho do operador quanto ao funcionamento do sistema e eficácia no controle do roubo.

A participação dos motoristas também foi muito importante para que as empresas obtivessem sucesso no gerenciamento do sistema, principalmente em função de: mudança cultural e social dos motoristas antes do treinamento, devido às expectativas de aumento na segurança pessoal e ao estímulo da vaidade por utilizar um tecnologia nova; criação de códigos e "macros" (palavras chaves para facilitar o envio e recebimento de mensagens) no computador de bordo; reciclagem periódicas 6 em 6 meses.

Além disso, todas as transportadoras utilizavam os serviços da Autotrac (e das empresas dos outros 2 sistemas utilizados) para que fosse realizada a manutenção dos equipamentos usados no rastreamento, assim como possuíam analistas de sistemas na empresa para desenvolver software específicos. No entanto, apenas em uma delas havia o desenvolvimento de outros software para interligar o rastreamento a outros sistemas da empresa.

\section{Segundo Grupo}

Este grupo caracterizou-se por empresas que utilizavam em sua grande maioria sistemas só por satélite (Combat; Controlsat - 6 num total de 8; Combat e Controlsat; Logiq; Motorola; Omnisat - 7 num total de 14) e várias faixas de faturamento anual e rastreavam basicamente produtos químicos, medicamentos, produtos agrícolas processados, pneus, eletrônicos, cosméticos e vestuários. 
Em geral não houve reestruturação das transportadoras em função do sistema, pois foi conseqüência do processo de informatização das empresas e, portanto, atuou como um instrumento adicional ao gerenciamento da frota e da segurança. Além disso, as transportadoras utilizavam os serviços das empresas fornecedoras para desenvolver o software adquirido (apesar de existirem analistas de sistemas nas transportadoras) e para realizar a manutenção dos equipamentos usados no rastreamento, conforme descrito no segundo grupo do segundo e terceiro planos fatoriais da análise de correspondência (Anexo B).

Por outro lado, houve pequeno treinamento de operadores (desde algumas horas até 3 ou 4 dias), pois a maioria considerou que o sistema era de fácil manuseio e existiam bons manuais em caso de dúvidas. Além disso, uma delas não possuía operador, pois era rastreada diretamente pela seguradora. Os motoristas também tiveram treinamento rápido, porém muitas transportadoras alegaram ter tido problemas de adaptação aos rastreadores, principalmente aquelas que utilizavam computador de bordo (com teclado). Uma delas informou que os motoristas usavam o telefone ao invés de usar o equipamento instalado no caminhão para se comunicar com a empresa.

\section{Terceiro Grupo}

Neste grupo foi incluída apenas uma empresa que transportava carga geral (com exceção de produtos perecíveis). Utilizava o sistema Teletracker em 100\% da frota própria (total de 16 caminhões) por oito meses e caracterizou-se por não ter realizado treinamento de operador, pois o funcionário já sabia usar o sistema e não ter obtido muito sucesso com o treinamento dos motoristas. Houve pouca reestruturação na empresa em função da adoção do rastreamento; por outro lado, a fornecedora do sistema desenvolvia o software adquirido (apesar de existirem analistas de sistemas na empresa) e realizava a manutenção dos equipamentos usados no rastreamento, conforme descrito no segundo grupo do primeiro plano fatorial da análise de correspondência (Anexo B). 


\section{Quarto Grupo}

Este grupo constituiu-se de apenas uma empresa que transportava apenas produtos farmacêuticos e cuja frota era toda rastreada pelo sistema Omnisat, da Autotrac (a mesma descrita no grupo 2 da questão 3). Possuía um faturamento anual em torno de US\$ 100-500 milhões.

Foi alocado grande volume de capital para melhorar o uso do sistema de rastreamento na empresa, principalmente, para minimizar o roubo por meio do gerenciamento de risco, do qual faziam parte sistemas de informações gerenciais para avaliar o desempenho do equipamento e sistemas de gerenciamento de roteirização integrados ao rastreamento (desenvolvidos pela Autotrac em parceria com os analistas da empresa para a sua utilização exclusiva), conforme especificado no primeiro grupo do primeiro plano fatorial da análise de correspondência (Anexo B).

O treinamento de motoristas teve grande participação no processo de adaptação da empresa ao sistema. Além disso, os operadores eram treinados continuamente (em torno de 6 horas por semana), por técnicos da Autotrac e da seguradora Pamcary, para que tivessem completa autonomia para tomar decisão sobre roubos ou logística dentro da transportadora. Nesse sentido, rotineiramente faziam viagens para checar as rotas seguidas pelos caminhões que transportavam as cargas.

\subsection{MAIORES BENEFícios OBTIDOS PELAS TRANSPORTADORAS COM O USO DOS SISTEMAS DE RASTREAMENTO}

A Figura 11 relaciona os benefícios usufruídos pelas transportadoras com o uso dos sistemas de rastreamento por satélite:

melhoria dos serviços ao cliente;

- redução de custos;

- redução de custos com segurança;

- redução do número de funcionários; 
- aumento da segurança da carga transportada;

- colocação da carga/caminhão no seguro;

- melhoria da decisão quanto à mudança de trajetos de coletas;

- diminuição do número de rotas;

- redução na ociosidade da frota;

- redução no tempo de entrega/coleta;

- obtenção de informação instantânea da posição do veículo;

- socorro de veículos quebrados;

- melhoria da manutenção dos veículos;

- melhoria da confiança do motorista em relação à empresa;

- melhor controle do motorista;

- obtenção de maiores vantagens competitivas em relação às outras empresas;

- exploração de novas tecnologias e redução de horas extras.

Os maiores benefícios observados pelas empresas foram, em ordem decrescente: aumento da segurança da carga transportada, melhor controle dos motoristas, melhoria dos serviços ao cliente, melhoria da decisão quanto à mudança de trajetos de coletas, socorro de veículos quebrados, melhoria da confiança do motorista em relação à empresa, obtenção de informação instantânea da posição do veículo e obtenção de maiores vantagens competitivas em relação às outras empresas, confirmando impressões relatadas por Hamilton (1993), Autotrac (1996) e Reis (1997).

Em relação aos sistemas adotados, $93 \%$ das usuárias do sistema Omnisat e 75\% do sistema Controlsat informaram que ocorreram significativos aumentos na segurança da carga transportada (contra 50\% do sistema Teletracker; os demais, 100\%); 62,5\% das empresas que utilizavam o sistema Controlsat afirmaram ter havido um grande diferencial no controle do motorista (em relação a 0\% do sistema Motorola e 100\% dos demais); houve grande melhoria do serviço ao cliente em 50\% das usuárias do Omnisat (contra $87,5 \%$ do sistema Controlsat e praticamente $100 \%$ dos demais), conforme mostra a Tabela 16. 


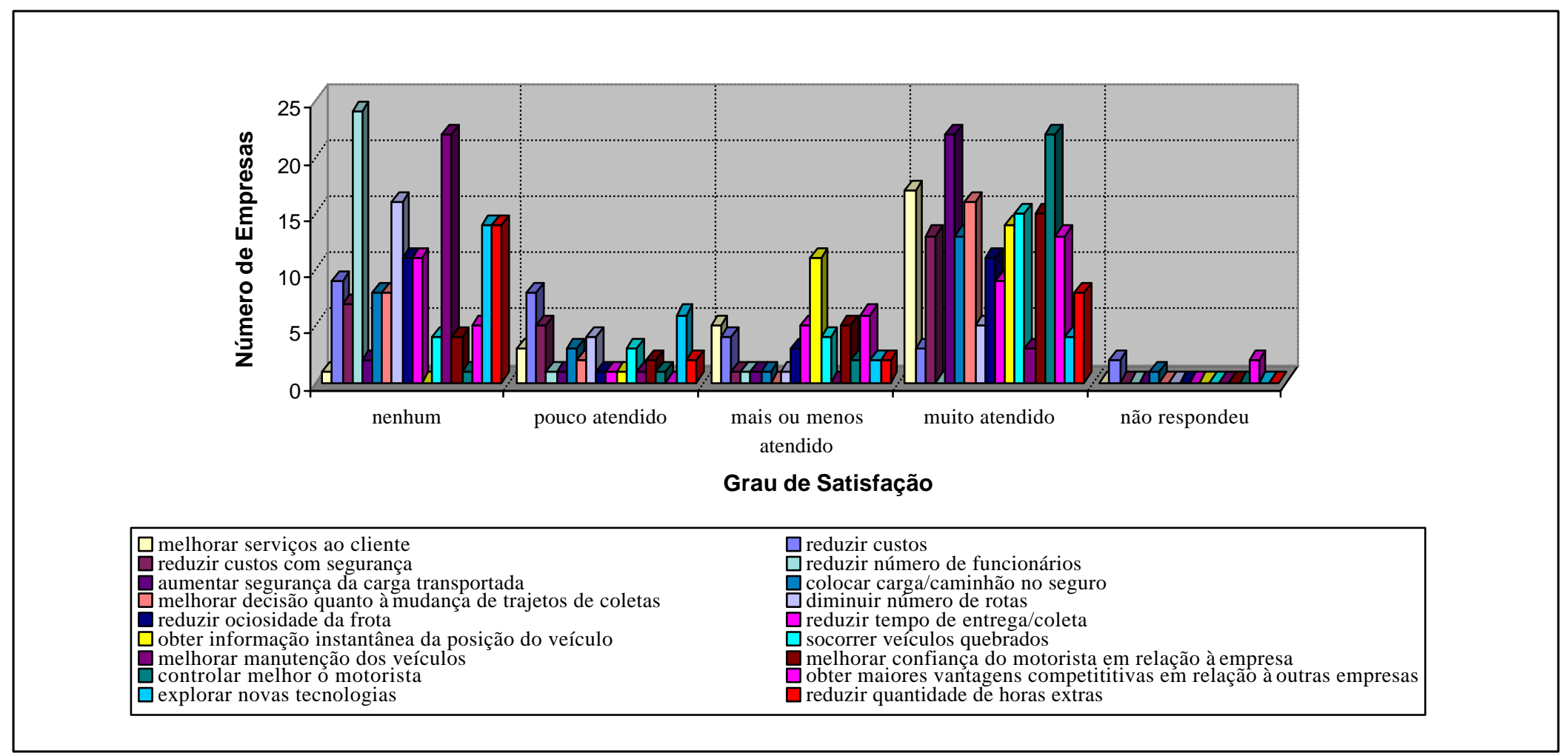

Figura 11 - Grau de Satisfação das Empresas em Relação aos Benefícios Obtidos dos Sistemas de Rastreamento por Satélite, Cidade de São Paulo, 1997-98. 


\section{Tabela 16. Principais Benefícios Observados em Relação aos Sistemas de Rastreamento por Satélite nas Empresas.}

\begin{tabular}{lccc}
\hline \multirow{2}{*}{ Tipos de sistemas } & \multicolumn{3}{c}{ Porcentagem das empresas com benefícios ${ }^{1}$ em: } \\
\cline { 2 - 4 } & $\begin{array}{c}\text { Melhoria no } \\
\text { serviço ao cliente }\end{array}$ & $\begin{array}{c}\text { Controle melhor o } \\
\text { motorista }\end{array}$ & $\begin{array}{c}\text { Aumento na segurança da } \\
\text { carga transportada }\end{array}$ \\
\hline Combat $^{2}$ & 100,0 & 100,0 & 100,0 \\
\hline \multicolumn{1}{c}{ Controlsat } & 83,3 & 66,7 & 66,7 \\
\hline Logiq $^{2}$ & - & 100,0 & 100,0 \\
\hline Motorola $^{2}$ & 100,0 & - & 100,0 \\
\hline Multisat $^{2}$ & 100,0 & 100,0 & 100,0 \\
\hline Omnisat $^{2}$ & 46,2 & 100,0 & 92,3 \\
\hline Teletracker & & - & 100,0 \\
\hline${\text { Combat }+ \text { Controlsat }^{2}}^{\text {Controlsat }+ \text { Omnisat }^{2}}$ & 100,0 & - & 100,0 \\
\hline $\begin{array}{l}\text { + Teletracker } \\
\end{array}$ & 100,0 & 100,0 & 100,0 \\
\hline Total & 100,0 & 84,6 & 84,6 \\
\hline
\end{tabular}

Fonte: Dados da pesquisa

${ }^{1}$ Referem-se a benefícios com alto grau de satisfação, ou seja, que foram "muito" atendidos.

${ }^{2}$ Há apenas 1 observação para compor a porcentagem.

Praticamente não se verificou nenhum efeito positivo na redução de custos totais e metade das empresas não obtiveram diminuição nos custos com segurança. Essa situação também foi verificada por Geraldo Vianna, diretor da NTC (Associação Nacional do Transporte Rodoviário de Carga) ${ }^{14}$, principalmente em função do aumento na frequiência de roubos, tendo como consequiência investimentos em rastreamento por satélite e serviços de segurança, ocasionando elevações de 10 a $12 \%$ nesses custos (NTC, 1998).

Em contraposição, não houve nenhum efeito em relação à redução do número de funcionários e à melhoria na manutenção dos veículos. Os principais motivos foram, respectivamente, remanejamento de funcionários para exercerem novas funções de operadores na empresa e serviço interno de manutenção da frota, já existente antes da instalação desses equipamentos em grande maioria das transportadoras.

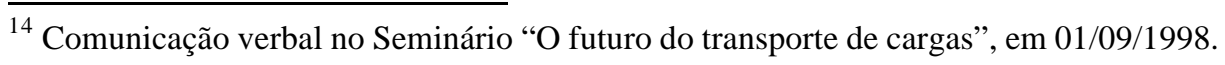


Em torno de $73 \%$ das empresas afirmaram que obtiveram maiores vantagens competitivas com o uso dos rastreadores. No entanto, $80 \%$ das transportadoras não exploraram novas tecnologias a partir desses sistemas. Aliado a isso, de $88 \%$ a $100 \%$ delas informaram que o sistema de rastreamento não se interligava com quaisquer outros tipos de sistemas, tais como: internet, intranet, EDI, código de barras, just in time, entre outros. Essas informações confirmaram que, de maneira geral, há uso mínimo dos recursos oferecidos pelos sistemas nas transportadoras.

É interessante observar que Brynjolfsson \& Hitt (1996a e 1996b) concluíram em suas pesquisas que a melhoria do serviço ao cliente foi a principal razão apontada por grandes empresas para que investissem em TI. Apesar das especificidade da tecnologia de informação pesquisada no presente estudo, a melhoria do serviço ao cliente foi um dos grandes benefícios alcançados pelas transportadoras com o uso dos rastreadores, também confirmando as impressões de Hamilton (1993), Autotrac (1996) e Reis (1997).

\subsubsection{Estudo dos Principais Benefícios Obtidos pelas Transportadoras através das Análises de Correspondência e de Conglome rados}

Foram analisadas as 18 variáveis ativas (características), já especificadas na seção 4.7, e 3 variáveis suplementares (porcentagem de caminhões rastreados, tempo de uso do sistema e faturamento anual da empresa), por meio do programa computacional SPAD, v. 3.5 (CISIA, 1998), para caracterizar a influência dos principais benefícios obtidos pelas transportadoras em relação ao uso dos sistemas de rastreamento.

Para identificar quantos eixos fatoriais deveriam ser considerados na interpretação dos dados, foram utilizadas informações advindas dos autovalores. No entanto, ao se calcular o autovalor médio (igual a 0,1177), notou-se que existiam 10 autovalores superiores a ele (Apêndice 14). Por outro lado, observou-se que a porcentagem da inércia diminuía de forma regular após o quarto eixo fatorial, indicando que seria razoável interpretar os quatro primeiros eixos fatoriais.

Além disso, também foram obtidas as coordenadas e contribuições relativas dos pontos-perfis e de cada fator relativas a cada uma das modalidades da questão 6 
(Apêndice 15) e a cada uma das empresas (Apêndice 16) a fim de distinguir grupos de modalidades e de sistemas a partir de suas maiores contribuições relativas. No Anexo C estão descritos os grupos presentes em cada um dos quatro planos fatoriais.

Como o primeiro plano fatorial relacionou melhor as modalidades das variáveis e os sistemas utilizados pelas empresas, concluiu-se que quatro grupos poderiam ser delineados por meio da análise de correspondência.

A partir das coordenadas obtidas nessa análise e com base no agrupamento do conjunto de sistemas de rastreamento, foi realizada uma análise mais aprimorada dos grupos, mediante análise de conglomerados (utilizando o módulo de classificação do programa SPAD, v. 3.5 (CISIA, 1998). Foi utilizado, primeiramente, o algoritmo de classificação hierárquica ascendente (método de Ward) para selecionar o número ótimo de classes a partir das coordenadas dos 4 primeiros eixos fatoriais discutidos anteriormente, conforme mostra a Tabela 17.

\section{Tabela 17. Classificação Hierárquica em Relação aos 4 Primeiros Eixos Fatoriais da Questão 6.}

\begin{tabular}{|c|c|c|c|c|}
\hline \multicolumn{5}{|c|}{$\mathrm{N}^{\circ}$ Início Fim Peso Índice Histograma dos índices } \\
\hline 27 & 6 & 4 & $2,00 \quad 0,00158$ & $*$ \\
\hline 28 & 13 & 17 & $2,00 \quad 0,00182$ & $*$ \\
\hline 29 & 26 & 8 & $2,00 \quad 0,00202$ & * \\
\hline 30 & 3 & 24 & $2,00 \quad 0,00202$ & $*$ \\
\hline 31 & 14 & 25 & $2,00 \quad 0,00222$ & $*$ \\
\hline 32 & 9 & 7 & $2,00 \quad 0,00295$ & $*$ \\
\hline 33 & 32 & 10 & $3,00 \quad 0,00328$ & $* *$ \\
\hline 34 & 12 & 11 & $2,00 \quad 0,00374$ & $* *$ \\
\hline 35 & 20 & 27 & $3,00 \quad 0,00416$ & $* *$ \\
\hline 36 & 29 & 28 & $4,00 \quad 0,00604$ & $* *$ \\
\hline 37 & 35 & 21 & $4,00 \quad 0,00675$ & $* * *$ \\
\hline 38 & 2 & 31 & $3,00 \quad 0,01052$ & $* * * *$ \\
\hline 39 & 22 & 34 & $3,00 \quad 0,01070$ & $* * * *$ \\
\hline 40 & 33 & 19 & $4,00 \quad 0,01144$ & $* * * *$ \\
\hline 41 & 18 & 23 & $2,00 \quad 0,01258$ & $* * * * *$ \\
\hline 42 & 30 & 38 & $5,00 \quad 0,01458$ & $* * * * *$ \\
\hline 43 & 37 & 36 & $8,00 \quad 0,02259$ & $* * * * * * * *$ \\
\hline 44 & 43 & 40 & $12,00 \quad 0,04079$ & $* * * * * * * * * * * * * * *$ \\
\hline 45 & 5 & 16 & $2,00 \quad 0,04644$ & $* * * * * * * * * * * * * * *$ \\
\hline 46 & 39 & 42 & $8,00 \quad 0,06095$ & $* * * * * * * * * * * * * * * * * * * *$ \\
\hline 47 & 15 & 45 & $3,00 \quad 0,09838$ & $* * * * * * * * * * * * * * * * * * * * * * * * * * * * * * * *$ \\
\hline 48 & 44 & 1 & $13,00 \quad 0,10715$ & $* * * * * * * * * * * * * * * * * * * * * * * * * * * * * * * * *$ \\
\hline 49 & 41 & 48 & $15,00 \quad 0,14273$ & $* * * * * * * * * * * * * * * * * * * * * * * * * * * * * * * * * * * * * * * * * * * * * *$ \\
\hline 50 & 47 & 49 & $18,00 \quad 0,18825$ & $* * * * * * * * * * * * * * * * * * * * * * * * * * * * * * * * * * * * * * * * * * * * * * * * * * * * * * * * * * * * * * * *$ \\
\hline 51 & 46 & 50 & $26,00 \quad 0,25082$ & $* * * * * * * * * * * * * * * * * * * * * * * * * * * * * * * * * * * * * * * * * * * * * * * * * * * * * * * * * * * * * * * * * * * * * * * *$ \\
\hline
\end{tabular}

Fonte: Dados da pesquisa 
Assim, o conjunto de pontos-individuais foi dividido com base no total de 4 classes por meio de método não-hierárquico (k-means). A composição final de cada classe (grupo) e as modalidades que mais influenciaram em cada classe estão descritas na Tabela 18.

\section{Tabela 18. Descrição dos Grupos (Classes) formados pela Análise de Conglomerados da Questão 6.}

\begin{tabular}{cll}
\hline $\begin{array}{c}\text { Grupos } \\
\text { (classes) }\end{array}$ & \multicolumn{1}{c}{ Empresas $^{1}$} & Modalidades (variável/grau de satisfação) mais características \\
\hline 1 & $\mathrm{C}, \mathrm{F}, \mathrm{G}, \mathrm{I}, \mathrm{J}, \mathrm{K}, \mathrm{L}, \mathrm{M}, \mathrm{N}$, & $\begin{array}{l}\text { Colocar a carga/caminhão no seguro/nenhum; reduzir a ociosidade } \\
\text { da frota/nenhum }\end{array}$ \\
\hline 2 & $\mathrm{O}, \mathrm{P}, \mathrm{S}, \mathrm{T}$ & Colocar a carga/caminhão no seguro/pouco atendido \\
\hline 3 & $\mathrm{D}, \mathrm{H}, \mathrm{R}$ & $\begin{array}{l}\text { Melhorar a confiança do motorista em relação à empresa/pouco } \\
\text { atendido; controlar melhor o motorista/mais ou menos atendido }\end{array}$ \\
\hline 4 & $\mathrm{~A}, \mathrm{~B}, \mathrm{Q}, \mathrm{U}, \mathrm{X}, \mathrm{Z}, \mathrm{W}, \mathrm{Y}$ & $\begin{array}{l}\text { Colocar a carga/caminhão no seguro/muito atendido; obter } \\
\text { informação instantânea dos veículos/muito atendido; reduzir a } \\
\text { ociosidade da frota/muito atendido }\end{array}$ \\
\hline
\end{tabular}

Fonte: Dados da pesquisa

1 Relação das transportadoras quanto ao uso dos sistemas de rastreamento: A (Combat); B a G (Controlsat); H (Controlsat+Combat); I (Logiq); J (Motorola); K (Multisat); L a Z (Omnisat); W (Teletracker); Y (Teletracker+Omnisat+Controlsat).

\section{Primeiro Grupo}

Este grupo caracterizou-se por empresas que utilizavam sistemas apenas por satélite (Controlsat, Logiq ou Omnisat), preocupadas exclusivamente com o gerenciamento de risco. $\mathrm{O}$ rastreamento incluía cargas de maior valor agregado, entre elas: produtos farmacêuticos, pneus, produtos químicos, produtos agrícolas processados, equipamentos eletrônicos.

De maneira geral, houve grande melhoria no serviço ao cliente em função do rastreamento, principalmente devido ao aumento da confiabilidade nos serviços prestados pelas transportadoras. No entanto, algumas não tiveram efeitos positivos em 
função da existência de poucos equipamentos (com conseqüente implantação do sistema em poucos veículos) ou mesmo por repassarem os custos para grandes clientes.

Não houve influência do sistema na inserção da carga no seguro, pois já utilizavam os serviços das seguradoras e implantaram os rastreadores por exigência delas. Por outro lado, houve aumento muito grande na segurança da carga transportada após o uso dos sistemas pelos transportadores, pois constituiu-se num meio concreto de intimidação de assaltantes.

As rotas praticamente não se alteraram porque as transportadoras utilizavam os mesmos trajetos já utilizados pelos motoristas. Nesse sentido, não ocorreu melhoria na decisão quanto à mudança de trajetos, nem redução na ociosidade da frota e no tempo de entrega das mercadorias. Em relação ao motorista, houve grande melhoria de sua confiança na empresa e também foi melhor monitorado pelas transportadoras. As empresas relacionadas neste grupo foram caracterizadas no segundo e terceiro grupos do quarto plano e no primeiro grupo do quinto e sexto planos fatoriais da análise de correspondência.

\section{Segundo Grupo}

Este grupo foi formado por apenas duas empresas que utilizavam sistemas só por satélite (Controlsat e Omnisat). Embora uma delas estivesse utilizando o sistema por 7 meses e a outra por 2,5 anos, respectivamente, ambas tiveram grande melhoria no serviço ao cliente, principalmente pela possibilidade de obtenção da posição do carro e do motorista, proporcionando redução nos atrasos e aumento na segurança da carga transportada (uma delas afirmou que os assaltantes experientes evitavam roubar caminhões rastreados). Por outro lado, houve pequena influência do sistema para que se colocasse a carga no seguro, apesar de uma das seguradoras oferecer desconto para seguro com rastreamento. A ociosidade da frota teve pequena redução com a implantação dos sistemas, porém não ocorreu alteração no número de rotas, pois não usavam roteirizadores. As principais características deste grupo foram mostradas no terceiro grupo do primeiro e segundo planos fatoriais da análise de correspondência. 
Além disso, verificou-se grande melhoria na obtenção de informação instantânea: a que usava o sistema Omnisat rastreava os caminhões de 5 em 5 minutos, estimando um erro de 5\% na posição real do veículo; a outra, que adotou o sistema Controlsat, rastreava a frota a cada 30 minutos, devido aos altos custos da ligação, além de observar dificuldades para acessar o sistema nos horários de pico (entre as $17 \mathrm{~h}$ e $18 \mathrm{~h}$ ), levando até 40 minutos para se conectar ao sistema por satélite.

\section{Terceiro Grupo}

Deste grupo fizeram parte empresas que utilizavam sistemas só por satélite (Controlsat e Omnisat) e dois tipos de sistemas (Controlsat e Combat) de 1 a 3 anos. Transportavam apenas cargas de alto valor agregado, entre elas: eletrônicos, produtos químicos (defensivos, tintas), produtos agrícolas processados, vestuários.

Houve grandes diferenças na redução dos custos com segurança, pois as empresas utilizavam diferentes estratégias para gerenciar a frota: regular, pela substituição da escolta por rastreadores, dividindo os custos com a seguradora; pequena, em função de existir uma estrutura não eficiente do sistema na transportadora; nenhuma, pois toda a frota era rastreada nas estradas e os caminhões rodavam em comboio (apenas um rastreado, num total de 8), além do uso de escolta. Mesmo assim, todas observaram aumento na segurança da carga transportada.

Em relação ao motorista, ocorreu pequena melhoria de sua confiança na empresa, pois sentia-se vigiado e com maior receio em relação aos assaltos, apresentando grande resistência em utilizar o sistema. A empresa, no entanto, obteve melhor controle do motorista, verificando-se, inclusive redução no número de horas extras nas coletas feitas dentro da cidade de São Paulo. Na distribuição das cargas nas estradas (só em relação aos sistemas apenas por satélite, pois o raio de ação é em todo território brasileiro), houve diminuição no tempo das entregas, evitando-se atrasos no cumprimento dos prazos.

Além disso, as empresas praticamente não exploraram novas tecnologias associadas ao rastreamento, embora duas delas já utilizassem internet, sistemas de 
informações gerenciais e EDI. Este grupo foi descrito, também, no terceiro grupo do sexto plano fatorial da análise de correspondência.

\section{Quarto Grupo}

As empresas deste grupo utilizavam, em sua maioria, sistemas só por satélite (Controlsat e Omnisat) - duas delas adotaram sistema satélite/rádio (Combat, Teletracker) e uma adotou três sistemas (Controlsat, Omnisat e Teletracker) e rastreavam quase toda a frota própria. Em geral transportavam produtos farmacêuticos, equipamentos eletrônicos, cosméticos, calçados, vestuários (apenas cargas fracionadas de alto valor agregado).

Houve grande melhoria no serviço ao cliente, pois este passou a exigir o rastreamento de sua carga para obter maior segurança no transporte de seus produtos. Algumas empresas, inclusive, implantaram o serviço de atendimento ao cliente (SAC) para que soubesse com exatidão o local onde o caminhão estava rodando e quanto tempo levaria para chegar ao destino final.

Os custos com segurança tiveram grande redução, principalmente em função da redução com despesas com escolta (substituída em parte pelo rastreamento) e redução nos sinistros, o que repercutiu diretamente no aumento da segurança da carga transportada.

Com a implantação do rastreamento houve maiores facilidades na colocação da carga no seguro, especialmente na negociação da apólice de seguro, obtendo-se preços relativamente mais baixos se comparados aos que se conseguia antes da implantação dos sistemas nas empresas. Isto se deve à preocupação das seguradoras com o gerenciamento de risco das mercadorias transportadas; no entanto, uma das transportadoras advertiu sobre a contradição existente entre os benefícios logísticos e de segurança, pois não se poderia utilizar todas as vantagens logísticas sem que houvesse redução no desempenho do gerenciamento de risco.

Nesse sentido, dentre os benefícios em logística, destacaram-se: redução na ociosidade da frota (condicionada à utilização de roterizadores junto com o 
rastreamento), que permitiu eliminação de vícios dos motoristas através da determinação prévia de rotas, além de viabilizar a volta rápida dos caminhões (quando retornava sem carreta) ou mesmo o engate de carretas cheias ou vazias (por meio da obtenção de informação instantânea da posição do veículo), reduzindo bastante o tempo de entrega ou coleta das mercadorias. As principais características deste grupo foram delineadas no primeiro grupo do primeiro e segundo planos fatoriais da análise de correspondência.

\subsection{ANÁlise Conjunta dos PRINCIPAis ImpaCtos FinanCEIRos, AÇões Tomadas E benefícios Obtidos pelas transportadoras através da análise de CONGLOMERADOS}

A partir da análise de correspondência foi identificado o número ideal de eixos fatoriais para analisar as três seções anteriores (4.5.1, 4.6.1 e 4.7.1). Assim, foram obtidos para os impactos financeiros, rês eixos; para as ações tomadas pelas empresas, três eixos; para os benefícios obtidos pelas transportadoras, quatro eixos.

Para que pudesse haver uma classificação geral das empresas analisadas, com base nas coordenadas dos 10 eixos fatoriais destes três grupos de variáveis, foi utilizado o programa computacional SAS, v. 6.12 para Windows (SAS Institute Inc., 1988), para realizar a análise de conglomerados.

Assim, por meio do procedimento cluster foi obtido o número ótimo de 4 grupos para que as empresas fossem agrupadas, utilizando-se novamente o método hierárquico de Ward, conforme especificado no Apêndice 23. Foram usadas três estatísticas para auxiliar na determinação do número de grupos (Sharma,1996): homogeneidade do novo agrupamento (ou seja, corresponde ao desvio padrão de todas as variáveis - seu valor deve ser o menor possível), perda de homogeneidade (SPR, mede a semelhança entre os grupos - seu valor deve ser o menor possível) e heterogeneidade dos conglomerados (RS, mede a diferença entre os grupos - seu valor deve ser o mais alto possível).

A composição final de cada grupo foi obtida com base no método nãohierárquico $k$-means (descrita na Tabela 19), utilizando o procedimento fastclus do 
pacote SAS, sendo que foram previamente eliminadas as coordenadas de 5 eixos fatoriais que apresentaram valores baixos de RS (abaixo de 0,50 - coordenadas 2 e 3 da questão 5; coordenadas 2, 3 e 4 da questão 6).

Tabela 19. Descrição dos Grupos (Classes) formados pela Análise de Conglomerados das 3 Questões.

\begin{tabular}{cl}
\hline Grupos (classes) & \multicolumn{1}{c}{ Empresas $^{1}$} \\
\hline 1 & $\mathrm{~A}, \mathrm{C}, \mathrm{E}, \mathrm{G}, \mathrm{I}, \mathrm{J}, \mathrm{K}, \mathrm{L}, \mathrm{M}, \mathrm{N}, \mathrm{T}, \mathrm{V}, \mathrm{X}$ \\
\hline 2 & $\mathrm{~B}, \mathrm{H}, \mathrm{Q}, \mathrm{S}, \mathrm{W}, \mathrm{Y}$ \\
\hline 3 & $\mathrm{U}$ \\
\hline 4 & $\mathrm{D}, \mathrm{F}, \mathrm{O}, \mathrm{P}, \mathrm{R}, \mathrm{Z}$ \\
\hline
\end{tabular}

Fonte: Dados da pesquisa

${ }^{1}$ Relação das transportadoras quanto ao uso dos sistemas de rastreamento: A (Combat); B a G (Controlsat); H (Controlsat+Combat); I (Logiq); J (Motorola); K (Multisat); L a Z (Omnisat); W (Teletracker); Y (Teletracker+Omnisat+Controlsat).

\section{Primeiro Grupo}

Este grupo foi composto basicamente por empresas do grupo 1 da questão 3 (proveniente da análise de conglomerados) que utilizavam, em sua grande maioria, sistemas só por satélite. A ausência de alguns impactos financeiros nessas empresas (tais como: em vendas; número de clientes; despesas com vendas; preço final do serviço vendido), o pequeno número de caminhões rastreados, a quase inexistência de reestruturação da empresa, a não alocação de capital em função do rastreamento e pequeno treinamento de funcionários e motoristas mostram que houve pequeno investimento nessa tecnologia.

Apesar disso, essas transportadoras obtiveram bons resultados em relação ao gerenciamento de risco, refletindo diretamente em grande melhoria no serviço ao cliente e aumento significativo na segurança da carga transportada. Embora não tivessem obtido benefícios logísticos, principalmente relacionados à redução do número de rotas, melhoria na decisão quanto à mudança de trajetos e diminuição ociosidade da frota, 
conseguiram grandes vantagens competitivas com o uso dos rastreadores em relação aos concorrentes.

\section{Segundo Grupo}

Este grupo caracterizou-se por empresas que utilizavam vários tipos de sistemas (sistemas só por satélite, satélite/rádio, 2 ou 3 sistemas distintos) em quase toda a frota da empresa (própria ou de terceiros). Houve, de maneira geral, impactos positivos nas vendas, no número de clientes, na quantidade vendida e na taxa de retorno ao investimento, embora tivessem alocado pouco capital adicional e não reestruturado a empresa para implementar o uso do sistema. Além disso, houve pouco treinamento de motoristas e operadores para que os mesmos se adaptassem aos rastreadores.

Embora essas empresas visassem principalmente o gerenciamento de risco, obtiveram benefícios em segurança (grande redução nos custo com segurança, grandes vantagens em colocar a carga no seguro, aumento significativo na segurança da carga transportada) e, também, vantagens logísticas, podendo-se citar entre elas: grande redução na ociosidade da frota e no tempo de entrega/coleta da carga. Além disso, houve grande melhoria no serviço ao cliente, obtenção de informação instantânea do veículo e melhor controle e maior confiança do motorista na empresa.

\section{Terceiro Grupo}

Este grupo constituiu-se de apenas uma empresa que usava o sistema Omnisat, também isolada nos grupos de variáveis das questões 3 e 5 . Na realidade, esta transportadora diferenciou-se das demais porque era a única especializada no transporte de produtos farmacêuticos e, por isso, fazia investimento freqüente nos sistemas de rastreamento, mobilizando todos os seus setores internos, para que fosse alcançado pleno sucesso com a implantação do gerenciamento de risco na empresa. 


\section{Quarto Grupo}

Este grupo foi composto por empresas que utilizavam os sistemas Controlsat e Omnisat (sistemas só por satélite). Caracterizaram-se por impactos positivos na quantidade vendida e por ausência de informação em relação ao lucro bruto e à taxa de retorno ao investimento (conforme já comentado na análise de conglomerados do Grupo 4 da questão 3).

Em relação aos benefícios obtidos com o rastreamento, houve redução nos custos com segurança (em função da redução ou eliminação da escolta) e grande aumento na segurança da carga transportada. Apesar disso, não exploraram novas tecnologias

associadas ao rastreamento, apesar de possuírem EDI, sistemas de informações gerenciais, internet, entre outros. 


\section{CONCLUSÕES}

Este trabalho foi realizado com o intuito de compreender melhor o uso de rastreamento por satélite no transporte rodoviário de cargas, uma vez que existiam apenas estudos pontuais para divulgação desses sistemas no Brasil.

Além disso, deve-se destacar a utilização da análise de correspondência para analisar os dados qualitativos levantados. Apesar de não ser ainda uma técnica multivariada disseminada em estudos dessa natureza, permitiu que informações relevantes fossem extraídas e agrupadas por meio da análise de conglomerados, a fim de melhor caracterizar o gerenciamento de frotas por meio de sistemas por satélite.

Objetivou-se, desta forma, captar o cenário real no qual estavam inseridas as transportadoras e essas novas tecnologias, na cidade de São Paulo, para despertar, tanto por parte do setor de transportes como dos provedores de sistemas, preocupações com as dificuldades, perspectivas e aprimoramento dessa tecnologia, para que sua adoção possa estender-se a várias regiões do Brasil, a outros países do Mercosul e a outros setores, permitindo assim a melhoria da qualidade dos serviços prestados através da integração das cadeias produtivas.

De maneira geral, o gerenciamento de frotas por satélite vem se expandindo lentamente desde 1994, ano em que o primeiro sistema (Omnisat) foi lançado oficialmente no mercado brasileiro. No entanto, há perspectivas de crescimento do rastreamento no setor de transporte rodoviário, vislumbradas pelo acirramento da concorrência entre as empresas que atualmente fornecem diferentes tipos de sistemas. Por outro lado, as empresas têm iniciado o seu processo de reestruturação antes da implantação desses sistemas nas empresas, com a finalidade de garantir serviços mais seguros e eficientes aos seus clientes. Porém, a mudança cultural, social e tecnológica 
tem sido muito lenta e incipiente, independente do tipo de sistema adotado pelas transportadoras.

Os sistemas que utilizavam apenas satélites e, portanto, com maior área de abrangência (Controlsat, Omnisat), dominaram o mercado embora seus preços fossem mais altos em relação aos sistemas que associavam satélite e rádio e as empresas usuárias demorassem quase o dobro do tempo para instalar os sistemas só por satélite em toda frota.

Outro ponto importante a ser ressaltado refere-se à grande concentração de cargas de alto valor agregado e com tendência de expansão para o setor agropecuário, especialmente com relação a produtos agrícolas processados, produtos químicos (insumos e defensivos químicos) e, em quantidade bem reduzida, medicamentos para animais. Essas informações sinalizam para a abertura de canais de comercialização mais eficientes no transporte rodoviário, à medida que há maiores controles sobre o trajeto das cargas e sobre os tipos de produtos transportados. Até o momento, houve grande concentração de entregas nas regiões sudeste e sul.

Os tipos de cargas predominantemente rastreados, aliados à abrangência das regiões de entrega, são fatores a serem considerados pelas transportadoras ao optarem pelos vários sistemas disponíveis no mercado, pois os mais baratos (rádio/satélite) restringem-se a áreas que tenham torres de retransmissão (praticamente a Grande São Paulo), ao contrário dos mais caros (só por satélite) que atuam em nível nacional, alguns deles estendendo-se até outros países do Mercosul.

Deve-se acrescentar também que a principal razão para que as empresas investissem em sistemas de rastreamento por satélite estava associada à necessidade de realizarem o gerenciamento de risco devido à pressão exercida por parte das seguradoras, em função dos assaltos freqüentes tanto na cidade de São Paulo como nas rodovias e da grande probabilidade de ocorrência de sinistro em cargas de alto valor agregado. Em alguns casos havia grandes incentivos para que as empresas implantassem essa nova tecnologia, tais como, redução de preços do seguro e descontos no preço do sistema de rastreamento. Essas estratégias poderiam ser levadas em conta pelas seguradoras e fornecedoras de sistemas a fim de ampliar as parcerias com as 
transportadoras e, consequentemente, elevar os benefícios e reduzir os custos com os rastreadores.

De maneira geral, o comportamento das transportadoras foi bastante diversificado em relação ao aproveitamento dessa nova tecnologia. Sob o ponto de vista dos impactos financeiros dos sistemas sobre as empresas, observou-se que os rastreadores proporcionaram efeitos positivos, principalmente com relação à quantidade vendida pelas transportadoras. Dentre as empresas entrevistadas, algumas delas destacaram-se em decorrência dos seus retornos financeiros terem sido superiores às demais, especialmente relacionados ao número de clientes, quantidade vendida e lucro bruto. Suas principais características eram: uso de sistemas que associavam rádio e satélite, transporte exclusivo de cargas mais valiosas, com alto risco de roubo, grande preocupação com a sua segurança. Por outro lado, ocorreram dificuldades na intensificação da eficiência logística sem que houvesse diminuição na segurança da carga transportada, pois isto implicaria, por exemplo, em mudança de rotas, nem sempre tão seguras quanto as normalmente utilizadas pelas empresas.

Dentre as principais ações tomadas pelas empresas para melhor se adequarem à utilização dos rastreadores, observou-se que a grande maioria usava o kit vendido pelas próprias fornecedoras de rastreadores e mais da metade optou por treinar rapidamente seus funcionários para que operassem os sistemas com maior eficiência. Algumas empresas, entretanto, deram atenção especial para treinamento de operadores e motoristas, capacitando-os através de reciclagem contínua de conhecimentos para que rastreassem as cargas (todas de alto valor agregado e de elevado risco de roubo) movimentadas pelas transportadoras.

Apesar das empresas estarem preocupadas essencialmente com aumentos na segurança das cargas transportadas, foram também detectados pela pesquisa outros benefícios importantes, entre eles, melhorias no monitoramento dos motoristas e dos serviços aos clientes. Além disso, deve-se ressaltar que empresas que rastreavam pequena quantidade de caminhões, ou cujos custos com os sistemas eram pagos pelos seus clientes, observaram poucos resultados positivos com o uso do rastreamento. Por outro lado, foi verificado em alguns grupos de empresas que, após a introdução dos 
rastreadores, houve redução nos custos com segurança, principalmente relacionada à diminuição ou extinção de serviços de escolta e abatimento dos custos com a seguradora (obtido na negociação da apólice de seguro).

A partir da análise conjunta dos principais impactos financeiros, ações tomadas e benefícios obtidos pelas transportadoras, observou-se que as transportadoras diferenciaram-se devido ao tipo de comportamento adotado em relação ao rastreamento. De maneira geral, alguns pontos devem ser considerados pelas empresas ao utilizarem os sistemas, destacando-se: o rastreamento de poucos caminhões da frota pode acarretar pequenos reflexos financeiros positivos na empresa, tendo como conseqüência elevados custos e pequenos benefícios com a utilização desses sistemas; o rastreamento da maioria dos caminhões pode ter como conseqüência melhorias nas vendas, no número de clientes, na quantidade vendida e na taxa de retorno do investimento, apesar das empresas alocarem pouco capital adicional e não se reestruturarem internamente para implementar o uso do sistema; o uso dos rastreadores em grande parte dos caminhões permite não apenas reduzir os sinistros, mas também possibilita a obtenção de vantagens competitivas em relação aos concorrentes, aprimoradas pelos benefícios logísticos e pela adoção de outras tecnologias associadas ao rastreamento (internet, sistemas de informações gerenciais, EDI, entre outras, praticamente não exploradas pelas transportadoras); o transporte exclusivo de produtos farmacêuticos exige investimento e treinamento contínuos para o gerenciamento de risco.

Em termos de limitações deste estudo e recomendações para trabalhos futuros, destaque-se que a abrangência deste estudo concentrou-se à cidade de São Paulo e à caracterização do uso dos sistemas de rastreamento por satélite, em apenas um período de tempo, o que sugere que outras pesquisas sejam conduzidas para acompanhar o impacto de sistemas de rastreamento no setor de transportes ao longo do tempo, em diferentes regiões do Brasil, para um maior número de empresas. Além disso, seria interessante verificar a tendência de uso desses sistemas e o seu nível de influência em outros setores da economia brasileira. 


\section{Anexo A}

\section{Análise de Correspondência da Questão 3}

\section{Primeiro plano fatorial (primeiro e segundo eixos principais)}

No primeiro plano fatorial, ilustrado no Apêndice 5, pôde-se distinguir 4 grupos de modalidades, sendo que as que possuíam as maiores contribuições relativas foram marcadas com asterisco $(*)$.

O primeiro grupo caracterizou-se por impactos muito fracos do uso dos sistemas de rastreamento nas vendas e no número de clientes e ausência de informações sobre impactos no custo do serviço vendido, no lucro bruto e na taxa de retorno ao investimento; foi formado por empresas que utilizavam os sistemas apenas por satélite por 4 ou 5 anos e por aquelas que possuíam os rastreadores por 1 a 3 anos.

No segundo grupo destacaram-se impactos nulos nas vendas, na quantidade vendida, no preço final do serviço vendido, nas despesas com vendas e na taxa de retorno ao investimento, associadas a empresas com faturamento entre US\$9-99 milhões ou menor que US\$ 1 milhão, que rastreavam menos que $20 \%$ da frota ou entre 51 e $70 \%$ da frota, respectivamente. Os sistemas utilizados eram em sua grande maioria só por satélite.

O terceiro grupo caracterizou-se por impactos negativos no custo do serviço vendido, impactos regulares nas vendas, na quantidade vendida e no lucro bruto e impactos muito fracos na taxa de retorno ao investimento, relacionados a transportadoras com faturamentos entre US\$1-9 milhões ou US\$ 100-500 milhões, que utilizavam sistemas por satélite/rádio ou que tinham 2 ou 3 sistemas (mesclando sistemas satélite/rádio e só por satélite) em mais de $70 \%$ da frota própria.

No quarto grupo prevaleceu redução no número de clientes e diminuição regular nas despesas com vendas em uma empresa que utilizava o sistema por satélite (Omnisat). 


\section{Segundo plano fatorial (primeiro e terceiro eixos principais)}

O segundo plano fatorial, expresso no Apêndice 6, permitiu distinguir 4 grupos de modalidades.

O primeiro grupo integrou impactos muito fracos nas despesas com vendas, muito fortes no número de clientes e na quantidade vendida; impactos negativos em relação ao preço final do serviço vendido e ao lucro operacional. Não houve resposta sobre os impactos nas vendas, lucro bruto e taxa de retorno ao investimento. Da mesma forma que o primeiro grupo do primeiro plano fatorial, este grupo caracterizou-se por empresas que utilizavam os sistemas apenas por satélite há 4 ou 5 anos.

No segundo grupo houve destaque para impactos negativos no número de clientes e na quantidade vendida e por redução regular nas despesas com vendas, relacionado a apenas uma empresa que utilizava o sistema por satélite (a mesma descrita no terceiro grupo do primeiro plano fatorial).

No terceiro grupo concentraram-se impactos nulos nas vendas, no número de clientes, na quantidade vendida e no lucro bruto, e muito fracos na taxa de retorno ao investimento, em empresas com faturamento menor do que US\$ 1 milhão, cujos sistemas eram em sua grande maioria só por satélite e rastreavam entre 51-70\% caminhões (muito semelhante ao segundo grupo do primeiro plano fatorial).

$\mathrm{O}$ quarto grupo caracterizou-se por impactos regulares no número de clientes, na quantidade vendida e no preço final do serviço vendido e impacto muito forte nas vendas em empresas que possuíam um faturamento entre US\$ 9.99 milhões. Além disso, neste grupo prevaleceram transportadoras que utilizavam sistemas por satélite/rádio ou que tinham 2 ou 3 sistemas (mesclando sistemas satélite/rádio e só por satélite), tal como no terceiro grupo do primeiro plano fatorial. 


\section{Terceiro plano fatorial (segundo e terceiro eixos principais)}

O terceiro plano fatorial, ilustrado no Apêndice 7, possibilitou distinguir apenas 2 grupos de modalidades.

No primeiro grupo predominaram impactos regulares no número de clientes, na quantidade vendida e no preço final do serviço vendido em transportadoras que utilizavam sistemas por satélite/rádio ou que tinham 2 ou 3 sistemas (mesclando sistemas satélite/rádio e só por satélite), confirmando a presença de algumas características relacionadas nos planos anteriores.

O segundo grupo destacou-se por impactos negativos no número de clientes e na quantidade vendida e por redução regular nas despesas com vendas, relacionado a apenas uma empresa que utilizava o sistema por satélite, já isolada nos planos anteriores. 


\section{Anexo B}

\section{Análise de Correspondência da Questão 5}

\section{Primeiro plano fatorial (primeiro e segundo eixos principais)}

No primeiro plano fatorial, ilustrado no Apêndice 11, pôde-se distinguir 2 grupos de modalidades, sendo que as que possuíam as maiores contribuições relativas foram marcadas com asterisco $(*)$.

O primeiro grupo caracterizou-se por grande participação da empresa no desenvolvimento de software específico para rastreamento, porém com compra regular de novos computadores pessoais para serem utilizados nesses sistemas e grande aproveitamento de analistas de sistemas ou programadores já existentes na empresa. Apenas uma empresa, que possuía um faturamento de US\$ 100-500 milhões e utilizava o sistema Omnisat foi incluída neste grupo. Deve-se ressaltar que a separação desta transportadora também foi obtida nos três planos fatoriais da questão 3.

No segundo grupo prevaleceram grande participação na terceirização de serviços de analistas de sistemas (ou programadores) para implementar o sistema de rastreamento utilizado e pouca reestruturação de todos os setores da empresa para sua adequação aos rastreadores. Apenas um tipo de sistema agregou-se a este grupo, Teletracker, representado por uma só transportadora.

\section{Segundo plano fatorial (primeiro e terceiro eixos principais)}

O segundo plano fatorial, expresso no Apêndice 12, distinguiu 3 grupos de modalidades.

O primeiro grupo destacou-se por grandes reestruturações em todos os setores das empresas em função dos sistemas de rastreamento, grande participação da empresa em contratações e treinamentos de funcionários para operação/digitação de rotinas para 
os rastreadores, e em treinamentos de motoristas. A grande maioria das empresas representadas neste grupo utilizava sistema por satélite (Controlsat, Logiq, Omnisat).

O segundo grupo caracterizou-se por não ter observado nenhuma alocação adicional de capital para melhorar o uso de sistemas de rastreamento e nenhuma compra de novos computadores pessoais para serem usados com rastreadores. Neste grupo destacaram-se empresas que utilizavam sistemas apenas por satélite por tempo de 1 a 3 anos, cujo faturamento era menor de US\$ 1 milhão.

No terceiro grupo prevaleceram as mesmas características obtidas no primeiro grupo do primeiro plano fatorial.

\section{Terceiro plano fatorial (segundo e terceiro eixos principais)}

No terceiro plano fatorial, ilustrado no Apêndice 13, sobressaíram 3 grupos de modalidades.

No primeiro grupo predominaram grandes participações das empresas na reestruturação de todos os setores da empresa e no treinamento de funcionários como operadores/digitadores e de motoristas, tal como foi obtido no primeiro grupo do segundo plano fatorial. Houve, também, associação de empresas que utilizavam em sua grande maioria sistemas só por satélite.

O segundo grupo destacou-se por pouca reestruturação de todos os setores da empresa para adequá-la ao sistema de rastreamento, ausência de treinamento dos funcionários da empresa para trabalhar como operadores e desenvolvimento de software específico para rastreamento através de terceirização de serviços.

No terceiro grupo prevaleceram as mesmas características obtidas no segundo grupo do segundo plano fatorial. 


\section{Anexo C}

\section{Análise de Correspondência da Questão 6}

\section{Primeiro plano fatorial (primeiro e segundo eixos principais)}

No primeiro plano fatorial, ilustrado no Apêndice 17, pôde-se distinguir 4 grupos de modalidades, sendo que as que possuíam as maiores contribuições relativas foram marcadas com asterisco (*).

O primeiro grupo destacou-se por alto grau de satisfação em relação à colocação da carga no seguro, diminuição do número de rotas, redução da ociosidade da frota, redução do tempo de entrega/coleta das cargas e regular em relação à redução de custos e à exploração de novas tecnologias, a partir da adoção dos sistemas de rastreamento. Essas modalidades relacionaram-se a empresas que utilizavam, em sua grande maioria, sistemas apenas por satélite por mais de um ano.

O segundo grupo destacou-se por não ter observado nenhuma alteração no número de rotas, apesar de ter ocorrido redução regular no tempo de entrega/coleta das mercadorias. A maioria das empresas relacionadas a este grupo possuía sistema apenas por satélite em menos de $20 \%$ da frota.

O terceiro grupo caracterizou-se por não sinalizar nenhum aumento na segurança da carga transportada, nenhuma melhoria na confiança do motorista na empresa e por não ter havido nenhum controle do motorista. Por outro lado, houve pequeno atendimento na colocação da carga no seguro. Neste grupo associaram-se apenas duas empresas que utilizavam sistemas só por satélite em 51-70\% dos caminhões rastreados.

No quarto grupo houve pouca melhoria na confiança do motorista em relação à empresa e incremento regular no serviço ao cliente e na segurança da carga transportada com o uso dos sistemas de rastreamento, relacionado a apenas uma empresa que utilizava o sistema Omnisat. 
Segundo plano fatorial (primeiro e terceiro eixos principais)

O segundo plano fatorial, expresso no Apêndice 18, permitiu distinguir 3 grupos de modalidades.

O primeiro grupo apresentou as mesmas características obtidas no segundo grupo do segundo plano fatorial e no quarto grupo do primeiro plano fatorial.

No segundo grupo prevaleceu pouco atendimento na diminuição do número de rotas, na melhoria da confiança do motorista em relação à empresa e na exp loração de novas tecnologias e atendimento regular na melhoria do serviço ao cliente, no controle melhor do motorista e na obtenção instantânea da posição do veículo. Neste grupo destacaram-se empresas que utilizavam sistemas apenas por satélite em 20 a $50 \%$ dos caminhões rastreados. Algumas modalidades deste grupo relacionam-se ao quarto grupo do primeiro plano fatorial.

O terceiro grupo caracterizou-se por nenhum atendimento na redução de custos com segurança, no aumento da segurança da carga transportada e na melhoria da confiança do motorista em relação à empresa e pouco atendimento na colocação da carga no seguro. Praticamente este grupo refere-se ao terceiro grupo do primeiro plano fatorial, inclusive em relação às empresas neles relacionadas.

\section{Terceiro plano fatorial (segundo e terceiro eixos principais)}

No terceiro plano fatorial, ilustrado no Apêndice 19, sobressaíram 2 grupos de modalidades.

O primeiro grupo apresentou as mesmas características obtidas no segundo grupo do segundo plano fatorial.

No segundo grupo nenhuma alteração prevaleceu na melhoria do serviço ao cliente, no aumento da segurança da carga transportada e na melhoria da confiança do motorista em relação à empresa e pequeno atendimento na colocação da carga no seguro. Esse grupo identificou-se com o terceiro grupo do segundo plano fatorial. 


\section{Quarto plano fatorial (primeiro e quarto eixos principais)}

No quarto plano fatorial, ilustrado no Apêndice 20, sobressaíram 3 grupos de modalidades.

O primeiro grupo possuiu as mesmas características do primeiro grupo do primeiro e segundo planos fatoriais.

No segundo grupo predominou pouca melhoria da decisão quanto à mudança de trajetos de coletas, pouca diminuição no número de rotas, nenhuma redução no tempo de entrega/coleta, nenhum socorro de veículos quebrados e nenhuma obtenção de vantagens competitivas em relação às outras empresas. Neste grupo associaram-se empresas com faturamento menor que US\$ 1 milhão e que utilizavam sistemas só por satélite por menos de 1 ano.

No terceiro grupo destacaram-se as mesmas modalidades descritas no segundo grupo do primeiro plano fatorial.

\section{Quinto plano fatorial (segundo e quarto eixos principais)}

No quinto plano fatorial, expresso no Apêndice 21, distinguiu-se 2 grupos de modalidades.

O primeiro grupo apresentou as mesmas características do segundo grupo do quarto plano fatorial.

No segundo grupo predominaram as mesmas modalidades do terceiro grupo do primeiro plano fatorial.

\section{Sexto plano fatorial (terceiro e quarto eixos principais)}

No sexto plano fatorial, mostrado no Apêndice 22, três grupos estavam representados.

O primeiro grupo caracterizou-se por nenhuma redução no tempo de entrega/coleta da carga, nenhuma alteração no socorro de veículos quebrados, nenhum 
obtenção de vantagens competitivas em relação aos concorrentes, pouco melhoria na decisão quanto à mudança de trajetos, pouca diminuição no número de rotas e grande exploração de novas tecnologias devido à utilização de rastreadores nas transportadoras. Neste grupo associaram-se empresas com faturamento menor que US\$ 1 milhão e que utilizavam sistemas só por satélite por 4 a 5 anos.

No segundo grupo predominaram as mesmas características descritas no primeiro grupo do quarto plano fatorial.

O terceiro grupo destacou-se por pouca melhoria na confiança do motorista em relação à empresa, pouca exploração de novas tecnologias a partir do uso de rastreadores e grande redução no tempo de entrega/coleta da carga. Neste grupo relacionaram-se transportadoras de médio ou grande porte que utilizavam em sua grande maioria sistemas por satélite em 20 a $50 \%$ dos caminhões da frota. 


\section{REFERÊNCIAS BIBLIOGRÁFICAS}

ALVES, D. S. Sistemas de informação geográfica. In: Geoprocessamento. São Paulo: USP, 1990. p.66-78.

ANDRADE, J. B. de; BLITZKOW, D. NAVSTAR/GPS: uma nova era para o posicionamento. In: Geoprocessamento. São Paulo: Escola Politécnica/USP, 1990, p.189-197.

ANUÁRIO DO TRANSPORTE RODOVIÁRIO DE CARGA 96, n.1, p.81-96, 1996.

APOSTOLOPOULOS, T. K.; PRAMATARIS, K. C. Information technology investment evaluation: investments in telecommunication infrastructure. International Journal of Information Management, v. 17, n.4, p.287-296, Aug. 1997.

AQUINO, M. Alta precisão no Brasil. Fator GIS: a revista do geoprocessamento, v. 3, n. 11, p.48-49, out./nov./dez.1995.

AQUINO, M. Avanços em WADGPS e WAAS. Fator GIS: a revista do geoprocessamento, v. 4, n. 13, p.49-50, abr./maio1996.

AS MAIORES DO TRANSPORTE, São Paulo, v.10, n.10, set/out. 1997. 112p.

AUTOTRAC. Omnisat: sistema de gerenciamento de frota e monitoramento de veículos por satélite. São Paulo: AUTOTRAC Comércio e Telecomunicações S.A, 1996. $15 \mathrm{p}$. 
BALLOU, R.H. Logística empresarial: transportes, administração de materiais e distribuição física. São Paulo: Atlas, 1993. 388p.

BENZÉCRI, J. P. Correspondence analysis handbook. New York: Marcel Dekker, 1992. 665p.

BRYNJOLFSSON, E.; HITT, L. Paradox Lost? Firm-level evidence on the returns to information systems spending. Management Science, v. 42, n. 4, p.541-558, Apr.1996a.

BRYNJOLFSSON, E.; HITT, L. The customer counts - investing in computers pays off: but to get the most value for your IT dollar, focus on customers. Information Week, n.596, p.48-54, Sep. 1996b.

BUARQUE, C. Avaliação Econômica de Projetos. São Paulo: Campos, 1991. 266p.

CHISHOLM, J. Cars of convenience: instant-rent-a-cars. GPS World, v.7, n. 4, p.4754, Apr. 1996.

CHISTYAKOV, V. V.; FILATCHENKOV, S. V.; KHIMULIN, V. I.; KORNYENKO, V V. Double Duty: Russia's DGPS/DGLONASS Maritime Service. GPS World, v.7, n. 3, p.59-62, Mar. 1996.

CONTADOR, C. R. Avaliação Social de Projetos. São Paulo: Atlas, 1981. 301p.

CRIVISQUI, E. M. Analisi Factorial de Correspondencias: un instrumento de investigación en ciencias sociales. Asunción: Universidad Católica "Nuestra Señora de la Asunción", 1993. 302p.

CRIVISQUI, E. M. Apresentação dos métodos de classificação. In: Seminário de métodos estatísticos multivariados aplicados às ciências humanas. Campinas: UNICAMP, 1998. p1-57. 
CRIVISQUI, E. M.; BATISTA, C. Apresentação da análise fatorial de correspondência simples. In: Seminário de métodos estatísticos multivariados aplicados às ciências humanas. Campinas: UNICAMP, 1998. p1-104.

CUSTÓDIO, I. Avaliação de sistemas de informação: um modelo para auxiliar na escolha de métodos e técnicas. Revista de Administração da USP, v.18, n.4, p.617, out/dez. 1983.

CUSTÓDIO, I. Um estudo sobre variáveis organizacionais e comportamentais que afetam a avaliação de sistemas de informação. Revista de Administração da USP, v.23, n.4, p.3-8, out/dez. 1988.

CISIA. SPAD version 3.5. Saint-Mandé: CISIA-CERESTA, 1998. (Tópicos de ajuda aide)

DANA, P. Global positioning system overview. http://www.utexas.du/depts/grg/geraft/ notes/gps/gps.html. (jun. 1998).

DILLON, W. R.; GOLDSTEIN, M. Multivariate analysis: methods and applications. New York: John Wiley \& Sons, 1984. 587p.

EARL, M. J. The risks of outsourcing IT. Sloan Management Review, p.26-32, Spring 1996.

ESCOFIER, B.; PAGÈS, J. Análisis factoriales simples y múltiples: objetivos, métodos e interpretación. Bilbao: Universidad del Pais Vasco, 1992, 285p.

EVANS, M.; HASTINGS, N.; PEACOCK, B. Statistical Distributions. 2 ed. New York: John Wiley \& Sons, 1993. 170p.

FERNANDES, A. A.; ALVES, M. M. Gerência estratégica da tecnologia da informação. Rio de Janeiro: LTC, 1992. 261p. 
FRANCO, L. C. S.; PESSOA, L. M. da C. Differential GPS: uma tendência mundial no uso do GPS em tempo real. Fator GIS: a revista do geoprocessamento, v.3, n.10, p.48-49, jul./ago./set.1995.

GEILING, K. A polêmica das antenas. Brasil Transportes, v. 32, n. 341, p.20-23, out.1995.

GRAVES, S.C.; KAN, A .H.G.R.; ZIPKIN, P.H. Logistics of production and inventory. North-Holland: Elsevier Science Publishers B.V., 1993. 760p.

GREENACRE, M. J. Theory and applications of correspondence analysis. Orlando: Academic Press Inc., 1984. 364p.

GREENE, W. H. Econometric analysis. 2 ed. New Jersey: Prentice-Hall, 1993. 791p.

HAIR, J. F.; ANDERSON, R. E.; TATHAM, R. L.; BLACK, W. C. Multivariate data analysis with readings. 4 ed. New Jersey: Prentice-Hall, 1995. 745p.

HAMILTON, J. W. Wireless communication systems: a satellite-based communications approach for competitive advantage in logistic and transportation support services. Computers in Industry, v.21, p.273-278, 1993.

HARES, J.; ROYLE, D. Measuring the value of information technology. Chichester: John Wiley \& Sons. 1994. 268p.

JOHNSON, R. A; WICHERN, D. W. Applied multivariate statistical analysis. 3 ed. New Jersey: Prentice-Hall Inc. 1992. 642p.

KISH, K. Survey sampling. 2 ed. New York: John Wiley \& Sons, 1965. 643p.

LANGLEY, R. Interference: sources and symptoms. GPS World. http:// www.gpsworld.com/columns/1197innov.htm. (nov. 1997) 
LOPEZ, I. Rastreadores aliam segurança a facilidades logísticas. Revista Tecnologística, v. 2, n.13, p. 30-40, out. 1996.

MANUAL de cálculo de custos e formação de preços do transporte rodoviário de cargas. São Paulo: NTC, 1970. 32p.

NTC debate o futuro do transporte de cargas. NTC Notícias, v. 7, n. 394, p.1-4, set. 1998.

OLIVEIRA, M. de. Até Scotland Yard vem ver a violência. Revista da Indústria, v.1, n.9, p.40-41, set. 1996.

PACE, S.; FROST, G.; LACHOW, I.; FRELINGER, D.; FOSSUM, D; WASSEM, D.; PINTO, M. At the crossroads: developing a national policy for GPS. GPS World, v.7, n. 3, p.53-58, Mar. 1996.

PARREIRAS, R.; MENDONÇA, D. F. Marketing de transporte de cargas. São Paulo: McGraw-Hill, 1990. 200p.

PENHA, G. Frotistas são o alvo preferencial. Anuário do Transporte de Carga, n.3, p.17-19, 1998.

PESSOA, L. M. da C. WADGPS: maior precisão a longas distâncias. Fator GIS: a revista do geoprocessamento, v. 4, n. 13, p.47-48, abr./mai.1996.

PINO, F. A.; CASER, D. V. Falta de resposta em levantamentos por amostragem um estudo de caso. São Paulo: IEA, 1984. 25p. (Relatório de pesquisa)

PINO, F. A.; IGUE, T.; AMARO, A. A. Delineamento amostral par levantamento de cancro cítrico no Estado de São Paulo. Agricultura em São Paulo, v.37, n.3, p.61$71,1990$.

PROGRAM: Inmarsat. The Satellite Encyclopedia. http://www.tbs-satellite.com/tse/ online/prog-inmarsat.html. (jul. 1998) 
REIS, N. G. dos. Estudos Técnicos do TRC: os rastreadores como ferramenta de logística e de segurança. São Paulo: NTC/ TM. 1997. 68p. (mímeo).

ROADTRAC and talk800 create trucking communications systems. Transport Technology Today, p.S-22, Mar. 1996.

SAS Institute Inc. SAS/STAT User's Guide, Release 6.03 Edition. Cary, NC: SAS Institute Inc, 1988, 1028p.

SHARMA, S. Applied Multivariate Techniques. New York: John Wiley \& Sons, 1996. 493p.

SHOW us the money. GPS World. http:// www.gpsworldcom/columns/roundtable. (Oct. 1997)

SILVA, J. G. S. Impactos das tecnologias da informação na agricultura. Revista de Economia e Sociologia Rural, v. 34, n.2, p.7-30, 1995.

TECNOLOGIA acelera transporte rodoviário. O Estado de São Paulo, 24 set. 1995. p. B14.

TIGRE, P.B.; ROVERE, R.L.L.; FAGUNDES, J. Tecnologias da informação e desenvolvimento: novas evidências sobre sua difusão e impactos econômicos. Revista Brasileira de Economia, v.49, n.4, p.697-732, out/dez. 1995.

VIOLINO, B. Measuring value: return on investment - the intangible benefits of technology are emerging as the most important of all. Information Week, n. 637, p.1-8, Jun. 1997.

WESTBROOK, M. N. Wireless Technologies: DSRC, cellular, and GPS. ITS World. http:// www.itsworld.com/ITS101/its101wt.htm. (nov/dez. 1996) 
WITTE, D. M. Full-life-cycle economics: an evaluation methodology for information tecnology projects. Journal of Organizational Computing, v. 4, n.4, p.393-403, 1994.

WOILER, S.; MATHIAS, W. F. Projetos: planejamento, elaboração e análise. São Paulo: Atlas, 1992. 294p. 


\section{Apêndice 1}

\section{Questionário - Empresas usuárias dos sistemas de rastreamento}

1. ASSINALAR COM UM $X$ O(S) PRODUTO(S) TRANSPORTADO(S) PELA EMPRESA SEM UTILIZAR O SISTEMA DE RASTREAMENTO (SEGUNDA COLUNA) E O(S) PRODUTO(S) TRANSPORTADO(S) COM SISTEMA DE RASTREAMENTO (TERCEIRA COLUNA):

\begin{tabular}{|c|c|c|c|c|}
\hline Produtos transportados & $\begin{array}{r}\text { Transpo } \\
\text { rastr }\end{array}$ & $\begin{array}{l}\text { SEM } \\
\text { or }\end{array}$ & $\begin{array}{r}\text { Transpo } \\
\text { rastr }\end{array}$ & $\begin{array}{l}\mathrm{OM} \\
\mathbf{r}\end{array}$ \\
\hline Equipamentos eletrônicos & & 101 & $\square$ & 141 \\
\hline Produtos farmacêuticos & & 102 & & 142 \\
\hline Cosméticos & & 103 & & 143 \\
\hline Eletrodomésticos & & 104 & & 144 \\
\hline Vestuários & & 105 & & 145 \\
\hline Valores & & 106 & & 146 \\
\hline Veículos & & 107 & & 147 \\
\hline Cigarros & 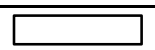 & 108 & & 148 \\
\hline Líquido engarrafado (engradados) & $\overline{7}$ & 109 & & 149 \\
\hline Produtos siderúrgicos & 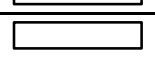 & 110 & & 150 \\
\hline Produtos químicos & & 111 & & 151 \\
\hline Produtos agrícolas in natura & 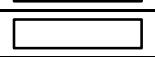 & 112 & & 152 \\
\hline Produtos agrícolas processados & & 113 & & 153 \\
\hline Animais & & 114 & & 154 \\
\hline Madeira & L & 115 & & 155 \\
\hline Mudanças & & 116 & & 156 \\
\hline Móveis novos & & 117 & & 157 \\
\hline Combustíveis e lubrificantes & $\bar{\square}$ & 118 & & 158 \\
\hline Carga geral & & 119 & & 159 \\
\hline Equipamentos de informática & & 120 & & 160 \\
\hline Autopeças & 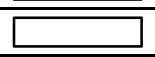 & 121 & & 161 \\
\hline Pneus e borrachas & & 122 & & 162 \\
\hline Material bélico & 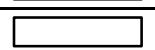 & 123 & & 163 \\
\hline Medicamento para animais & $\square$ & 124 & & 164 \\
\hline Calçados & $\square$ & 125 & & 165 \\
\hline Outros: & $\begin{array}{ll} \\
\end{array}$ & 140 & & 180 \\
\hline
\end{tabular}




\section{ASSINAlar COM UM X A(S) REgião(ÕES) DAS ENTREgas MAIS FREQÜENTES AO LONGO} DO ANO:

\begin{tabular}{|c|c|c|c|c|}
\hline Região de Entrega & \multicolumn{2}{|c|}{ Transporte SEM rastreador } & \multicolumn{2}{|c|}{ Transporte COM rastreador } \\
\hline Norte do Brasil & $\square$ & 201 & & 221 \\
\hline Nordeste do Brasil & $\square$ & 202 & & 222 \\
\hline Centro-oeste do Brasil & + & 203 & $\square$ & 223 \\
\hline Sudeste do Brasil & & 204 & & 224 \\
\hline Sul do Brasil & $\square$ & 205 & & 225 \\
\hline Argentina & 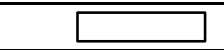 & 206 & $\bar{\square}$ & 226 \\
\hline Bolívia & & 207 & $\square$ & 227 \\
\hline Chile & प & 208 & $\bar{\square}$ & 228 \\
\hline Paraguai & $\square$ & 209 & & 229 \\
\hline Uruguai & $\square$ & 210 & & 230 \\
\hline outros países: & प & 211 & $\square$ & 231 \\
\hline
\end{tabular}

3. POR FAVOR, DAR NOTAS (DE 0 A 5) AOS ITENS ABAIXO LISTADOS CONFORME O IMPACTO QUE OS MESMOS SOFRERAM COM O USO DO(S) SISTEMA(S) DE RASTREAMENTO EM 1997:

\begin{tabular}{|l||c|c||c|c||c||c||}
\hline $\begin{array}{l}\text { NOTAS } \\
\text { DE 0 A 5: }\end{array}$ & (0) Não sabe & $\begin{array}{c}\text { (1) Nega- } \\
\text { tivo }\end{array}$ & (2) Nenhum & $\begin{array}{c}\text { (3) Muito } \\
\text { fraco }\end{array}$ & $\begin{array}{c}\text { (4) Nem forte/ } \\
\text { nem fraco }\end{array}$ & $\begin{array}{c}\text { (5) Muito } \\
\text { forte }\end{array}$ \\
\hline
\end{tabular}

\begin{tabular}{|ll|l|l|}
\hline[ & ] & $\mathbf{3 0 1}$ & Vendas \\
\hline[ & ] & $\mathbf{3 0 2}$ & Número de clientes \\
\hline[ & ] & $\mathbf{3 0 3}$ & Quantidade vendida \\
\hline[ & ] & $\mathbf{3 0 4}$ & Preço final do serviço vendido \\
\hline[ & ] & $\mathbf{3 0 5}$ & Custo do serviço vendido \\
\hline[ & ] & $\mathbf{3 0 6}$ & Lucro bruto \\
\hline[ & ] & $\mathbf{3 0 7}$ & Despesas com vendas \\
\hline[ & ] & $\mathbf{3 0 8}$ & Lucro operacional \\
\hline[ & ] & $\mathbf{3 0 9}$ & Taxa de retorno do investimento (lucro líquido/ativo médio) \\
\hline[ & ] & $\mathbf{3 1 1}$ & Outros: \\
\hline
\end{tabular}


4. favor responder às perguntas relacionadas ao(s) sistema(s) utilizado(s) pela empresa:

\begin{tabular}{|c|c|c|c|c|c|c|c|}
\hline \multirow[t]{2}{*}{$\begin{array}{c}\text { TIPOS DE SISTEMAS EXISTENTES NO } \\
\text { MERCADO }\end{array}$} & \multicolumn{4}{|c|}{$\begin{array}{l}\text { QUAL É A PORCENTAGEM DE } \\
\text { CAMINHÕES COM } \\
\text { RASTREADORES EM RELAÇÃO À } \\
\text { FROTA }\end{array}$} & \multirow[t]{2}{*}{$\begin{array}{l}\text { HÁ QUANTOS } \\
\text { ANOS } \\
\text { USA O(s) } \\
\text { SISTEMA(s)? }\end{array}$} & \multirow{2}{*}{\multicolumn{2}{|c|}{$\begin{array}{l}\text { QUAL É O NíVEL DE } \\
\text { S ATISFAÇÃO EM } \\
\text { RELAÇÃO AO(S) } \\
\text { SISTEMA(S) } \\
\text { UTILIZADO(S)? } \\
\text { NOTAS DE (0) A (4): } \\
\text { (0) NÃO USA } \\
\text { (1) RUIM } \\
\text { (2) REGULAR } \\
\text { (3) BOM } \\
\text { (4) ÓTIMO }\end{array}$}} \\
\hline & \multicolumn{2}{|c|}{ própria? } & \multicolumn{2}{|l|}{ total? } & & & \\
\hline Braslaser/Motorola(Braslaser) & $\%$ & 401 & $\%$ & 461 & 421 & {[} & 441 \\
\hline Cargosat (Prosat Comum.) & $\%$ & 402 & $\%$ & 462 & 422 & {[} & 442 \\
\hline Teletracker (Vence Eng.) & $\%$ & 403 & $\%$ & 463 & 423 & {[} & 443 \\
\hline Logiq (Avibrás Telecom.) & $\%$ & 404 & $\%$ & 464 & 424 & {[} & 444 \\
\hline Omnisat (Autotrac) & $\%$ & 405 & $\%$ & 465 & 425 & {[} & 445 \\
\hline Radiototal (Radiotrack) & $\%$ & 406 & $\%$ & 466 & 426 & {[} & 446 \\
\hline Controlsat (Schahin Cury) & $\%$ & 407 & $\%$ & 467 & 427 & {[} & 447 \\
\hline Satcom (Geo Ecosat) & $\%$ & 408 & $\%$ & 468 & 428 & {[} & 448 \\
\hline Sky Mark (Combat) & $\%$ & 409 & $\%$ & 469 & 429 & {[} & 449 \\
\hline Trucksat (Trucksat Systems) & $\%$ & 410 & $\%$ & 470 & 430 & {[} & 450 \\
\hline Outros:__-_-__-__-_-_ & $\%$ & 411 & $\%$ & 471 & 431 & {[} & 451 \\
\hline
\end{tabular}

5. POR FAVOR, DAR NOTAS (DE 0 A 3) AS PRINCIPAIS AÇÕES ABAIXO LISTADAS, SEGUNDO SUAS PARTICIPAÇÕES NO PROCESSO DE ADEQUAÇÃO DA EMPRESA AOS SISTEMAS DE RASTREAMENTO :

\begin{tabular}{|l|l|l||l||l|}
\hline NOTAS DE 0 A 3: & (0) nenhuma & (1) pouca participação & (2) participação regular & (3) partic. grande \\
\hline
\end{tabular}

\begin{tabular}{|ll|l|l|}
\hline[ & ] & $\mathbf{5 0 1}$ & Reestruturar a administração da empresa \\
\hline[ & ] & $\mathbf{5 0 2}$ & Reestruturar todos os setores da empresa \\
\hline[ & ] & $\mathbf{5 0 3}$ & Alocar mais capital para melhorar o uso de sistemas de rastreamento \\
\hline[ & ] & $\mathbf{5 0 4}$ & Treinar funcionários da empresa para trabalhar como operadores/digitadores \\
\hline[ & ] & $\mathbf{5 0 5}$ & Contratar novos funcionários para a área de informática (operadores/digitadores) \\
\hline[ & ] & $\mathbf{5 0 6}$ & Treinar motoristas \\
\hline[ & ] & $\mathbf{5 0 7}$ & Contratar novos motoristas \\
\hline[ & ] & $\mathbf{5 0 8}$ & Comprar novos computadores pessoais \\
\hline[ & ] & $\mathbf{5 0 9}$ & Substituir equipamentos de informática \\
\hline[ & ] & $\mathbf{5 1 0}$ & Contratar pessoal para manutenção dos equipamentos usados para rastreamento \\
\hline[ & ] & $\mathbf{5 1 1}$ & Terceirizar serviços para manutenção dos equipamentos usados para rastreamento \\
\hline[ & ] & $\mathbf{5 1 2}$ & Contratar analistas de sistemas/programadores \\
\hline[ & ] & $\mathbf{5 1 3}$ & Utilizar analistas de sistemas/programadores já existentes na empresa \\
\hline[ & ] & $\mathbf{5 1 4}$ & Terceirizar serviços de analistas de sistemas/programadores \\
\hline[ & ] & $\mathbf{5 1 5}$ & Desenvolver software específico/banco de dados para rastreamento dentro da empresa \\
\hline[ & ] & $\mathbf{5 1 6}$ & Desenvolver software específico/banco dados através de terceirização de serviços \\
\hline[ & ] & $\mathbf{5 1 7}$ & Outros fatores relevantes: \\
\hline
\end{tabular}


6. POR FAVOR, DAR NOTAS (DE O A 4) AO GRAU DE SATISFAÇÃo COM RELAÇÃo AOS BENEFíCIOS, ABAIXO RELACIONADOS, OBTIDOS COM O USO DOS SISTEMAS DE RASTREAMENTO :

\begin{tabular}{|c||c||c|c||c||c||}
\hline $\begin{array}{c}\text { NOTAS DE } \\
\text { 0 A 4: }\end{array}$ & (0) Não sabe & (1) Nenhum & $\begin{array}{c}\text { (2) Pouco } \\
\text { atendido }\end{array}$ & $\begin{array}{c}\text { (3) Mais ou menos } \\
\text { atendido }\end{array}$ & $\begin{array}{c}\text { (4) Muito } \\
\text { atendido }\end{array}$ \\
\hline
\end{tabular}

\begin{tabular}{|ll|l|l|}
\hline[ & ] & $\mathbf{6 0 1}$ & Melhorar o serviço ao cliente \\
\hline[ & ] & $\mathbf{6 0 2}$ & Reduzir custos \\
\hline[ & ] & $\mathbf{6 0 3}$ & Redução dos custos com segurança \\
\hline[ & ] & $\mathbf{6 0 4}$ & Reduzir o número de funcionários \\
\hline[ & ] & $\mathbf{6 0 5}$ & Aumentar a segurança da carga transportada \\
\hline[ & ] & $\mathbf{6 0 6}$ & Colocar a carga/caminhão no seguro \\
\hline[ & ] & $\mathbf{6 0 7}$ & Melhorar a decisão quanto à mudança de trajetos de coletas, etc. \\
\hline[ & ] & $\mathbf{6 0 8}$ & Diminuir o número de rotas \\
\hline[ & ] & $\mathbf{6 0 9}$ & Reduzir a ociosidade da frota \\
\hline[ & ] & $\mathbf{6 1 0}$ & Reduzir o tempo de entrega/coleta \\
\hline[ & ] & $\mathbf{6 1 1}$ & Obter informação instantânea da posição do veículo \\
\hline[ & ] & $\mathbf{6 1 2}$ & Socorrer veículos quebrados \\
\hline[ & ] & $\mathbf{6 1 3}$ & Melhorar a manutenção dos veículos \\
\hline[ & ] & $\mathbf{6 1 4}$ & Melhorar a confiança do motorista em relação à empresa \\
\hline[ & ] & $\mathbf{6 1 5}$ & Controlar melhor o motorista \\
\hline[ & ] & $\mathbf{6 1 6}$ & Obter maiores vantagens competitivas em relação às outras empresas \\
\hline[ & ] & $\mathbf{6 1 7}$ & Explorar novas tecnologias \\
\hline[ & ] & $\mathbf{6 1 8}$ & Redução da quantidade de horas extras \\
\hline[ & ] & $\mathbf{6 1 9}$ & Outros fatores relevantes: \\
\hline
\end{tabular}

7. Por Favor, indiQue Na(S) LINHa(S) ABAIXo, QUal(IS) O(S) TIPO(S) DE ANÁlise(S)S UTILIZADA(S) PARA DECIDIR SOBRE A COMPRA DO(S) SISTEMA(S) DE RASTREAMENTO:

\section{ASSINALAR COM UM X:}

\begin{tabular}{|l|l|l|}
\hline \multicolumn{3}{|c|}{ SE A EMPRESA É : } \\
\hline$\square$ & $\mathbf{8 0 1}$ & Matriz \\
\hline$\square$ & $\mathbf{8 0 2}$ & Filial \\
\hline
\end{tabular}

\begin{tabular}{|l|l|l|}
\hline \multicolumn{3}{|c|}{ TIPO DE FROTA UTILIZADA PELA } \\
EMPRESA: \\
\hline & $\mathbf{8 1 1}$ & Própria \\
\hline & $\mathbf{8 1 2}$ & de Terceiros \\
\hline
\end{tabular}


9. POR FAVOR, COLOCAR O NÚMERO DE FILIAIS POR ESTADO QUE USAM E QUE NÃo USAM RASTREADORES :

\begin{tabular}{|c|c|c|c|c|}
\hline ESTADO & $\begin{array}{l}\text { QUANTAS FI } \\
\text { RASTREAD }\end{array}$ & $\frac{\text { NÃO USAM }}{\text { TEM POR }}$ & $\begin{array}{r}\text { QUANT } \\
\text { RASTRE } \\
\end{array}$ & $\begin{array}{l}\text { JE USAM } \\
\text { TEM POR }\end{array}$ \\
\hline Acre & ] & 901 & {[} & 931 \\
\hline Alagoas & ] & 902 & {[} & 932 \\
\hline Amapá & ] & 903 & {[} & 933 \\
\hline Bahia & ] & 904 & {[} & 934 \\
\hline Ceará & ] & 905 & {[} & 935 \\
\hline Dist. Federal & ] & 906 & {[} & 936 \\
\hline Espírito Santo & ] & 907 & {[} & 937 \\
\hline Goiás & ] & 908 & [ & 938 \\
\hline Maranhão & ] & 909 & {[} & 939 \\
\hline Minas Gerais & ] & 910 & {[} & 940 \\
\hline Mato Grosso Sul & ] & 911 & {[} & 941 \\
\hline Mato Grosso & ] & 912 & {[} & 942 \\
\hline Pará & ] & 913 & {[} & 943 \\
\hline Paraíba & ] & 914 & {[} & 944 \\
\hline Pernambuco & ] & 915 & {[} & 945 \\
\hline Piauí & ] & 916 & {[} & 946 \\
\hline Paraná & {[} & 917 & {[} & 947 \\
\hline Rio de Janeiro & ] & 918 & {[} & 948 \\
\hline Rio Grande Norte & ] & 919 & [ & 949 \\
\hline Rondônia & ] & 920 & {[} & 950 \\
\hline Roraima & ] & 921 & {[} & 951 \\
\hline Rio Grande Sul & ] & 922 & {[} & 952 \\
\hline Santa Catarina & {[} & 923 & {[} & 953 \\
\hline Sergipe & ] & 924 & {[} & 954 \\
\hline São Paulo & [ & 925 & [ & 955 \\
\hline Amazonas & {[} & 926 & {[} & 956 \\
\hline Tocantins & [ & 927 & [ & 957 \\
\hline
\end{tabular}


10. ASSINALAR COM UM X OS OUTROS TIPOS DE SISTEMAS QUE ESTÃO INTERLIGADOS AOS SISTEMAS DE RASTREAMENTO UTILIZADOS :

\begin{tabular}{|l|l|l|}
\hline$\square$ & $\mathbf{1 0 0 1}$ & Internet \\
\hline$\square$ & $\mathbf{1 0 0 2}$ & Intranet \\
\hline$\square$ & $\mathbf{1 0 0 3}$ & Troca eletrônica de documentos (EDI) \\
\hline$\square$ & $\mathbf{1 0 0 4}$ & Código de barras \\
\hline & $\mathbf{1 0 0 5}$ & Just in time (JIT) \\
\hline & $\mathbf{1 0 0 6}$ & Recursos de automação \\
\hline & $\mathbf{1 0 0 7}$ & Sistemas de informações gerenciais \\
\hline & $\mathbf{1 0 0 8}$ & Outros sistemas: \\
\hline
\end{tabular}

11. aSSinalar COM UM $X$ QUAL É a FaiXa de Faturamento ANUAL da EMPReSa PREVISTA PARA O ANO DE 1997?

\begin{tabular}{|ll|l|}
\hline & $\mathbf{1 1 0 1}$ & Acima de US\$ 500 milhões \\
\hline & $\mathbf{1 1 0 2}$ & Entre US\$ 100-500 milhões \\
\hline & $\mathbf{1 1 0 3}$ & Entre US\$ 9-99 milhões \\
\hline$\square$ & $\mathbf{1 1 0 4}$ & Entre US\$ 1-9 milhões \\
\hline & $\mathbf{1 1 0 5}$ & Abaixo de US\$ 1 milhão \\
\hline & $\mathbf{1 1 0 6}$ & Não quer informar \\
\hline & $\mathbf{1 1 0 7}$ & Outro indicador: \\
\hline
\end{tabular}

12. POR FAVOR, QUAL É O VOLUME TOTAL TRANSPORTAdo EM MÉdia POR ANO ELA EMPRESA?

\begin{tabular}{|l|l|l|l|l|l|}
\hline & $\mathbf{1 2 0 1}$ & t/km/ano & & $\mathbf{1 2 0 5}$ & t/ano \\
\hline & $\mathbf{1 2 0 2}$ & Viagens/ano & & $\mathbf{1 2 0 6}$ & Coletas (entregas)/ano \\
\hline & $\mathbf{1 2 0 3}$ & Caixas/ano & & $\mathbf{1 2 0 7}$ & Não informado \\
\hline & $\mathbf{1 2 0 4}$ & Pelets/ano & & $\mathbf{1 2 0 8}$ & Outros: \\
\hline
\end{tabular}

\section{Por FAVOR, RESPONDA AS QUeSTões ABAIXo:}

\begin{tabular}{|l|l|l|}
\hline QUESTão & RESPOSTA & $\mathbf{1 3 0 1}$ \\
\hline Tempo de existência da empresa (anos)? & & $\mathbf{1 3 0 2}$ \\
\hline Idade do entrevistado (anos)? & & $\mathbf{1 3 0 3}$ \\
\hline Cargo que ocupa na empresa? & & $\mathbf{1 3 0 4}$ \\
\hline Quanto tempo atua nesse cargo (anos)? & & $\mathbf{1 3 0 5}$ \\
\hline Tempo de atuação na empresa (anos)? & & $\mathbf{1 3 0 6}$ \\
\hline Nível de instrução? & & \\
\hline
\end{tabular}

\section{SUGESTÕES, CRÍTICAS OU COMENTÁRIOS:}




\section{Apêndice 2}

\section{Histograma dos 25 Primeiros Autovalores da Questão 3}

Traço da diagonalização: 4,5556

Soma dos autovalores: $\quad 4,5556$

\begin{tabular}{|c|c|c|c|c|}
\hline $\mathbf{N}^{\mathbf{0}}$ & Autovalor & $\begin{array}{c}\text { Porcentagem } \\
(\%)\end{array}$ & $\begin{array}{c}\text { Porcentagem } \\
\text { acumulada }\end{array}$ & Representação da importância relativa da porcentagem dos autovalores \\
\hline 1 & 0,5212 & 11,44 & 11,44 & 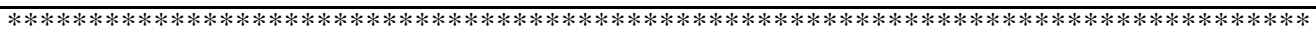 \\
\hline 2 & 0,4970 & 10,91 & 22,35 & 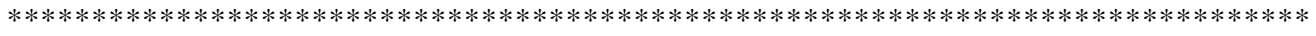 \\
\hline 3 & 0,4034 & 8,85 & 31,21 & $* * * * * * * * * * * * * * * * * * * * * * * * * * * * * * * * * * * * * * * * * * * * * * * * * * * * * * * * * * * * * *$ \\
\hline 4 & 0,3493 & 7,67 & 38,87 & $* * * * * * * * * * * * * * * * * * * * * * * * * * * * * * * * * * * * * * * * * * * * * * * * * * * * * *$ \\
\hline 5 & 0,3277 & 7,19 & 46,07 & $* * * * * * * * * * * * * * * * * * * * * * * * * * * * * * * * * * * * * * * * * * * * * * * * * * *$ \\
\hline 6 & 0,2904 & 6,38 & 52,44 & $* * * * * * * * * * * * * * * * * * * * * * * * * * * * * * * * * * * * * * * * * * * * *$ \\
\hline 7 & 0,2805 & 6,16 & 58,60 & $* * * * * * * * * * * * * * * * * * * * * * * * * * * * * * * * * * * * * * *$ \\
\hline 8 & 0,2534 & 5,56 & 64,16 & $* * * * * * * * * * * * * * * * * * * * * * * * * * * * * * * * * * * * * * *$ \\
\hline 9 & 0,2107 & 4,62 & 68,79 & $* * * * * * * * * * * * * * * * * * * * * * * * * * * * * * * * *$ \\
\hline 10 & 0,1999 & 4,39 & 73,17 & $* * * * * * * * * * * * * * * * * * * * * * * * * * * * * * *$ \\
\hline 11 & 0,1856 & 4,07 & 77,25 & $* * * * * * * * * * * * * * * * * * * * * * * * * * * * *$ \\
\hline 12 & 0,1760 & 3,86 & 81,11 & $* * * * * * * * * * * * * * * * * * * * * * * * * * * *$ \\
\hline 13 & 0,1441 & 3,16 & 84,28 & $* * * * * * * * * * * * * * * * * * * * * * *$ \\
\hline 14 & 0,1242 & 2,73 & 87,00 & $* * * * * * * * * * * * * * * * * * * *$ \\
\hline 15 & 0,1238 & 2,72 & 89,72 & $* * * * * * * * * * * * * * * * * * * *$ \\
\hline 16 & 0,0930 & 2,04 & 91,76 & $* * * * * * * * * * * * * * *$ \\
\hline 17 & 0,0782 & 1,72 & 93,48 & $* * * * * * * * * * * * *$ \\
\hline 18 & 0,0699 & 1,53 & 95,01 & $* * * * * * * * * * *$ \\
\hline 19 & 0,0657 & 1,44 & 96,45 & $* * * * * * * * * * *$ \\
\hline 20 & 0,0579 & 1,27 & 97,73 & $* * * * * * * * *$ \\
\hline 21 & 0,0382 & 0,84 & 98,56 & $* * * * * *$ \\
\hline 22 & 0,0266 & 0,58 & 99,15 & $* * * * *$ \\
\hline 23 & 0,0169 & 0,37 & 99,52 & $* * *$ \\
\hline 24 & 0,0148 & 0,33 & 99,84 & $* * *$ \\
\hline 25 & 0,0071 & 0,16 & 100,00 & $* *$ \\
\hline
\end{tabular}

Fonte: Dados da pesquisa 


\section{Apêndice 3}

Coordenadas e Contribuições Relativas para cada uma das Modalidades das

Variáveis Ativas e Suplementares da Questão 3

\begin{tabular}{|c|c|c|c|c|c|c|c|c|c|c|c|}
\hline \multirow[t]{2}{*}{$\begin{array}{l}\text { Modali- } \\
\text { dades }^{1}\end{array}$} & \multirow[t]{2}{*}{$\begin{array}{c}\text { Pesos } \\
\text { Relativos }\end{array}$} & \multirow[t]{2}{*}{$\begin{array}{l}\text { Distân- } \\
\text { cias }\end{array}$} & \multicolumn{3}{|c|}{ Coordenadas } & \multicolumn{3}{|c|}{$\begin{array}{c}\text { Contribuições relativas } \\
\text { dos pontos-perfis }\end{array}$} & \multicolumn{3}{|c|}{$\begin{array}{l}\text { Contribuições } \\
\text { relativas de um } \\
\text { fator }^{2}\end{array}$} \\
\hline & & & 1 & 2 & 3 & 1 & 2 & 3 & 1 & 2 & 3 \\
\hline $\mathrm{P} 1=0$ & 0,85 & 12,00 & $-1,60$ & $-0,98$ & $-0,29$ & 4,20 & 1,70 & 0,20 & 0,21 & 0,08 & 0,01 \\
\hline $\mathrm{P} 1=2$ & 3,42 & 2,25 & 0,90 & $-0,64$ & $-0,11$ & 5,30 & 2,80 & 0,10 & 0,36 & 0,18 & 0,01 \\
\hline$P 1=3$ & 2,14 & 4,20 & $-0,72$ & $-0,26$ & 0,12 & 2,10 & 0,30 & 0,10 & 0,12 & 0,02 & 0,00 \\
\hline $\mathrm{P} 1=4$ & 2,99 & 2,71 & 0,39 & 0,81 & $-0,37$ & 0,90 & 4,00 & 1,00 & 0,06 & 0,24 & 0,05 \\
\hline $\mathrm{P} 1=5$ & 1,71 & 5,50 & $-0,78$ & 0,68 & 0,87 & 2,00 & 1,60 & 3,20 & 0,11 & 0,08 & 0,14 \\
\hline$P 2=0$ & 0,43 & 25,00 & $-0,53$ & $-0,91$ & 1,05 & 0,20 & 0,70 & 1,20 & 0,01 & 0,03 & 0,04 \\
\hline$P 2=1$ & 0,43 & 25,00 & 0,60 & 2,49 & $-3,43$ & 0,30 & 5,30 & 12,50 & 0,01 & 0,25 & 0,47 \\
\hline$P 2=2$ & 3,85 & 1,89 & 0,81 & $-0,58$ & $-0,22$ & 4,80 & 2,60 & 0,50 & 0,35 & 0,18 & 0,03 \\
\hline$P 2=3$ & 1,71 & 5,50 & $-0,97$ & $-0,52$ & $-0,27$ & 3,10 & 0,90 & 0,30 & 0,17 & 0,05 & 0,01 \\
\hline$P 2=4$ & 2,99 & 2,71 & 0,35 & 0,72 & 0,96 & 0,70 & 3,10 & 6,80 & 0,05 & 0,19 & 0,34 \\
\hline$P 2=5$ & 1,71 & 5,50 & $-1,48$ & 0,17 & $-0,31$ & 7,20 & 0,10 & 0,40 & 0,40 & 0,01 & 0,02 \\
\hline$P 3=0$ & 0,43 & 25,00 & $-1,81$ & $-1,27$ & $-0,75$ & 2,70 & 1,40 & 0,60 & 0,13 & 0,06 & 0,02 \\
\hline $\mathrm{P} 3=1$ & 0,85 & 12,00 & 0,89 & 1,24 & $-2,04$ & 1,30 & 2,70 & 8,80 & 0,07 & 0,13 & 0,35 \\
\hline$P 3=2$ & 2,56 & 3,33 & 0,82 & $-0,96$ & $-0,17$ & 3,30 & 4,80 & 0,20 & 0,20 & 0,28 & 0,01 \\
\hline$P 3=3$ & 1,28 & 7,67 & $-0,74$ & 0,21 & $-0,74$ & 1,30 & 0,10 & 1,80 & 0,07 & 0,01 & 0,07 \\
\hline$P 3=4$ & 3,85 & 1,89 & 0,35 & 0,53 & 0,89 & 0,90 & 2,10 & 7,60 & 0,06 & 0,15 & 0,42 \\
\hline$P 3=5$ & 2,14 & 4,20 & $-1,16$ & $-0,16$ & 0,01 & 5,50 & 0,10 & 0,00 & 0,32 & 0,01 & 0,00 \\
\hline$P 4=1$ & 2,14 & 4,20 & $-1,22$ & 0,45 & $-0,15$ & 6,10 & 0,90 & 0,10 & 0,36 & 0,05 & 0,01 \\
\hline$P 4=2$ & 5,98 & 0,86 & 0,40 & $-0,54$ & 0,05 & 1,80 & 3,50 & 0,00 & 0,19 & 0,34 & 0,00 \\
\hline$P 4=3$ & 2,1 & 4,20 & 0,16 & 0,60 & $-0,54$ & 0,10 & 1,50 & 1,50 & 0,01 & 0,09 & 0,07 \\
\hline$P 4=4$ & 0,85 & 12,00 & $-0,16$ & 1,14 & 1,36 & 0,00 & 2,20 & 3,90 & 0,00 & 0,11 & 0,15 \\
\hline$P 5=0$ & 0,85 & 12,00 & $-0,49$ & $-1,39$ & $-0,75$ & 0,40 & 3,30 & 1,20 & 0,02 & 0,16 & 0,05 \\
\hline$P 5=1$ & 2,14 & 4,20 & $-0,28$ & 1,33 & $-0,46$ & 0,30 & 7,60 & 1,10 & 0,02 & 0,42 & 0,05 \\
\hline$P 5=2$ & 3,42 & 2,25 & 0,33 & $-0,24$ & 0,46 & 0,70 & 0,40 & 1,80 & 0,05 & 0,03 & 0,10 \\
\hline$P 5=3$ & 1,71 & 5,50 & $-0,68$ & $-0,61$ & $-0,27$ & 1,50 & 1,30 & 0,30 & 0,08 & 0,07 & 0,01 \\
\hline$P 5=4$ & 0,43 & 25,00 & 0,62 & 1,32 & 1,16 & 0,30 & 1,50 & 1,40 & 0,02 & 0,07 & 0,05 \\
\hline$P 5=5$ & 2,56 & 3,33 & 0,31 & $-0,13$ & 0,00 & 0,50 & 0,10 & 0,00 & 0,03 & 0,01 & 0,00 \\
\hline$P 6=0$ & 2,56 & 3,33 & $-1,04$ & $-0,73$ & 0,20 & 5,30 & 2,70 & 0,20 & 0,32 & 0,16 & 0,01 \\
\hline$P 6=1$ & 1,71 & 5,50 & $-0,37$ & $-0,47$ & $-0,79$ & 0,50 & 0,80 & 2,70 & 0,03 & 0,04 & 0,11 \\
\hline$P 6=2$ & 1,71 & 5,50 & 1,05 & $-0,25$ & 0,35 & 3,60 & 0,20 & 0,50 & 0,20 & 0,01 & 0,02 \\
\hline$P 6=3$ & 2,99 & 2,71 & 0,19 & 0,49 & $-0,43$ & 0,20 & 1,50 & 1,40 & 0,01 & 0,09 & 0,07 \\
\hline$P 6=4$ & 1,71 & 5,50 & 0,32 & 1,03 & 0,77 & 0,30 & 3,70 & 2,50 & 0,02 & 0,19 & 0,11 \\
\hline$P 6=5$ & 0,43 & 25,00 & 0,93 & $-0,34$ & 0,57 & 0,70 & 0,10 & 0,30 & 0,03 & 0,00 & 0,01 \\
\hline $\mathrm{P} 7=0$ & 0,43 & 25,00 & $-0,53$ & $-0,91$ & 1,05 & 0,20 & 0,70 & 1,20 & 0,01 & 0,03 & 0,04 \\
\hline $\mathrm{P} 7=1$ & 2,56 & 3,33 & $-0,64$ & 0,92 & 0,56 & 2,00 & 4,40 & 2,00 & 0,12 & 0,26 & 0,09 \\
\hline $\mathrm{P} 7=2$ & 6,41 & 0,73 & 0,46 & $-0,52$ & $-0,11$ & 2,60 & 3,60 & 0,20 & 0,29 & 0,38 & 0,02 \\
\hline $\mathrm{P} 7=3$ & 0,85 & 12,00 & $-1,46$ & $-0,41$ & $-0,37$ & 3,50 & 0,30 & 0,30 & 0,18 & 0,01 & 0,01 \\
\hline
\end{tabular}




\begin{tabular}{|c|c|c|c|c|c|c|c|c|c|c|c|}
\hline \multirow[t]{2}{*}{$\begin{array}{l}\text { Modali- } \\
\text { dades }^{1}\end{array}$} & \multirow[t]{2}{*}{$\begin{array}{c}\text { Pesos } \\
\text { Relativos }\end{array}$} & \multirow[t]{2}{*}{$\begin{array}{l}\text { Distân- } \\
\text { cias }\end{array}$} & \multicolumn{3}{|c|}{ Coordenadas } & \multicolumn{3}{|c|}{$\begin{array}{l}\text { Contribuições relativas } \\
\text { dos pontos-perfis }^{2}\end{array}$} & \multicolumn{3}{|c|}{$\begin{array}{l}\text { Contribuições } \\
\text { relativas de um } \\
\text { fator }^{2}\end{array}$} \\
\hline & & & 1 & 2 & 3 & 1 & 2 & 3 & 1 & 2 & 3 \\
\hline $\mathrm{P} 7=4$ & 0,43 & 25,00 & 0,60 & 2,49 & $-3,43$ & 0,30 & 5,30 & 12,50 & 0,01 & 0,25 & 0,47 \\
\hline $\mathrm{P} 7=5$ & 0,43 & 25,00 & $-0,29$ & 1,57 & 1,48 & 0,10 & 2,10 & 2,30 & 0,00 & 0,10 & 0,09 \\
\hline $\mathrm{P} 8=0$ & 0,43 & 25,00 & $-1,39$ & $-0,89$ & 0,15 & 1,60 & 0,70 & 0,00 & 0,08 & 0,03 & 0,00 \\
\hline$P 8=1$ & 1,71 & 5,50 & $-0,57$ & 1,18 & $-1,02$ & 1,10 & 4,80 & 4,40 & 0,06 & 0,25 & 0,19 \\
\hline $\mathrm{P} 8=2$ & 2,14 & 4,20 & 0,08 & $-0,75$ & $-0,47$ & 0,00 & 2,40 & 1,10 & 0,00 & 0,13 & 0,05 \\
\hline$P 8=3$ & 2,56 & 3,33 & 0,63 & $-0,34$ & 0,07 & 2,00 & 0,60 & 0,00 & 0,12 & 0,04 & 0,00 \\
\hline$P 8=4$ & 2,14 & 4,20 & 0,59 & 0,31 & 0,67 & 1,40 & 0,40 & 2,40 & 0,08 & 0,02 & 0,11 \\
\hline$P 8=5$ & 2,14 & 4,20 & $-0,69$ & 0,09 & 0,50 & 1,90 & 0,00 & 1,30 & 0,11 & 0,00 & 0,06 \\
\hline$P 9=0$ & 2,14 & 4,20 & $-1,37$ & $-0,67$ & $-0,08$ & 7,70 & 1,90 & 0,00 & 0,45 & 0,11 & 0,00 \\
\hline$P 9=2$ & 1,28 & 7,67 & 0,72 & $-1,32$ & $-0,68$ & 1,30 & 4,50 & 1,50 & 0,07 & 0,23 & 0,00 \\
\hline$P 9=3$ & 2,14 & 4,20 & 0,82 & 0,50 & $-0,74$ & 2,80 & 1,10 & 2,90 & 0,16 & 0,06 & 0,10 \\
\hline$P 9=4$ & 3,42 & 2,25 & $-0,38$ & 0,42 & 0,34 & 0,90 & 1,20 & 1,00 & 0,06 & 0,08 & 0,00 \\
\hline$P 9=5$ & 2,14 & 4,20 & 0,72 & 0,30 & 0,69 & 2,10 & 0,40 & 2,60 & 0,12 & 0,02 & 0,10 \\
\hline $\mathrm{S} 1=0$ & - & 1,00 & 0,05 & 0,49 & $-0,08$ & - & - & - & - & - & - \\
\hline $\mathrm{S} 1=1$ & - & 25,00 & 0,33 & $-1,35$ & $-0,70$ & - & - & - & - & - & - \\
\hline$S 1=2$ & - & 3,33 & $-0,31$ & $-0,39$ & 0,14 & - & - & - & - & - & - \\
\hline$S 1=3$ & - & 3,33 & 0,16 & $-0,44$ & 0,15 & - & - & - & - & - & - \\
\hline $\mathrm{S} 2=0$ & - & 25,00 & $-1,62$ & $-0,15$ & 0,05 & - & - & - & - & - & - \\
\hline $\mathrm{S} 2=1$ & - & 0,62 & $-0,13$ & 0,08 & $-0,19$ & - & - & - & - & - & - \\
\hline$S 2=2$ & - & 1,89 & 0,41 & $-0,12$ & 0,33 & - & - & - & - & - & - \\
\hline$S 3=1$ & - & 12,00 & $-0,51$ & 1,17 & $-1,69$ & - & - & - & - & - & - \\
\hline $\mathrm{S} 3=2$ & - & 1,89 & 0,05 & $-0,04$ & 0,36 & - & - & - & - & - & - \\
\hline$S 3=3$ & - & 1,89 & 0,13 & 0,44 & 0,00 & - & - & - & - & - & - \\
\hline$S 3=4$ & - & 25,00 & 0,83 & $-1,52$ & $-0,75$ & - & - & - & - & - & - \\
\hline $\mathrm{S} 3=6$ & - & 4,20 & $-0,29$ & $-0,88$ & 0,19 & - & - & - & - & - & - \\
\hline
\end{tabular}

Fonte: Dados da pesquisa

${ }^{1}$ Os códigos utilizados para a análise dos planos fatoriais da questão 3 foram os seguintes:

- Variáveis ativas: p1 - vendas; p2 - número de clientes; p3 - quantidade vendida; p4 - preço final do serviço vendido; p5 - custo do serviço vendido; p6 - lucro bruto; p7 - despesas com vendas; $\mathrm{p} 8$ - lucro operacional; $\mathrm{p} 9$ - taxa de retorno ao investimento;

- Impactos analisados: 0 - sem nota; 1 - negativo; 2 - nenhum; 3 - muito fraco; 4 - nem forte/nem fraco; 5 - muito forte);

- Variáveis suplementares: s1 - porcentagem de caminhões rastreados (0 - >70; 1 - 51-70; 2 - 20-50; 3 $<20 \%)$; s2 - tempo de uso do sistema (0 - 4-5; 1 - 1-3; 2 - menor que 1 ano); s3 - faturamento da empresa (0 - >500; 1 - 100-500; 2 - 9-99; 3 - 1-9; 4 - <1 milhão de dólares anual; 5 - outro indicador).

${ }^{2}$ Os valores em itálico correspondem às maiores contribuições. 


\section{Apêndice 4}

\section{Coordenadas e Contribuições Relativas para cada uma das empresas da Questão 3}

\begin{tabular}{|c|c|c|c|c|c|c|c|c|c|c|c|}
\hline \multirow[t]{2}{*}{ Empresas $^{1}$} & \multirow[t]{2}{*}{ Sistemas $^{2}$} & \multirow{2}{*}{$\begin{array}{l}\text { Distância } \\
\text { s }\end{array}$} & \multicolumn{3}{|c|}{ Coordenadas } & \multicolumn{3}{|c|}{$\begin{array}{c}\text { Contribuições } \\
\text { relativas dos } \\
\text { pontos-perfis }\end{array}$} & \multicolumn{3}{|c|}{$\begin{array}{c}\text { Contribuições relativas } \\
\text { de um fator }\end{array}$} \\
\hline & & & 1 & 2 & 3 & 1 & 2 & 3 & 1 & 2 & 3 \\
\hline 12 & $\mathrm{~A}$ & 2,60 & 0,56 & 0,33 & 0,12 & 2,3 & 0,9 & 0,1 & 0,12 & 0,04 & 0,01 \\
\hline 3 & B & 4,01 & $-0,99$ & 0,69 & 0,16 & 7,3 & 3,7 & 0,2 & 0,25 & 0,12 & 0,01 \\
\hline 8 & $\mathrm{C}$ & 4,71 & 0,67 & $-0,24$ & 0,36 & 3,3 & 0,4 & 1,3 & 0,10 & 0,01 & 0,03 \\
\hline 16 & $\mathrm{D}$ & 7,91 & $-1,31$ & $-0,90$ & $-0,47$ & 12,6 & 6,2 & 2,1 & 0,22 & 0,10 & 0,03 \\
\hline 18 & $\mathrm{E}$ & 3,16 & $-0,02$ & $-0,05$ & $-0,36$ & 0,0 & 0,0 & 1,2 & 0,00 & 0,00 & 0,04 \\
\hline 20 & $\mathrm{~F}$ & 6,09 & $-1,01$ & $-0,62$ & 0,10 & 7,5 & 3,0 & 0,1 & 0,17 & 0,06 & 0,00 \\
\hline 26 & $\mathrm{G}$ & 3,00 & 0,72 & $-0,78$ & $-0,38$ & 3,9 & 4,7 & 1,3 & 0,17 & 0,20 & 0,05 \\
\hline 5 & $\mathrm{H}$ & 6,16 & $-0,21$ & 1,11 & 0,94 & 0,3 & 9,5 & 8,4 & 0,01 & 0,20 & 0,14 \\
\hline 4 & I & 3,08 & 0,91 & $-0,42$ & 0,07 & 6,1 & 1,3 & 0,1 & 0,27 & 0,06 & 0,00 \\
\hline 6 & $\mathrm{~J}$ & 2,80 & 0,74 & $-0,53$ & 0,25 & 4,0 & 2,2 & 0,6 & 0,19 & 0,10 & 0,02 \\
\hline 21 & $\mathrm{~K}$ & 2,78 & 0,65 & 0,04 & 0,18 & 3,1 & 0,0 & 0,3 & 0,15 & 0,00 & 0,01 \\
\hline 1 & $\mathrm{~L}$ & 3,79 & 0,85 & 0,00 & $-0,41$ & 5,4 & 0,0 & 1,6 & 0,19 & 0,00 & 0,04 \\
\hline 7 & $\mathrm{M}$ & 2,78 & 0,73 & 0,21 & 0,38 & 3,9 & 0,3 & 1,4 & 0,19 & 0,02 & 0,05 \\
\hline 9 & $\mathrm{~N}$ & 3,28 & 0,31 & $-0,25$ & $-0,32$ & 0,7 & 0,5 & 1,0 & 0,03 & 0,02 & 0,03 \\
\hline 10 & $\mathrm{O}$ & 5,79 & $-1,09$ & $-0,10$ & $-0,58$ & 8,8 & 0,1 & 3,2 & 0,21 & 0,00 & 0,06 \\
\hline 13 & $\mathrm{P}$ & 7,78 & $-0,38$ & $-0,64$ & 0,66 & 1,1 & 3,2 & 4,2 & 0,02 & 0,05 & 0,06 \\
\hline 14 & $\mathrm{Q}$ & 4,52 & $-0,17$ & 0,87 & 0,70 & 0,2 & 5,9 & 4,6 & 0,01 & 0,17 & 0,11 \\
\hline 15 & $\mathrm{R}$ & 5,18 & $-1,01$ & $-0,48$ & 0,11 & 7,6 & 1,8 & 0,1 & 0,20 & 0,05 & 0,00 \\
\hline 17 & $S$ & 4,54 & $-0,81$ & 0,79 & $-0,52$ & 4,9 & 4,9 & 2,5 & 0,15 & 0,14 & 0,06 \\
\hline 19 & $\mathrm{~T}$ & 4,17 & 0,60 & $-1,07$ & $-0,48$ & 2,6 & 8,8 & 2,2 & 0,09 & 0,27 & 0,05 \\
\hline 22 & $\mathrm{U}$ & 9,50 & 0,43 & 1,75 & $-2,18$ & 1,4 & 23,8 & 45,4 & 0,02 & 0,32 & 0,50 \\
\hline 23 & V & 3,76 & 0,23 & $-0,95$ & $-0,45$ & 0,4 & 7,0 & 1,9 & 0,01 & 0,24 & 0,05 \\
\hline 24 & $X$ & 2,56 & 0,37 & $-0,33$ & 0,32 & 1,0 & 0,8 & 1,0 & 0,05 & 0,04 & 0,04 \\
\hline 25 & $\mathrm{Z}$ & 4,30 & $-1,17$ & $-0,10$ & 0,03 & 10,1 & 0,1 & 0,0 & 0,32 & 0,00 & 0,00 \\
\hline 2 & W & 5,88 & 0,45 & 0,93 & 0,73 & 1,5 & 6,7 & 5,1 & 0,03 & 0,15 & 0,09 \\
\hline 11 & Y & 4,31 & $-0,05$ & 0,73 & 1,03 & 0,0 & 4,1 & 10,0 & 0,00 & 0,12 & 0,24 \\
\hline
\end{tabular}

Fonte: Dados da pesquisa

${ }^{1} \mathrm{O}$ peso relativo a cada empresa (ou sistema) possui o valor de 3,85 .

2 Relação das transportadoras quanto ao uso dos sistemas de rastreamento: A (Combat); B a $\mathrm{G}$ (Controlsat); H (Controlsat+Combat); I (Logiq); J (Motorola); K (Multisat); L a Z (Omnisat); W (Teletracker); Y (Teletracker+Omnisat+Controlsat). 


\section{Apêndice 5}

Primeiro Plano Fatorial Relacionando as Variáveis da Questão 3

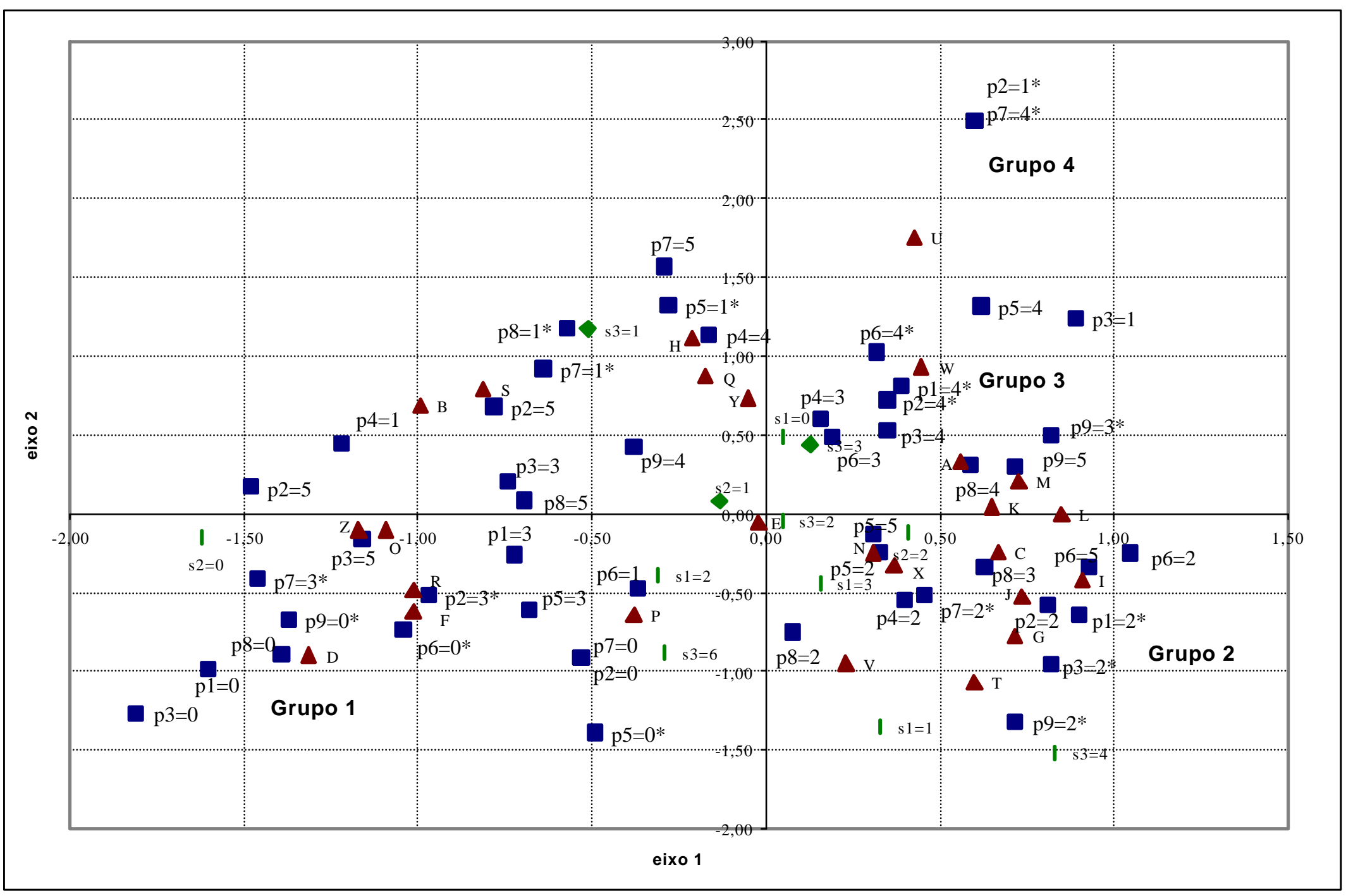


Apêndice 6

Segundo Plano Fatorial Relacionando as Variáveis da Questão 3

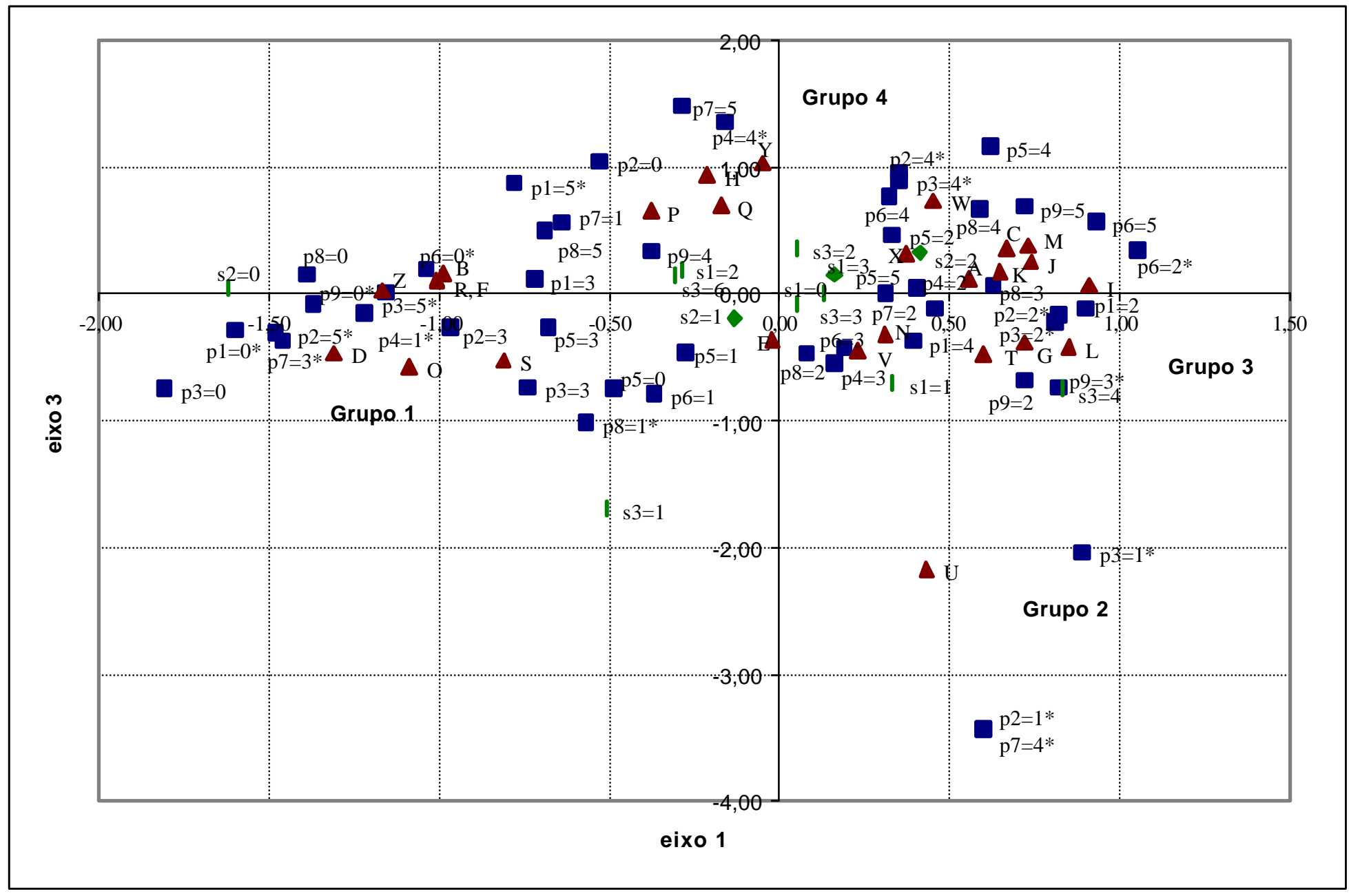




\section{Apêndice 7}

Terceiro Plano Fatorial Relacionando as Variáveis da Questão 3

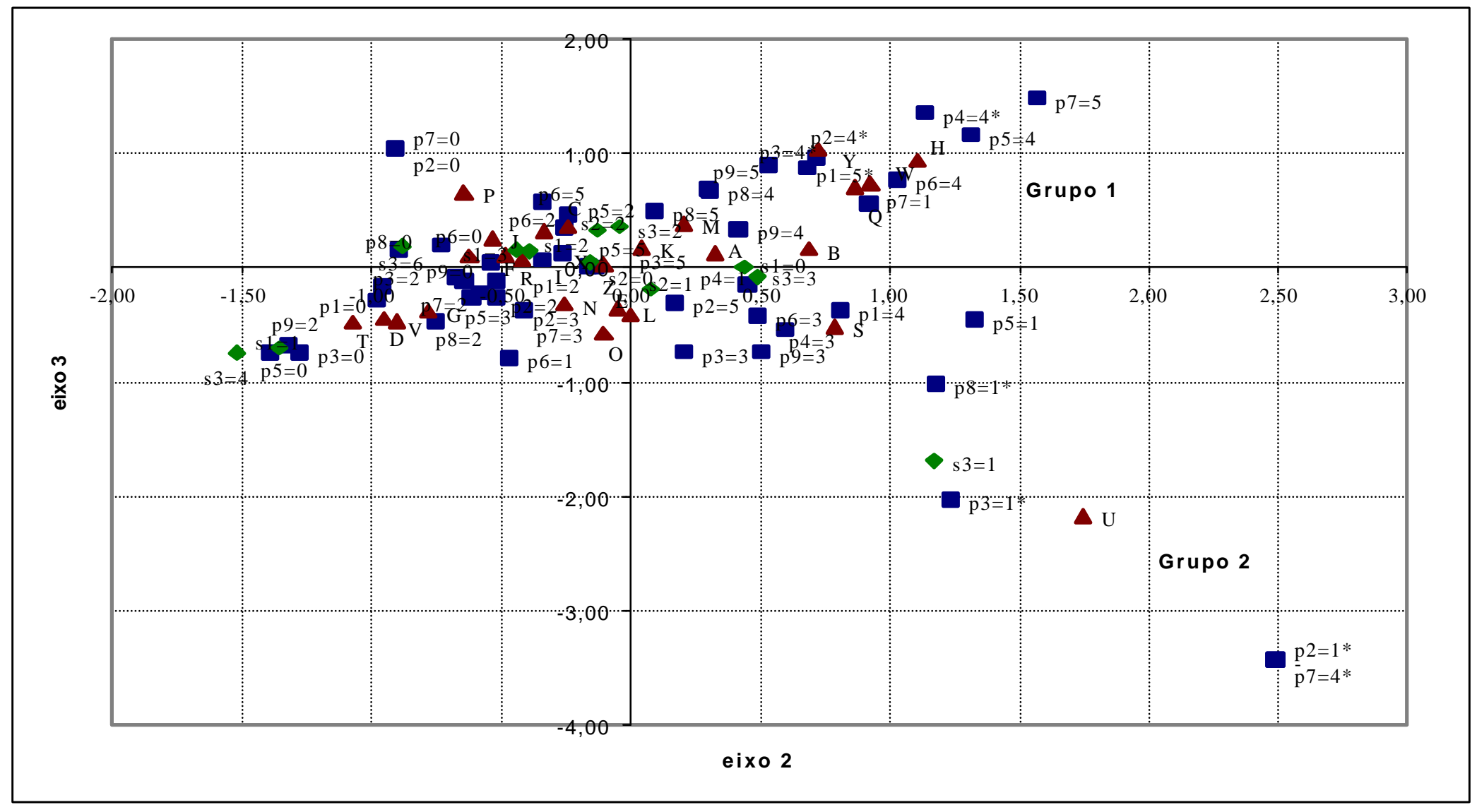


Apêndice 8

Histograma dos 25 Primeiros Autovalores da Questão 5

Traço da diagonalização: 2,0625 Soma dos autovalores: 2,0625

\begin{tabular}{|c|c|c|c|c|}
\hline $\mathbf{N}^{\mathbf{0}}$ & Autovalor & $\begin{array}{c}\text { Porcentagem } \\
(\%)\end{array}$ & $\begin{array}{c}\text { Porcentagem } \\
\text { acumulada }\end{array}$ & Representação da importância relativa da porcentagem dos autovalores \\
\hline 1 & 0,4837 & 23,45 & 23,45 & 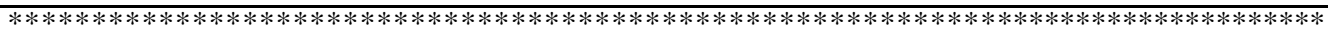 \\
\hline 2 & 0,2812 & 13,64 & 37,09 & $* * * * * * * * * * * * * * * * * * * * * * * * * * * * * * * * * * * * * * * * * * * * * * *$ \\
\hline 3 & 0,2316 & 11,23 & 48,31 & $* * * * * * * * * * * * * * * * * * * * * * * * * * * * * * * * * * * * * * *$ \\
\hline 4 & 0,1952 & 9,46 & 57,78 & $* * * * * * * * * * * * * * * * * * * * * * * * * * * * * * * * *$ \\
\hline 5 & 0,1613 & 7,82 & 65,60 & $* * * * * * * * * * * * * * * * * * * * * * * * * * *$ \\
\hline 6 & 0,1260 & 6,11 & 71,71 & $* * * * * * * * * * * * * * * * * * * * *$ \\
\hline 7 & 0,1102 & 5,34 & 77,05 & $* * * * * * * * * * * * * * * * * * *$ \\
\hline 8 & 0,0846 & 4,10 & 81,15 & $* * * * * * * * * * * * * *$ \\
\hline 9 & 0,0684 & 3,32 & 84,47 & $* * * * * * * * * * * *$ \\
\hline 10 & 0,0544 & 2,64 & 87,11 & $* * * * * * * * * *$ \\
\hline 11 & 0,0490 & 2,37 & 89,48 & $* * * * * * * * *$ \\
\hline 12 & 0,0480 & 2,32 & 91,81 & $* * * * * * * *$ \\
\hline 13 & 0,0368 & 1,79 & 93,59 & $* * * * * * *$ \\
\hline 14 & 0,0307 & 1,49 & 95,08 & $* * * * * *$ \\
\hline 15 & 0,0218 & 1,05 & 96,13 & $* * * *$ \\
\hline 16 & 0,0202 & 0,98 & 97,11 & $* * * *$ \\
\hline 17 & 0,0192 & 0,93 & 98,05 & $* * * *$ \\
\hline 18 & 0,0171 & 0,83 & 98,88 & $* * *$ \\
\hline 19 & 0,0096 & 0,46 & 99,34 & $* *$ \\
\hline 20 & 0,0073 & 0,35 & 99,69 & $* *$ \\
\hline 21 & 0,0047 & 0,23 & 99,92 & $*$ \\
\hline 22 & 0,0017 & 0,08 & 100,00 & $*$ \\
\hline 23 & 0,0000 & 0,00 & 100,00 & $*$ \\
\hline 24 & 0,0000 & 0,00 & 100,00 & $*$ \\
\hline 25 & 0,0000 & 0,00 & 100,00 & $*$ \\
\hline
\end{tabular}

Fonte: Dados da pesquisa 


\section{Apêndice 9}

\section{Coordenadas e Contribuições Relativas para cada uma das Modalidades das}

\section{Variáveis Ativas e Suplementares da Questão 5}

\begin{tabular}{|c|c|c|c|c|c|c|c|c|c|c|c|}
\hline \multirow[t]{2}{*}{$\begin{array}{l}\text { Modali- } \\
\text { dades }^{1}\end{array}$} & \multirow[t]{2}{*}{$\begin{array}{c}\text { Pesos } \\
\text { Relativos }\end{array}$} & \multirow[t]{2}{*}{ Distâncias } & \multicolumn{3}{|c|}{ Coordenadas } & \multicolumn{3}{|c|}{$\begin{array}{l}\text { Contribuições } \\
\text { relativas dos } \\
\text { pontos-perfis }\end{array}$} & \multicolumn{3}{|c|}{$\begin{array}{c}\text { Contribuições } \\
\text { relativas de um } \\
\text { fator }^{2}\end{array}$} \\
\hline & & & 1 & 2 & 3 & 1 & 2 & 3 & 1 & 2 & 3 \\
\hline $\mathrm{R} 1=1$ & 4,57 & 0,37 & 0,00 & 0,29 & $-0,23$ & 0,00 & 1,30 & 1,00 & 0,00 & 0,22 & 0,14 \\
\hline $\mathrm{R} 1=2$ & 0,72 & 7,67 & 0,17 & $-2,20$ & $-0,46$ & 0,00 & 12,40 & 0,70 & 0,00 & 0,63 & 0,03 \\
\hline $\mathrm{R} 1=3$ & 0,48 & 12,00 & $-0,36$ & 0,48 & 1,15 & 0,10 & 0,40 & 2,80 & 0,01 & 0,02 & 0,11 \\
\hline $\mathrm{R} 1=4$ & 0,48 & 12,00 & 0,08 & 0,09 & 1,68 & 0,00 & 0,00 & 5,80 & 0,00 & 0,00 & 0,23 \\
\hline $\mathrm{R} 2=1$ & 4,09 & 0,53 & $-0,02$ & 0,39 & $-0,43$ & 0,00 & 2,30 & 3,20 & 0,00 & 0,29 & 0,35 \\
\hline $\mathrm{R} 2=2$ & 0,72 & 7,67 & 0,17 & $-2,20$ & $-0,46$ & 0,00 & 12,40 & 0,70 & 0,00 & 0,63 & 0,03 \\
\hline $\mathrm{R} 2=3$ & 0,48 & 12,00 & 0,10 & $-0,13$ & 2,01 & 0,00 & 0,00 & 8,40 & 0,00 & 0,00 & 0,34 \\
\hline $\mathrm{R} 2=4$ & 0,96 & 5,50 & $-0,10$ & 0,04 & 1,16 & 0,00 & 0,00 & 5,60 & 0,00 & 0,00 & 0,24 \\
\hline $\mathrm{R} 3=1$ & 2,64 & 1,36 & $-0,34$ & 0,47 & $-0,61$ & 0,60 & 2,00 & 4,20 & 0,08 & 0,16 & 0,27 \\
\hline $\mathrm{R} 3=2$ & 0,72 & 7,67 & 0,05 & $-1,45$ & $-0,32$ & 0,00 & 5,40 & 0,30 & 0,00 & 0,27 & 0,01 \\
\hline $\mathrm{R} 3=3$ & 0,96 & 5,50 & $-0,16$ & 0,27 & 1,37 & 0,10 & 0,30 & 7,80 & 0,00 & 0,01 & 0,34 \\
\hline $\mathrm{R} 3=4$ & 1,92 & 2,25 & 0,53 & $-0,23$ & 0,27 & 1,10 & 0,40 & 0,60 & 0,12 & 0,02 & 0,03 \\
\hline $\mathrm{R} 4=1$ & 0,72 & 7,67 & 0,06 & $-1,51$ & $-0,76$ & 0,00 & 5,90 & 1,80 & 0,00 & 0,30 & 0,08 \\
\hline $\mathrm{R} 4=2$ & 3,61 & 0,73 & $-0,36$ & 0,19 & $-0,41$ & 1,00 & 0,50 & 2,60 & 0,18 & 0,05 & 0,23 \\
\hline $\mathrm{R} 4=4$ & 1,92 & 2,25 & 0,66 & 0,21 & 1,06 & 1,70 & 0,30 & 9,30 & 0,19 & 0,02 & 0,50 \\
\hline R5=1 & 3,85 & 0,62 & $-0,34$ & 0,39 & $-0,31$ & 0,90 & 2,10 & 1,60 & 0,19 & 0,25 & 0,15 \\
\hline R5=2 & 1,44 & 3,33 & 0,63 & $-0,29$ & 0,14 & 1,20 & 0,40 & 0,10 & 0,12 & 0,03 & 0,01 \\
\hline $\mathrm{R} 5=4$ & 0,96 & 5,50 & 0,42 & $-1,13$ & 1,01 & 0,30 & 4,40 & 4,20 & 0,03 & 0,23 & 0,19 \\
\hline R6=2 & 4,33 & 0,44 & $-0,37$ & 0,12 & $-0,24$ & 1,30 & 0,20 & 1,10 & 0,32 & 0,03 & 0,13 \\
\hline R6=3 & 0,24 & 25,00 & 0,80 & $-4,00$ & $-0,95$ & 0,30 & 13,70 & 0,90 & 0,03 & 0,64 & 0,04 \\
\hline $\mathrm{R} 6=4$ & 1,68 & 2,71 & 0,85 & 0,27 & 0,76 & 2,50 & 0,40 & 4,10 & 0,27 & 0,03 & 0,21 \\
\hline $\mathrm{R} 7=1$ & 4,57 & 0,37 & $-0,25$ & $-0,06$ & $-0,15$ & 0,60 & 0,10 & 0,50 & 0,17 & 0,01 & 0,06 \\
\hline $\mathrm{R} 7=2$ & 1,20 & 4,20 & 0,06 & 0,30 & 0,79 & 0,00 & 0,40 & 3,30 & 0,00 & 0,02 & 0,15 \\
\hline $\mathrm{R} 7=3$ & 0,24 & 25,00 & $-0,15$ & $-1,45$ & $-0,22$ & 0,00 & 1,80 & 0,10 & 0,00 & 0,08 & 0,00 \\
\hline $\mathrm{R} 7=4$ & 0,24 & 25,00 & 4,67 & 1,12 & $-0,84$ & 10,80 & 1,10 & 0,70 & 0,87 & 0,05 & 0,03 \\
\hline $\mathrm{R} 8=1$ & 1,92 & 2,25 & $-0,52$ & 0,59 & $-0,77$ & 1,10 & 2,40 & 4,90 & 0,12 & 0,15 & 0,26 \\
\hline $\mathrm{R} 8=2$ & 3,85 & 0,62 & $-0,05$ & $-0,37$ & 0,29 & 0,00 & 1,90 & 1,40 & 0,00 & 0,22 & 0,13 \\
\hline $\mathrm{R} 8=3$ & 0,48 & 12,00 & 2,50 & 0,63 & 0,78 & 6,20 & 0,70 & 1,30 & 0,52 & 0,03 & 0,05 \\
\hline R9=1 & 6,01 & 0,04 & $-0,19$ & $-0,04$ & 0,03 & 0,40 & 0,00 & 0,00 & 0,87 & 0,05 & 0,03 \\
\hline R9=2 & 0,24 & 25,00 & 4,67 & 1,12 & $-0,84$ & 10,80 & 1,10 & 0,70 & 0,87 & 0,05 & 0,03 \\
\hline $\mathrm{R} 10=1$ & 5,53 & 0,13 & $-0,21$ & 0,07 & 0,14 & 0,50 & 0,10 & 0,50 & 0,34 & 0,04 & 0,15 \\
\hline $\mathrm{R} 10=2$ & 0,48 & 12,00 & 2,73 & $-1,44$ & $-0,90$ & 7,40 & 3,50 & 1,70 & 0,62 & 0,17 & 0,07 \\
\hline $\mathrm{R} 10=4$ & 0,24 & 25,00 & $-0,64$ & 1,21 & $-1,41$ & 0,20 & 1,20 & 2,10 & 0,02 & 0,06 & 0,08 \\
\hline $\mathrm{R} 11=1$ & 0,48 & 12,00 & $-0,60$ & 0,98 & $-1,29$ & 0,40 & 1,60 & 3,40 & 0,03 & 0,08 & 0,14 \\
\hline R11=2 & 0,24 & 25,00 & 4,67 & 1,12 & $-0,84$ & 10,80 & 1,10 & 0,70 & 0,87 & 0,05 & 0,03 \\
\hline R11=4 & 5,53 & 0,13 & $-0,15$ & $-0,13$ & 0,15 & 0,30 & 0,40 & 0,50 & 0,17 & 0,14 & 0,17 \\
\hline $\mathrm{R} 12=1$ & 6,01 & 0,04 & $-0,19$ & $-0,04$ & 0,03 & 0,40 & 0,00 & 0,00 & 0,87 & 0,05 & 0,03 \\
\hline
\end{tabular}




\begin{tabular}{|c|c|c|c|c|c|c|c|c|c|c|c|}
\hline \multirow[t]{2}{*}{$\begin{array}{l}\text { Modali- } \\
\text { dades }{ }^{1}\end{array}$} & \multirow[t]{2}{*}{$\begin{array}{c}\text { Pesos } \\
\text { Relativos }\end{array}$} & \multirow[t]{2}{*}{ Distâncias } & \multicolumn{3}{|c|}{ Coordenadas } & \multicolumn{3}{|c|}{$\begin{array}{c}\text { Contribuições } \\
\text { relativas dos } \\
\text { pontos-perfis }{ }^{2}\end{array}$} & \multicolumn{3}{|c|}{$\begin{array}{l}\text { Contribuições } \\
\text { relativas de um } \\
\text { fator }^{2}\end{array}$} \\
\hline & & & 1 & 2 & 3 & 1 & 2 & 3 & 1 & 2 & 3 \\
\hline $\mathrm{R} 12=4$ & 0,24 & 25,00 & 4,67 & 1,12 & $\begin{array}{l}-0,84 \\
\end{array}$ & 10,80 & 1,10 & 0,70 & 0,87 & 0,05 & 0,03 \\
\hline $\mathrm{R} 13=1$ & 5,05 & 0,24 & $-0,23$ & $-0,14$ & $-0,11$ & 0,50 & 0,30 & 0,30 & 0,22 & 0,08 & 0,05 \\
\hline $\mathrm{R} 13=2$ & 0,48 & 12,00 & $-0,43$ & 0,77 & 0,52 & 0,20 & 1,00 & 0,60 & 0,02 & 0,05 & 0,02 \\
\hline $\mathrm{R} 13=4$ & 0,72 & 7,67 & 1,87 & 0,44 & 0,44 & 5,20 & 0,50 & 0,60 & 0,46 & 0,03 & 0,02 \\
\hline $\mathrm{R} 14=1$ & 5,05 & 0,24 & $-0,27$ & 0,17 & 0,05 & 0,80 & 0,50 & 0,10 & 0,32 & 0,13 & 0,01 \\
\hline $\mathrm{R} 14=2$ & 0,48 & 12,00 & 2,36 & 0,79 & $-0,62$ & 5,60 & 1,10 & 0,80 & 0,47 & 0,05 & 0,03 \\
\hline $\mathrm{R} 14=4$ & 0,72 & 7,67 & 0,35 & $-1,75$ & 0,05 & 0,20 & 7,80 & 0,00 & 0,02 & 0,40 & 0,00 \\
\hline $\mathrm{R} 15=1$ & 5,53 & 0,13 & $-0,22$ & $-0,10$ & $-0,09$ & 0,50 & 0,20 & 0,20 & 0,36 & 0,07 & 0,07 \\
\hline $\mathrm{R} 15=2$ & 0,24 & 25,00 & $-0,22$ & 0,32 & 2,45 & 0,00 & 0,10 & 6,20 & 0,00 & 0,00 & 0,24 \\
\hline $\mathrm{R} 15=4$ & 0,48 & 12,00 & 2,60 & 0,95 & $-0,13$ & 6,70 & 1,50 & 0,00 & 0,56 & 0,07 & 0,00 \\
\hline $\mathrm{R} 16=1$ & 5,77 & 0,08 & $-0,23$ & 0,12 & 0,07 & 0,60 & 0,30 & 0,10 & 0,62 & 0,17 & 0,07 \\
\hline R16=4 & 0,48 & 12,00 & 2,73 & $-1,44$ & $-0,90$ & 7,40 & 3,50 & 1,70 & 0,62 & 0,17 & 0,07 \\
\hline $\mathrm{S} 1=0$ & - & 1,00 & 0,32 & $-0,45$ & 0,19 & - & - & - & - & - & - \\
\hline $\mathrm{S} 1=1$ & - & 25,00 & $-0,50$ & 0,51 & $-0,78$ & - & - & - & - & - & - \\
\hline $\mathrm{S} 1=2$ & - & 3,33 & $-0,23$ & 0,61 & $-0,31$ & - & - & - & - & - & - \\
\hline $\mathrm{S} 1=3$ & - & 3,33 & $-0,38$ & 0,27 & 0,03 & - & - & - & - & - & - \\
\hline $\mathrm{S} 2=0$ & - & 25,00 & $-0,27$ & $-0,21$ & 0,41 & - & - & - & - & - & - \\
\hline $\mathrm{S} 2=1$ & - & 0,62 & 0,05 & 0,24 & $-0,11$ & - & - & - & - & - & - \\
\hline $\mathrm{S} 2=2$ & - & 1,89 & $-0,06$ & $-0,40$ & 0,14 & - & - & - & - & - & - \\
\hline $\mathrm{S} 3=1$ & - & 12,00 & 2,20 & 0,46 & $-0,21$ & - & - & - & - & - & - \\
\hline $\mathrm{S} 3=2$ & - & 1,89 & $-0,07$ & 0,27 & 0,47 & - & - & - & - & - & - \\
\hline $\mathrm{S} 3=3$ & - & 1,89 & $-0,16$ & $-0,51$ & $-0,20$ & - & - & - & - & - & - \\
\hline $\mathrm{S} 3=4$ & - & 25,00 & $-0,44$ & 0,29 & $-0,49$ & - & - & - & - & - & - \\
\hline $\mathrm{S} 3=6$ & - & 4,20 & $-0,37$ & 0,19 & $-0,31$ & - & - & - & - & - & - \\
\hline
\end{tabular}

Fonte: Dados da pesquisa

${ }^{1}$ Os códigos utilizados para a análise dos planos fatoriais da questão 5 foram os seguintes:

- Variáveis ativas: r1 - reestruturar a administração da empresa; $r 2$ - reestruturar todos os setores da empresa; $\mathrm{r} 3$ - alocar mais capital para melhorar o uso dos sistemas; r4 - treinar funcionários da empresa para trabalhar como operadores/digitadores; r5 - contratar novos funcionários para trabalhar como operadores/digitadores; $r 6$ - treinar motoristas; $r 7$-contratar novos motoristas; $r 8$ - comprar novos computadores pessoais; r9 -substituir equipamentos de informática; r10 - contratar pessoal para manutenção dos equipamentos usados para rastreamento; r11 - terceirizar serviços para manutenção dos equipamentos usados para rastreamento; r12 - contratar analistas de sistemas/programadores; r13 utilizar analistas de sistemas/programadores já existentes na empresa; r14 - terceirizar serviços de analistas/programadores; r15 - desenvolver software específico para rastreamento dentro da empresa; r16 - desenvolver software específico através de terceirização de serviços;

- Ações tomadas pelas empresas em relação aos sistemas de rastreamento: 0 - nenhuma; 1 - pouca; 2 regular; 3 - grande;

- Variáveis suplementares: s1 - porcentagem de caminhões rastreados (0 - >70; 1 - 51-70; 2 - 20-50; 3 $<20 \%)$; s2 - tempo de uso do sistema $(0-4-5 ; 1$ - 1-3; 2 - menor que 1 ano); s3 - faturamento da empresa (0 - >500; 1 - 100-500; 2 - 9-99; 3 - 1-9; 4 - <1 milhão de dólares anual; 5 - outro indic ador).

${ }^{2}$ Os valores em itálico correspondem às maiores contribuições. 


\section{Apêndice 10}

\section{Coordenadas e Contribuições Relativas para cada uma das empresas da Questão 5}

\begin{tabular}{|c|c|c|c|c|c|c|c|c|c|c|c|}
\hline \multirow{2}{*}{$\begin{array}{l}\text { Empre- } \\
\text { sas }^{1}\end{array}$} & \multirow[t]{2}{*}{ Sistemas } & \multirow{2}{*}{$\begin{array}{l}\text { Distân } \\
\text {-cias }\end{array}$} & \multicolumn{3}{|c|}{ Coordenadas } & \multicolumn{3}{|c|}{$\begin{array}{l}\text { Contribuições relativas } \\
\text { dos pontos-perfis }\end{array}$} & \multicolumn{3}{|c|}{$\begin{array}{c}\text { Contribuições relativas } \\
\text { de um fator }\end{array}$} \\
\hline & & & 1 & 2 & 3 & 1 & 2 & 3 & 1 & 2 & 3 \\
\hline 12 & A & 1,51 & $-0,11$ & $-0,60$ & $-0,10$ & 0,10 & 5,00 & 0,20 & 0,01 & 0,24 & 0,01 \\
\hline 3 & B & 1,45 & $-0,35$ & 0,33 & $-0,07$ & 1,00 & 1,50 & 0,10 & 0,09 & 0,08 & 0,00 \\
\hline 8 & $\mathrm{C}$ & 1,26 & 0,04 & 0,25 & $-0,19$ & 0,00 & 0,80 & 0,60 & 0,00 & 0,05 & 0,03 \\
\hline 16 & D & 0,74 & $-0,33$ & 0,25 & $-0,12$ & 0,90 & 0,80 & 0,20 & 0,15 & 0,08 & 0,02 \\
\hline 18 & E & 0,48 & $-0,35$ & 0,27 & $-0,37$ & 1,00 & 1,00 & 2,30 & 0,25 & 0,15 & 0,29 \\
\hline 20 & $\mathrm{~F}$ & 0,77 & $-0,27$ & $-0,07$ & $-0,20$ & 0,60 & 0,10 & 0,60 & 0,10 & 0,01 & 0,05 \\
\hline 26 & G & 1,22 & $-0,39$ & 0,40 & $-0,56$ & 1,20 & 2,20 & 5,20 & 0,12 & 0,13 & 0,26 \\
\hline 5 & $\mathrm{H}$ & 3,05 & $-0,10$ & $-0,77$ & $-0,11$ & 0,10 & 8,10 & 0,20 & 0,00 & 0,19 & 0,00 \\
\hline 4 & I & 3,51 & $-0,45$ & 0,64 & $-0,68$ & 1,60 & 5,60 & 7,60 & 0,06 & 0,12 & 0,13 \\
\hline 6 & $\mathrm{~J}$ & 1,45 & $-0,13$ & $-0,35$ & $-0,22$ & 0,10 & 1,70 & 0,80 & 0,01 & 0,09 & 0,03 \\
\hline 21 & K & 0,92 & $-0,31$ & 0,07 & $-0,42$ & 0,80 & 0,10 & 2,90 & 0,11 & 0,01 & 0,19 \\
\hline 1 & $\mathrm{~L}$ & 2,62 & 0,30 & $-0,31$ & 0,76 & 0,70 & 1,30 & 9,60 & 0,03 & 0,04 & 0,22 \\
\hline 7 & M & 4,64 & $-0,15$ & 0,17 & 1,18 & 0,20 & 0,40 & 23,10 & 0,01 & 0,01 & 0,30 \\
\hline 9 & $\mathrm{~N}$ & 1,04 & $-0,21$ & 0,09 & 0,42 & 0,30 & 0,10 & 2,90 & 0,04 & 0,01 & 0,17 \\
\hline 10 & $\mathrm{O}$ & 1,22 & 0,07 & $-0,04$ & 0,49 & 0,00 & 0,00 & 4,00 & 0,00 & 0,00 & 0,20 \\
\hline 13 & $\mathrm{P}$ & 1,62 & $-0,12$ & 0,03 & 0,46 & 0,10 & 0,00 & 3,50 & 0,01 & 0,00 & 0,13 \\
\hline 14 & Q & 0,84 & $-0,11$ & 0,04 & 0,06 & 0,10 & 0,00 & 0,10 & 0,02 & 0,00 & 0,00 \\
\hline 15 & $\mathrm{R}$ & 0,44 & $-0,23$ & 0,07 & $-0,12$ & 0,40 & 0,10 & 0,20 & 0,12 & 0,01 & 0,03 \\
\hline 17 & S & 0,48 & $-0,35$ & 0,27 & $-0,37$ & 1,00 & 1,00 & 2,30 & 0,25 & 0,15 & 0,29 \\
\hline 19 & $\mathrm{~T}$ & 0,38 & $-0,31$ & 0,16 & $-0,24$ & 0,70 & 0,30 & 0,90 & 0,25 & 0,06 & 0,15 \\
\hline 22 & $\mathrm{U}$ & 11,19 & 3,25 & 0,60 & $-0,40$ & 83,90 & 4,80 & 2,70 & 0,94 & 0,03 & 0,01 \\
\hline 23 & V & 0,48 & $-0,35$ & 0,27 & $-0,37$ & 1,00 & 1,00 & 2,30 & 0,25 & 0,15 & 0,29 \\
\hline 2 & W & 5,90 & 0,56 & $-2,12$ & $-0,46$ & 2,50 & 61,50 & 3,50 & 0,05 & 0,76 & 0,04 \\
\hline 24 & $X$ & 2,06 & 0,36 & 0,41 & 0,27 & 1,10 & 2,30 & 1,20 & 0,06 & 0,08 & 0,04 \\
\hline 11 & Y & 3,17 & 0,24 & 0,07 & 1,15 & 0,40 & 0,10 & 22,10 & 0,02 & 0,00 & 0,42 \\
\hline 25 & Z & 1,18 & $-0,19$ & $-0,11$ & 0,20 & 0,30 & 0,20 & 0,70 & 0,03 & 0,01 & 0,03 \\
\hline
\end{tabular}

Fonte: Dados da pesquisa

${ }^{1} \mathrm{O}$ peso relativo a cada empresa (ou sistema) possui o valor de 3,85 .

2 Relação das transportadoras quanto ao uso dos sistemas de rastreamento: A (Combat); B a G (Controlsat); H (Controlsat+Combat); I (Logiq); J (Motorola); K (Multisat); L a Z (Omnisat); W (Teletracker); Y (Teletracker+Omnisat+Controlsat). 


\section{Apêndice 11}

Primeiro Plano Fatorial Relacionando as Variáveis da Questão 5

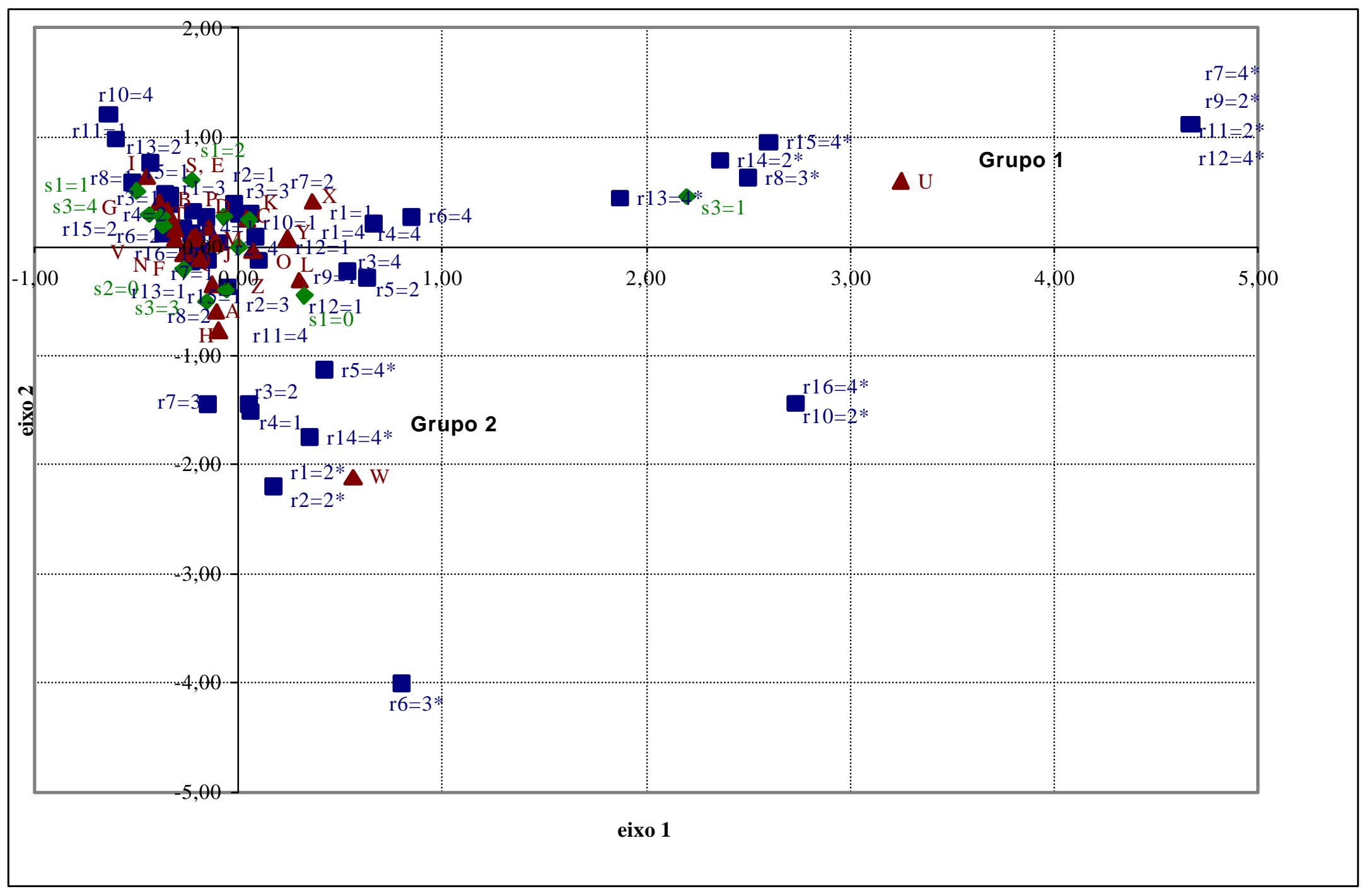


Apêndice 12

Segundo Plano Fatorial Relacionando as Variáveis da Questão 5

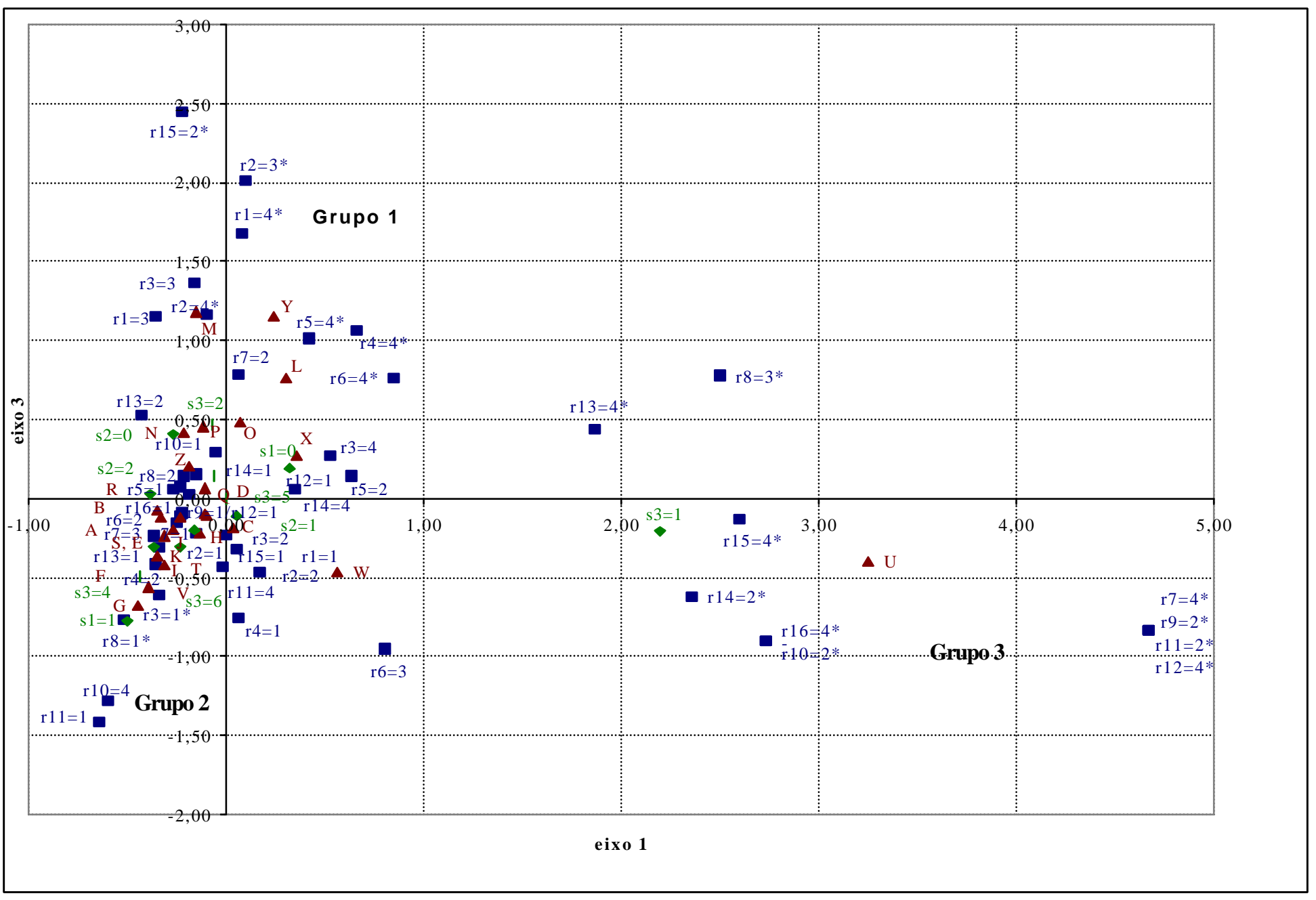


Apêndice 13

Terceiro Plano Fatorial Relacionando as Variáveis da Questão 5

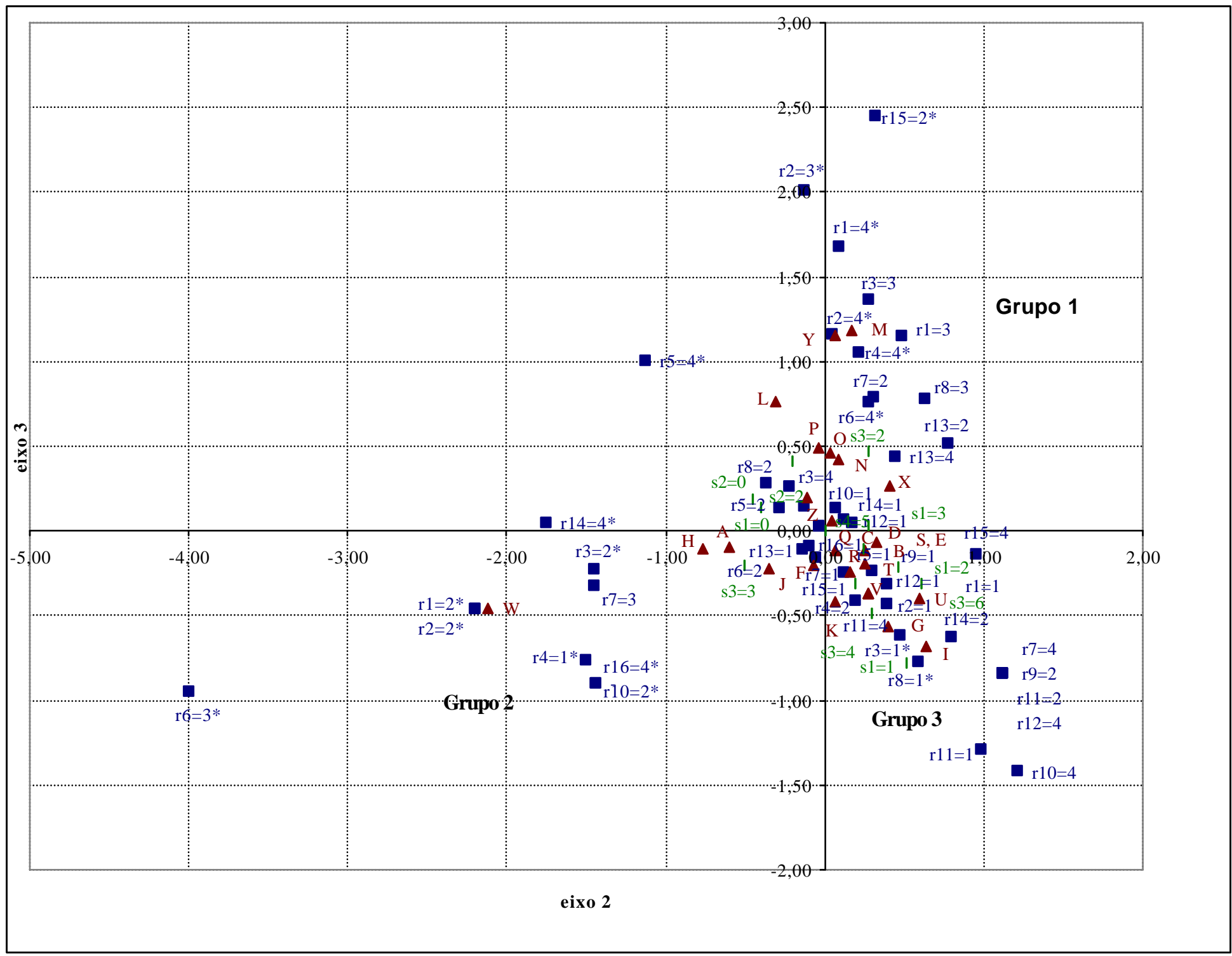


Apêndice 14

Histograma dos 25 Primeiros Autovalores da Questão 6

Traço da diagonalização: 2,9444

\begin{tabular}{|c|c|c|c|c|}
\hline $\mathbf{N}^{\mathbf{0}}$ & Autovalor & $\begin{array}{c}\text { Porcentagem } \\
(\%)\end{array}$ & $\begin{array}{l}\text { Porcentagem } \\
\text { acumulada }\end{array}$ & Representação da importância relativa da porcentagem de autovalores \\
\hline 1 & 0,3423 & 11,62 & 11,62 & 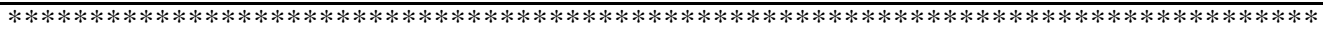 \\
\hline 2 & 0,2560 & 8,69 & 20,32 & $* * * * * * * * * * * * * * * * * * * * * * * * * * * * * * * * * * * * * * * * * * * * * * * * * * * * * * * * * * * *$ \\
\hline 3 & 0,2483 & 8,43 & 28,75 & $* * * * * * * * * * * * * * * * * * * * * * * * * * * * * * * * * * * * * * * * * * * * * * * * * * * * * * * * * * *$ \\
\hline 4 & 0,2078 & 7,06 & 35,81 & $* * * * * * * * * * * * * * * * * * * * * * * * * * * * * * * * * * * * * * * * * * * * * * * * * * * *$ \\
\hline 5 & 0,1976 & 6,71 & 42,52 & $* * * * * * * * * * * * * * * * * * * * * * * * * * * * * * * * * * * * * * * * * * * * * * * *$ \\
\hline 6 & 0,1862 & 6,32 & 48,85 & $* * * * * * * * * * * * * * * * * * * * * * * * * * * * * * * * * * * * * * * * * * * *$ \\
\hline 7 & 0,1786 & 6,07 & 54,91 & $* * * * * * * * * * * * * * * * * * * * * * * * * * * * * * * * * * * * * * * * * * *$ \\
\hline 8 & 0,1525 & 5,18 & 60,09 & $* * * * * * * * * * * * * * * * * * * * * * * * * * * * * * * * * * * *$ \\
\hline 9 & 0,1347 & 4,57 & 64,67 & $* * * * * * * * * * * * * * * * * * * * * * * * * * * * * * * *$ \\
\hline 10 & 0,1234 & 4,19 & 68,86 & $* * * * * * * * * * * * * * * * * * * * * * * * * * * * *$ \\
\hline 11 & 0,1130 & 3,84 & 72,70 & $* * * * * * * * * * * * * * * * * * * * * * * * * * * *$ \\
\hline 12 & 0,1066 & 3,62 & 76,31 & $* * * * * * * * * * * * * * * * * * * * * * * * *$ \\
\hline 13 & 0,1061 & 3,60 & 79,92 & $* * * * * * * * * * * * * * * * * * * * * * * * *$ \\
\hline 14 & 0,0938 & 3,19 & 83,10 & $* * * * * * * * * * * * * * * * * * * * * *$ \\
\hline 15 & 0,0799 & 2,71 & 85,82 & $* * * * * * * * * * * * * * * * * * *$ \\
\hline 16 & 0,0760 & 2,58 & 88,40 & $* * * * * * * * * * * * * * * * * *$ \\
\hline 17 & 0,0633 & 2,15 & 90,55 & $* * * * * * * * * * * * * * *$ \\
\hline 18 & 0,0609 & 2,07 & 92,61 & $* * * * * * * * * * * * * * *$ \\
\hline 19 & 0,0444 & 1,51 & 94,12 & $* * * * * * * * * * *$ \\
\hline 20 & 0,0381 & 1,29 & 95,42 & $* * * * * * * * *$ \\
\hline 21 & 0,0338 & 1,15 & 96,57 & $* * * * * * * *$ \\
\hline 22 & 0,0303 & 1,03 & 97,60 & $* * * * * * * *$ \\
\hline 23 & 0,0285 & 0,97 & 98,56 & $* * * * * * *$ \\
\hline 24 & 0,0257 & 0,87 & 99,44 & $* * * * * * *$ \\
\hline 25 & 0,0165 & 0,56 & 100,00 & $* * * *$ \\
\hline
\end{tabular}

Fonte: Dados de pesquisa 


\section{Apêndice 15}

\section{Coordenadas e Contribuições Relativas para cada uma das Modalidades das}

\section{Variáveis Ativas e Suplementares da Questão 6}

\begin{tabular}{|c|c|c|c|c|c|c|c|c|c|c|c|c|c|c|}
\hline \multirow[t]{2}{*}{$\begin{array}{l}\text { Moda- } \\
\text { lidades }\end{array}$} & \multirow{2}{*}{$\begin{array}{l}\text { Pesos } \\
\text { Rela- } \\
\text { tivos }\end{array}$} & \multirow[t]{2}{*}{$\begin{array}{l}\text { Distân- } \\
\text { cias }\end{array}$} & \multicolumn{4}{|c|}{ Coordenadas } & \multicolumn{4}{|c|}{$\begin{array}{c}\text { Contribuições relativas } \\
\text { dos pontos-perfis }^{2}\end{array}$} & \multicolumn{4}{|c|}{$\begin{array}{c}\text { Contribuições relativas } \\
\text { de um fator }\end{array}$} \\
\hline & & & 1 & 2 & 3 & 4 & 1 & 2 & 3 & 4 & 1 & 2 & 3 & 4 \\
\hline $\mathrm{T} 1=1$ & 0,21 & 25,00 & 0,61 & $-3,4$ & 1,74 & $\overline{0,53}$ & 0,20 & 9,80 & 2,60 & $\longdiv { 0 , 3 0 }$ & $\overline{0,02}$ & 0,47 & 0,12 & $\overline{0,01}$ \\
\hline $\mathrm{T} 1=2$ & 64 & 67 & -0, & & & & & 0 & 0 & & 3 & 00 & 1 & 07 \\
\hline $\mathrm{T} 1=3$ & & 20 & -0, & & & 0,54 & & 70 & 3,70 & 1,50 & 03 & ,04 & 0,20 & 0,07 \\
\hline $\mathrm{T} 1=4$ & 53 & 53 & & & & $-0,26$ & 30 & 10 & 2,50 & 20 & 05 &, 01 & ),33 & 0,13 \\
\hline $\mathrm{T} 2=0$ & 43 & 12,00 & & & & 49 & 90 & 00 & 10 & 50 & 06 & ,00 & 0,00 &, 02 \\
\hline $\mathrm{T} 2=1$ & 92 & & $-0,67$ & & & 0,04 & 2,50 & 2,10 & 1,70 & 0,00 &, 24 & 0,15 &, 11 & 0,00 \\
\hline $\mathrm{T} 2=2$ & 1 & & $-0,57$ & $-0,32$ & -0 , & 0,02 & 1,60 & 0,70 & 1,10 & 0,00 & 0,14 & 0,05 & 0,07 & 0,00 \\
\hline $\mathrm{T} 2=3$ & & & 1 & -0 & & $-0,72$ & 5,40 & 1,20 & 0,20 & 10 & 0,39 & 0,07 & 0,01 & 09 \\
\hline $\mathrm{T} 2=4$ & 0,64 & 7,67 & 8 & $-0,01$ & $-0,52$ & 0,48 & 1,80 & 0,00 & 0,70 & 70 & 0,12 & 0,00 & 0,04 & 03 \\
\hline $\mathrm{T} 3=1$ & & 2,71 & $-0,71$ & $-0,90$ & $-0,35$ & 0,17 & 2,20 & 4,70 & 0,70 & 0,20 & 19 & 0,30 & 0,05 & 0,01 \\
\hline $\mathrm{T} 3=2$ & & & & & & & & & 20 & & 33 & 3 & 01 & 09 \\
\hline $\mathrm{T} 3=3$ & & & -0 & & & & & 0 & 8,30 & 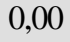 & ,00 & , 01 & 0,38 & 0,00 \\
\hline $\mathrm{T} 3=4$ & & & & & & 17 & 2,50 & 1,70 & 0,20 & 30 & 0,30 & 0,15 & 02 & 02 \\
\hline$=1$ & & & $-0,19$ & 3 & & & 50 & 00 & 0,00 & 20 & 43 & 1 & 01 & 08 \\
\hline $\mathrm{T} 4=2$ & & 25,00 & 2,03 & $-0,06$ & & $-0,96$ & 2,60 & 0,00 & 0,10 & 1,00 & ,16 & 00 & 0,01 & 0,04 \\
\hline $\mathrm{T} 4=3$ & 21 & 00 & 2,51 & 0 & $-0,12$ & $-0,98$ & 3,90 & 0,60 & 0,00 & 1,00 & 0,25 & 0,03 & 0,00 & 0,04 \\
\hline & & & -1 , & $-1,02$ & & & 1,4 & 1,70 & 3,20 & & 0 & 0,09 & 15 & 01 \\
\hline $\mathrm{T} 5=2$ & & 00 & 0 & 0, & -1 & 1,00 & 0,20 & 0,00 & 1,10 & 0 & 01 & 0,00 & 05 & 0,04 \\
\hline $\mathrm{T} 5=3$ & & 00 & & -3 , & & $-0,53$ & 0 , & 9,80 & 2,60 & 30 & 0,02 & 0,47 & 0,12 & 0,01 \\
\hline & & & & & & & & 0 & 20 & 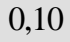 & 01 & T & 05 & 01 \\
\hline $\mathrm{T} 6=0$ & & & -0 & & & -1 & 0,10 & 10 & 0,00 & 0 & 0,00 & 0 & 0,00 & 0,07 \\
\hline $\mathrm{T} 6=1$ & & & $-0,74$ & & & $-0,16$ & 2,70 & 2,10 & 0,30 & 0,20 & 24 & 14 & 0,02 & 0,01 \\
\hline T6 $=2$ & & & $-0,68$ & $-1,08$ & & & 0,90 & 2,90 & 3,40 & 0,10 & 06 & 15 & 0,17 & 0,00 \\
\hline $\mathrm{T} 6=3$ & & 00 & $-1,47$ & 0,4 & & $-2,13$ & 1,30 & 0,20 & 1,20 & 4,70 & 0,09 & 0,01 & 0,06 & 0,18 \\
\hline $\mathrm{T} 6=4$ & & & & $-0,15$ & & & 4,60 & 0,30 & 1,00 & 1,50 & 0,56 & 0,02 & 0,09 & 0,11 \\
\hline $\mathrm{T} 7=1$ & & & -0, & & & -0 & 2 , & 0 & 0,20 & 0,90 & 0,18 & 0,11 & 0,01 & 0,05 \\
\hline$=2$ & & 0 & -0, & & & & 0,2 & 1,40 & 1,10 & 6,40 & 0,02 & 0,07 & 0,05 & 0,26 \\
\hline $\mathrm{T} 7=4$ & & & 0 , & -0 & -0, & $-0,05$ & 1,4 & 1,80 & 0,00 & 0,00 & 0,23 & 0,21 & 0,00 & 0,00 \\
\hline & & & -0 & & -0 , & & 3,10 & & & & 0,49 & 0,02 & & 0,04 \\
\hline $\mathrm{T} 8=2$ & & & & & & & 0,00 & 0,30 & 5,90 & 5,80 & 0,00 & 0,02 & 0,31 & 0,26 \\
\hline $\mathrm{T} 8=3$ & 100 & 25,00 & & & $-0,12$ & $-0,98$ & 3,90 & 0,60 & 0,00 & 1,00 & 0,25 & 0,03 & 0,00 & 0,04 \\
\hline & & & & & & & 4,30 & 2,40 & 0,00 & 0,30 & 0,32 & 4 & 0,00 & 0,01 \\
\hline $\mathrm{T} 9=1$ & & & & & & $-0,28$ & 2,10 & 0,30 & 0,70 & 0,90 & 0,22 & 0,03 & 0,05 & 0,06 \\
\hline & & & -1, & & & & 0,60 & 1,10 & 1,70 & 0,00 & 0,04 & 0,05 & 0,08 & 0,00 \\
\hline & & & -0, & -0, & -0 , & & 0,2 & 1, & 2,30 & 0,20 & 0,01 & 0,05 & 0,11 & 0,01 \\
\hline $\mathrm{T} 9=4$ & 2,53 & 1,36 & 0,72 & 0,09 & 0,12 & 0,21 & 3,60 & 0,10 & 0,10 & 0,50 & 0,38 & 0,01 & 0,01 & 0,03 \\
\hline
\end{tabular}




\begin{tabular}{|c|c|c|c|c|c|c|c|c|c|c|c|c|c|c|}
\hline \multirow[t]{2}{*}{$\begin{array}{l}\text { Moda- } \\
\text { lidades }\end{array}$} & \multirow{2}{*}{$\begin{array}{c}\text { Pesos } \\
\text { Rela- } \\
\text { tivos }\end{array}$} & \multirow[t]{2}{*}{$\begin{array}{l}\text { Distân- } \\
\text { cias }\end{array}$} & \multicolumn{4}{|c|}{ Coordenadas } & \multicolumn{4}{|c|}{$\begin{array}{c}\text { Contribuições relativas } \\
\text { dos pontos-perfis }^{2}\end{array}$} & \multicolumn{4}{|c|}{$\begin{array}{c}\text { Contribuições relativas } \\
\text { de um } \text { fator }^{2}\end{array}$} \\
\hline & & & 1 & 2 & 3 & 4 & 1 & 2 & 3 & 4 & 1 & 2 & 3 & 4 \\
\hline $\mathrm{T} 10=1$ & 2,35 & 1,36 & $-0,03$ & $-0,49$ & $-0,04$ & 0,78 & 0,00 & 2,20 & 0,00 & 6,90 & 0,00 & 0,18 & 0,00 & 0,45 \\
\hline $\mathrm{T} 10=2$ & 0,21 & 25,00 & $-0,72$ & 0,96 & $-0,76$ & $-0,88$ & 0,30 & 0,80 & 0,50 & 0,80 & 0,02 & 0,04 & 0,02 & 0,03 \\
\hline $\mathrm{T} 10=3$ & 1,07 & 4,20 & $-1,13$ & 0,54 & 0,07 & $-0,47$ & 4,00 & 1,20 & 0,00 & 1,10 & 0,31 & 0,07 & 0,00 & 0,05 \\
\hline $\mathrm{T} 10=4$ & 1,92 & 1,89 & 0,74 & 0,20 & 0,09 & $-0,60$ & 3,10 & 0,30 & 0,10 & 3,30 & 0,29 & 0,02 & 0,00 & 0,19 \\
\hline $\mathrm{T} 11=2$ & 0,21 & 25,00 & 0,04 & 1,22 & 1,34 & 3,15 & 0,00 & 1,30 & 1,50 & 10,20 & 0,00 & 0,06 & 0,07 & 0,40 \\
\hline $\mathrm{T} 11=3$ & 2,35 & 1,36 & $-0,45$ & $-0,16$ & 0,62 & $-0,22$ & 1,40 & 0,20 & 3,60 & & 0,15 & 0,02 & 0,28 & 0,04 \\
\hline $\mathrm{T} 11=4$ & 2,99 & 0,86 & 0,35 & 0,04 & $-0,58$ & $-0,05$ & 1,10 & 0,00 & 4,10 & 0,00 & 0,15 & 0,00 & 0,39 & 0,00 \\
\hline $\mathrm{T} 12=1$ & 0,85 & 5,50 & 0,24 & 0,13 & 0,03 & 1,51 & 0,10 & 0,10 & 0,00 & 9,40 & 0,01 & 0,00 & 0,00 & 0,41 \\
\hline $\mathrm{T} 12=2$ & 0,64 & 7,67 & 0,13 & 0,47 & $-0,19$ & $-0,51$ & 0,00 & 0,60 & 0,10 & 0,80 & 0,00 & 0,03 & 0,00 & 0,03 \\
\hline $\mathrm{T} 12=3$ & 0,85 & 5,50 & $-0,96$ & $-0,21$ & 0,68 & $-0,69$ & 2,30 & 0,20 & 1,60 & 2,00 & 0,17 & 0,01 & 0,08 & 0,09 \\
\hline $\mathrm{T} 12=4$ & 3,21 & 0,73 & 0,17 & $-0,07$ & $-0,15$ & $-0,12$ & 0,30 & 0,10 & 0,30 & 0,20 & 0,04 & 0,01 & 0,03 & 0,02 \\
\hline $\mathrm{T} 13=1$ & 4,70 & 0,18 & $-0,21$ & $-0,04$ & 0,06 & 0,04 & 0,60 & 0,00 & 0,10 & 0,00 & 0,24 & 0,01 & 0,02 & 0,01 \\
\hline $\mathrm{T} 13=2$ & 0,21 & 25,00 & 2,51 & 0,85 & $-0,12$ & $-0,98$ & 3,90 & 0,60 & 0,00 & 1,00 & 0,25 & 0,03 & 0,00 & 0,04 \\
\hline $\mathrm{T} 13=4$ & 0,64 & 7,67 & 0,71 & 0,00 & $-0,37$ & 0,03 & 0,90 & 0,00 & 0,40 & 0,00 & 0,06 & 0,00 & 0,02 & 0,00 \\
\hline $\mathrm{T} 14=1$ & 0,85 & 5,50 & $-0,43$ & $-1,05$ & $-1,19$ & 0,76 & 0,50 & 3,70 & 4,90 & 2,40 & 0,03 & 0,20 & 0,26 & 0,10 \\
\hline $\mathrm{T} 14=2$ & 0 & 12,00 & 0,14 & $-1,98$ & 2,42 & $-0,34$ & 0,00 & 6,60 & 10,10 & 0,20 & 0,00 & 0,33 & 0,49 & 0,01 \\
\hline $\mathrm{T} 14=3$ & 1,07 & 4,20 & $-0,91$ & 0,41 & 0,11 & $-0,70$ & 2,60 & 0,70 & 0 & 2,50 & 0,20 & 0,04 & 0,00 & 0,12 \\
\hline $\mathrm{T} 14=4$ & 3,21 & 0,73 & 0,40 & 0,41 & $-0,04$ & 0,07 & 1,50 & 2,10 & 0,00 & 0,10 & 0,22 & 0,23 & 0,00 & 0,01 \\
\hline $\mathrm{T} 15=1$ & 0,21 & 25,00 & $-0,88$ & $-2,46$ & $-2,06$ & 0,79 & 0,50 & 5,00 & 3,60 & 0,60 & 0,03 & 0,24 & 0,17 & 0,03 \\
\hline $\mathrm{T} 15=2$ & 0,21 & 25,00 & $-0,20$ & 0,78 & $-0,31$ & $-0,68$ & 0,00 & 0,50 & 0,10 & 0,50 & 0,00 & 0,02 & 0,00 & 0,02 \\
\hline $\mathrm{T} 15=3$ & 0,43 & 12,00 & $-0,90$ & $-0,04$ & 2,14 & $-1,14$ & 1,00 & 0,00 & 7,90 & 2,70 & 0,07 & 0,00 & 0,38 & 0,11 \\
\hline $\mathrm{T} 15=$ & & & 0,13 & 0 & & & 0,20 & 0,10 & & & 0,09 & 0,04 & 0,04 & 0,05 \\
\hline $\mathrm{T} 16=0$ & 0 & 12,00 & $-0,13$ & $-2,94$ & & 0,13 & 0,00 & 14,50 & & 0,00 & 0,00 & 0,72 & 0,00 & 0,00 \\
\hline $\mathrm{T} 16=1$ & 1 , & 4,20 & $-0,33$ & 0,5 & & & 0,30 & 1,40 & , & 3,70 & 0,03 & 0,08 & 0,00 & 0,17 \\
\hline $\mathrm{T} 16=3$ & 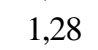 & 3,33 & $-0,48$ & $-0,35$ & 0,4 & $-0,19$ & 0,90 & 0,60 & 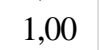 & 0,20 & 0,07 & 0,04 & 0,06 & 0,01 \\
\hline $\mathrm{T} 16=4$ & 2 & 1,00 & 0,37 & 0,39 & $-0,21$ & $-0,26$ & 1,10 & 1,70 & 0,50 & 0,90 & 0,14 & 0,15 & 0,05 & 0,07 \\
\hline $\mathrm{T} 17=0$ & 1,07 & 4,20 & $-0,33$ & $-0,29$ & $-0,28$ & $-0,31$ & 0,30 & 0,40 & 0,30 & 0,50 & 0,03 & 0,02 & 0,02 & 0,02 \\
\hline $\mathrm{T} 17=1$ & & 1,60 & $-0,56$ & 0,20 & $-0,47$ & $-0,06$ & 1,90 & 0,30 & 1,90 & 0,00 & 0,19 & 0,03 & 0,14 & 0,00 \\
\hline $\mathrm{T} 17=2$ & 1,28 & 3,33 & 0,04 & $-0,51$ & 0,95 & 0,01 & 0,00 & 1,30 & 4,70 & 0,00 & 0,00 & 0,08 & 0,27 & 0,00 \\
\hline $\mathrm{T} 17=3$ & 0,43 & 12,00 & 1,79 & 0,02 & $-0,47$ & $-0,61$ & 4,00 & 0,00 & 0,40 & 0,80 & 0,27 & 0,00 & 0,02 & 0,03 \\
\hline $\mathrm{T} 17=$ & & & & & & & 2,40 & & & 3,70 & 0,17 & 0,09 & 0,03 & 0,16 \\
\hline $\mathrm{T} 18=$ & & & $-0,38$ & & & & 1,20 & $0, \angle 0$ & 0,20 & 2,60 & 0,17 & 0,02 & 0,02 & 0,21 \\
\hline $\mathrm{T} 18=2$ & 0,43 & 12,00 & $-0,86$ & $-0,10$ & $-1,08$ & $-0,41$ & 0,90 & 0,00 & 2,00 & 0,30 & 0,06 & 0,00 & 0,10 & 0,01 \\
\hline $\mathrm{T} 18=3$ & 0,43 & 12,00 & 1,21 & $-0,09$ & $-0,52$ & $-0,20$ & 1,80 & 0,00 & 0,50 & 0,10 & 0,12 & 0,00 & 0,02 & 0,00 \\
\hline $\mathrm{T} 18=4$ & 1,71 & 2,25 & 0,57 & $-0,20$ & 0,16 & $-0,59$ & 1,60 & 0,30 & 0,20 & 2,80 & 0,15 & 0,02 & 0,01 & 0,15 \\
\hline $\mathrm{S} 1=0$ & - & 00 & 0,35 & 0,3 & 0,0 & 0,2 & - & - & - & - & 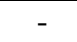 & - & - & - \\
\hline $\mathrm{S} 1=1$ & 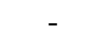 & 25,00 & $-1,00$ & $-1,16$ & $-1,39$ & & 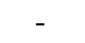 & 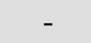 & 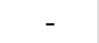 & - & 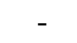 & 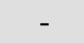 & 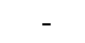 & - \\
\hline $\mathrm{S} 1=2$ & - & 3,33 & 0,11 & $-0,54$ & 0,6 & $-0,37$ & 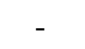 & 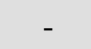 & 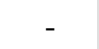 & 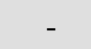 & - & 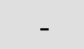 & - & - \\
\hline & 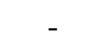 & & $-0,7$ & & & & - & 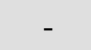 & 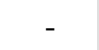 & 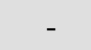 & - & - & - & - \\
\hline $\mathrm{S} 2=0$ & 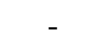 & 25,00 & 0,87 & 0,42 & 0,14 & 1,12 & - & - & - & - & 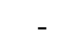 & 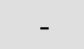 & - & - \\
\hline $\mathrm{S} 2=1$ & - & 0,62 & 0,11 & 0,07 & 0,05 & $-0,26$ & - & - & 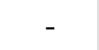 & - & 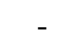 & 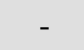 & 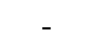 & - \\
\hline $\mathrm{S} 2=2$ & 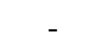 & 1,89 & $-0,29$ & $-0,17$ & $-0,10$ & 0,34 & - & - & - & 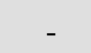 & 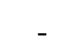 & 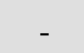 & - & - \\
\hline $\mathrm{S} 3=1$ & - & 12,00 & 1,69 & 0,63 & 0,01 & 0,07 & 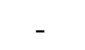 & 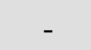 & - & - & 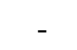 & - & - & - \\
\hline $\mathrm{S} 3=2$ & - & 1,89 & 0,08 & $-0,32$ & $-0,10$ & $-0,06$ & - & - & - & - & - & - & - & - \\
\hline
\end{tabular}




\begin{tabular}{|c|c|c|c|c|c|c|c|c|c|c|c|c|c|c|}
\hline \multirow[t]{2}{*}{$\begin{array}{l}\text { Moda- } \\
\text { lidades }{ }^{1}\end{array}$} & \multirow{2}{*}{$\begin{array}{c}\text { Pesos } \\
\text { Rela- } \\
\text { tivos }\end{array}$} & \multirow[t]{2}{*}{$\begin{array}{l}\text { Distân- } \\
\text { cias }\end{array}$} & \multicolumn{4}{|c|}{ Coordenadas } & \multicolumn{4}{|c|}{$\begin{array}{c}\text { Contribuições relativas } \\
\text { dos pontos-perfis }\end{array}$} & \multicolumn{4}{|c|}{$\begin{array}{c}\text { Contribuiçõos relativas } \\
\text { de um fator }\end{array}$} \\
\hline & & & 1 & 2 & 3 & 4 & 1 & 2 & 3 & 4 & 1 & 2 & 3 & 4 \\
\hline $\mathrm{S} 3=3$ & - & 1,89 & $-0,18$ & 0,05 & $-0,15$ & 0,19 & - & - & - & - & - & - & - & - \\
\hline $\mathrm{S} 3=4$ & - & 25,00 & $-0,45$ & $-0,61$ & $-0,19$ & 1,18 & - & - & - & - & - & - & - & - \\
\hline $\mathrm{S} 3=6$ & - & 4,20 & $-0,39$ & 0,36 & 0,49 & $-0,50$ & - & - & - & - & - & - & - & - \\
\hline
\end{tabular}

Fonte: Dados da pesquisa

${ }^{1}$ Os códigos utilizados para a análise dos planos fatoriais da questão 6 foram os seguintes:

- Variáveis ativas: t1 - melhorar o serviço ao cliente; t2 - reduzir custos; $\mathrm{t} 3$ - reduzir custos com segurança; 4 - reduzir o número de funcionários; t5 - aumentar a segurança da carga transportada; t6 colocar a carga/caminhão no seguro; $\mathrm{t} 7$ - melhorar a decisão quanto à mudança de trajetos de coletas; $\mathrm{t} 8$ - diminuir o número de rotas; $\mathrm{t} 9$ - reduzir a ociosidade da frota; $\mathrm{t} 10$ - reduzir o tempo de entrega/coleta; t11 - obter informação instantânea da posição do veículo; t12 - socorrer veículos quebrados; t13 melhorar a manutenção dos veículos; t14 - melhorar a confiança do motorista em relação à empresa; t15 - controlar melhor o motorista; r16 - obter maiores vantagens competitivas em relação às outras empresas; r17 - explorar novas tecnologias; r18 - reduzir a quantidade de horas extras;

- Grau de satisfação em relação aos benefícios obtidos pelas empresas em relação aos sistemas de rastreamento: 0 - nenhum; 1 - pouco atendido; 2 - mais ou menos atendido; 3 - muito atendido;

- Variáveis suplementares: s1 - porcentagem de caminhões rastreados (0 - >70;1 - 51-70; 2 - 20-50; 3 $<20 \%)$; s2 - tempo de uso do sistema (0 - 4-5; 1 - 1-3; 2 - menor que 1 ano); s3 - faturamento da empresa ( 0 - >500; 1 - 100-500; 2 - 9-99; 3 - 1-9; 4 - <1 milhão de dólares anual; 5 - outro indicador).

${ }^{2}$ Os valores em itálico correspondem às maiores contribuições. 


\section{Apêndice 16}

\section{Coordenadas e Contribuições Relativas para cada uma das empresas da Questão 6}

\begin{tabular}{|c|c|c|c|c|c|c|c|c|c|c|c|c|c|c|}
\hline \multirow{2}{*}{$\begin{array}{l}\text { Empre- } \\
\operatorname{sas}^{1}\end{array}$} & \multirow{2}{*}{$\begin{array}{l}\text { Siste- } \\
\operatorname{mas}^{2}\end{array}$} & \multirow[b]{2}{*}{$\begin{array}{l}\text { Distân } \\
\text {-cias }\end{array}$} & \multicolumn{4}{|c|}{ Coordenadas } & \multicolumn{4}{|c|}{$\begin{array}{c}\text { Contribuições relativas } \\
\text { dos pontos-perfis }\end{array}$} & \multicolumn{4}{|c|}{$\begin{array}{c}\text { Contribuições } \\
\text { relativas de um fator }\end{array}$} \\
\hline & & & 1 & 2 & 3 & 4 & 1 & 2 & 3 & 4 & 1 & 2 & 3 & 4 \\
\hline 12 & $\bar{A}$ & 3,71 & 1,19 & $-0,03$ & $-0,20$ & $-0,44$ & 15,80 & 0,00 & 0,60 & 3,60 & 0,38 & 0,00 & 0,01 & 0,05 \\
\hline 3 & B & 1,58 & 0,43 & 0,13 & $-0,14$ & $-0,19$ & 2,10 & 0,20 & 0,30 & 0,70 & 0,12 & 0,01 & 0,01 & 0,02 \\
\hline 8 & $\mathrm{C}$ & 1,55 & $-0,62$ & 0,20 & $-0,08$ & $-0,25$ & 4,30 & 0,60 & 0,10 & 1,10 & 0,25 & 0,02 & 0,00 & 0,04 \\
\hline 16 & $\mathrm{D}$ & 4,46 & $-0,19$ & $-0,27$ & 1,54 & $-0,07$ & 0,40 & 1,10 & 36,90 & 0,10 & 0,01 & 0,02 & 0,53 & 0,00 \\
\hline 18 & $\mathrm{E}$ & 4,71 & $-0,52$ & $-1,24$ & $-1,03$ & 0,36 & 3,00 & 23,20 & 16,30 & 2,40 & 0,06 & 0,33 & 0,22 & 0,03 \\
\hline 20 & $\mathrm{~F}$ & 2,68 & $-0,20$ & 0,15 & $-0,07$ & $-0,62$ & 0,50 & 0,30 & 0,10 & 7,00 & 0,02 & 0,01 & 0,00 & 0,14 \\
\hline 26 & G & 2,26 & $-0,74$ & 0,21 & $-0,32$ & $-0,07$ & 6,20 & 0,70 & 1,60 & 0,10 & 0,24 & 0,02 & 0,05 & 0,00 \\
\hline 5 & $\mathrm{H}$ & 4,08 & $-0,86$ & 0,23 & 0,59 & $-0,97$ & 8,30 & 0,80 & 5,40 & 17,40 & 0,18 & 0,01 & 0,09 & 0,23 \\
\hline 4 & I & 1,92 & $-0,09$ & 0,19 & 0,01 & $-0,20$ & 0,10 & 0,50 & 0,00 & 0,70 & 0,00 & 0,02 & 0,00 & 0,02 \\
\hline 6 & $\mathrm{~J}$ & 2,89 & $-0,12$ & 0,40 & $-0,15$ & $-0,31$ & 0,20 & 2,40 & 0,40 & 1,80 & 0,00 & 0,05 & 0,01 & 0,03 \\
\hline 21 & $\mathrm{~K}$ & 3,09 & $-0,42$ & 0,48 & $-0,38$ & $-0,40$ & 2,00 & 3,50 & 2,20 & 3,00 & 0,06 & 0,08 & 0,05 & 0,05 \\
\hline 1 & $\mathrm{~L}$ & 4,05 & 0,02 & 0,62 & 0,67 & 1,44 & 0,00 & 5,80 & 6,90 & 38,10 & 0,00 & 0,09 & 0,11 & 0,51 \\
\hline 7 & M & 1,90 & $-0,06$ & 0,09 & 0,33 & 0,29 & 0,00 & 0,10 & 1,70 & 1,60 & 0,00 & 0,00 & 0,06 & 0,05 \\
\hline 9 & $\mathrm{~N}$ & 1,98 & $-0,30$ & 0,03 & 0,20 & 0,02 & 1,00 & 0,00 & 0,60 & 0,00 & 0,05 & 0,00 & 0,02 & 0,00 \\
\hline 10 & $\mathrm{O}$ & 1,10 & $-0,15$ & 0,25 & $-0,03$ & 0,20 & 0,20 & 0,90 & 0,00 & 0,80 & 0,02 & 0,06 & 0,00 & 0,04 \\
\hline 13 & $\mathrm{P}$ & 2,06 & $-0,55$ & 0,44 & $-0,12$ & 0,05 & 3,30 & 2,80 & 0,20 & 0,00 & 0,14 & 0,09 & 0,01 & 0,00 \\
\hline 14 & Q & 2,14 & 0,46 & $-0,06$ & 0,04 & 0,32 & 2,40 & 0,10 & 0,00 & 1,90 & 0,10 & 0,00 & 0,00 & 0,05 \\
\hline 15 & $\mathrm{R}$ & 5,49 & 0,36 & $-1,74$ & 0,87 & $-0,24$ & 1,40 & 45,30 & 11,70 & 1,10 & 0,02 & 0,55 & 0,14 & 0,01 \\
\hline 17 & $\mathrm{~S}$ & 2,35 & $-0,55$ & 0,29 & 0,12 & 0,17 & 3,30 & 1,30 & 0,20 & 0,50 & 0,13 & 0,04 & 0,01 & 0,01 \\
\hline 19 & $\mathrm{~T}$ & 2,02 & $-0,27$ & $-0,31$ & $-0,09$ & 0,54 & 0,80 & 1,40 & 0,10 & 5,40 & 0,03 & 0,05 & 0,00 & 0,14 \\
\hline 22 & $\mathrm{U}$ & 5,58 & 1,47 & 0,43 & $-0,06$ & $-0,45$ & 24,30 & 2,70 & 0,10 & 3,70 & 0,39 & 0,03 & 0,00 & 0,04 \\
\hline 23 & V & 3,90 & $-0,59$ & $-0,59$ & $-0,69$ & 0,03 & 3,90 & 5,20 & 7,40 & 0,00 & 0,09 & 0,09 & 0,12 & 0,00 \\
\hline 2 & $X$ & 2,86 & 0,51 & $-0,14$ & $-0,25$ & $-0,07$ & 2,90 & 0,30 & 1,00 & 0,10 & 0,09 & 0,01 & 0,02 & 0,00 \\
\hline 24 & Z & 1,99 & 0,51 & 0,21 & 0,07 & 0,51 & 2,90 & 0,70 & 0,10 & 4,80 & 0,13 & 0,02 & 0,00 & 0,13 \\
\hline 11 & W & 3,64 & 0,36 & 0,01 & $-0,56$ & 0,46 & 1,40 & 0,00 & 4,90 & 3,80 & 0,03 & 0,00 & 0,09 & 0,06 \\
\hline 25 & Y & 2,57 & 0,90 & 0,05 & $-0,26$ & $-0,12$ & 9,10 & 0,00 & 1,10 & 0,30 & 0,32 & 0,00 & 0,03 & 0,01 \\
\hline
\end{tabular}

Fonte: Dados da pesquisa

${ }^{1} \mathrm{O}$ peso relativo a cada empresa (ou sistema) possui o valor de 3,85 .

2 Relação das transportadoras quanto ao uso dos sistemas de rastreamento: A (Combat); B a G (Controlsat); H (Controlsat+Combat); I (Logiq); J (Motorola); K (Multisat); L a Z (Omnisat); W (Teletracker); Y (Teletracker+Omnisat+Controlsat). 
Apêndice 17

Primeiro Plano Fatorial Relacionando as Variáveis da Questão 6

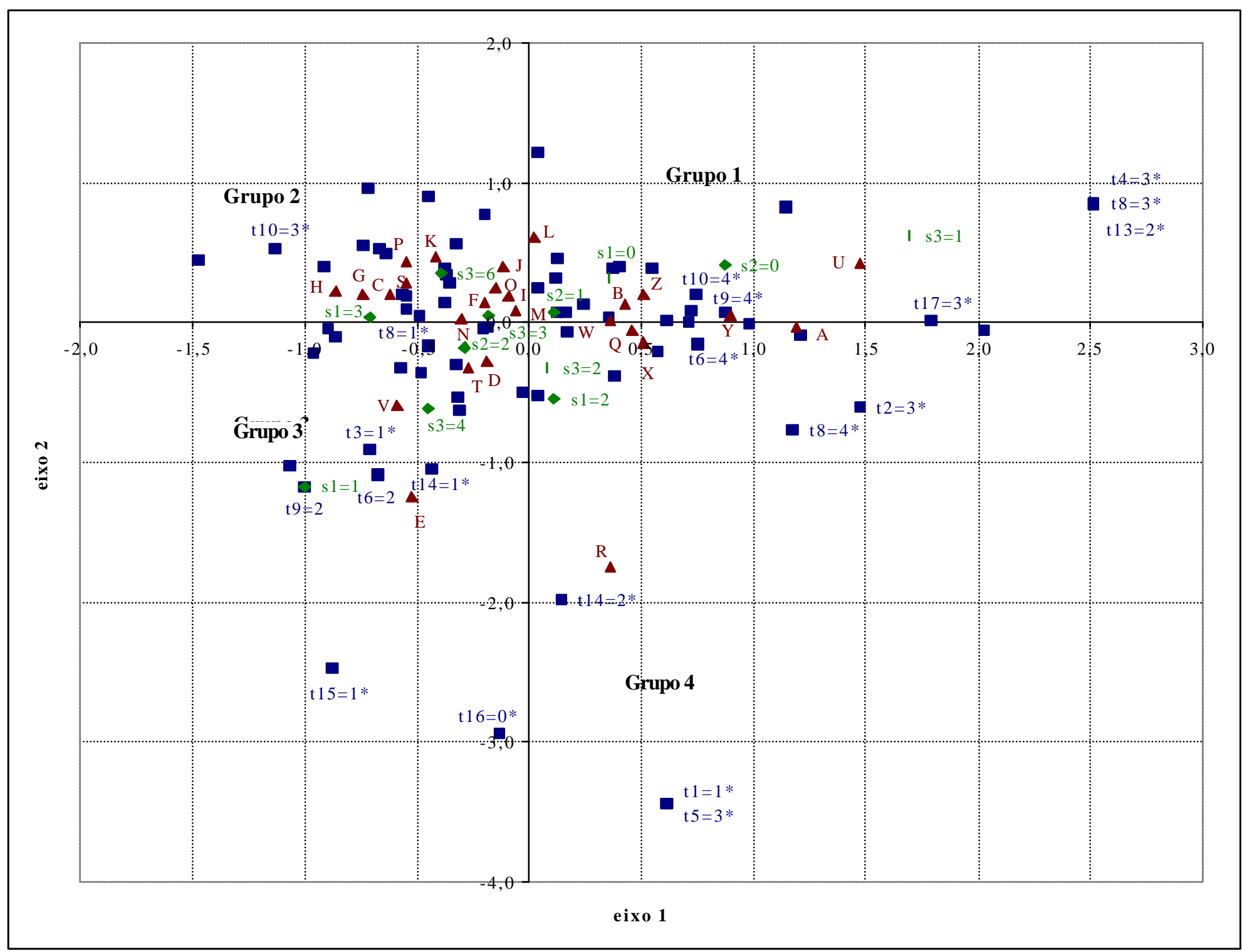


Apêndice 18

Segundo Plano Fatorial Relacionando as Variáveis da Questão 6

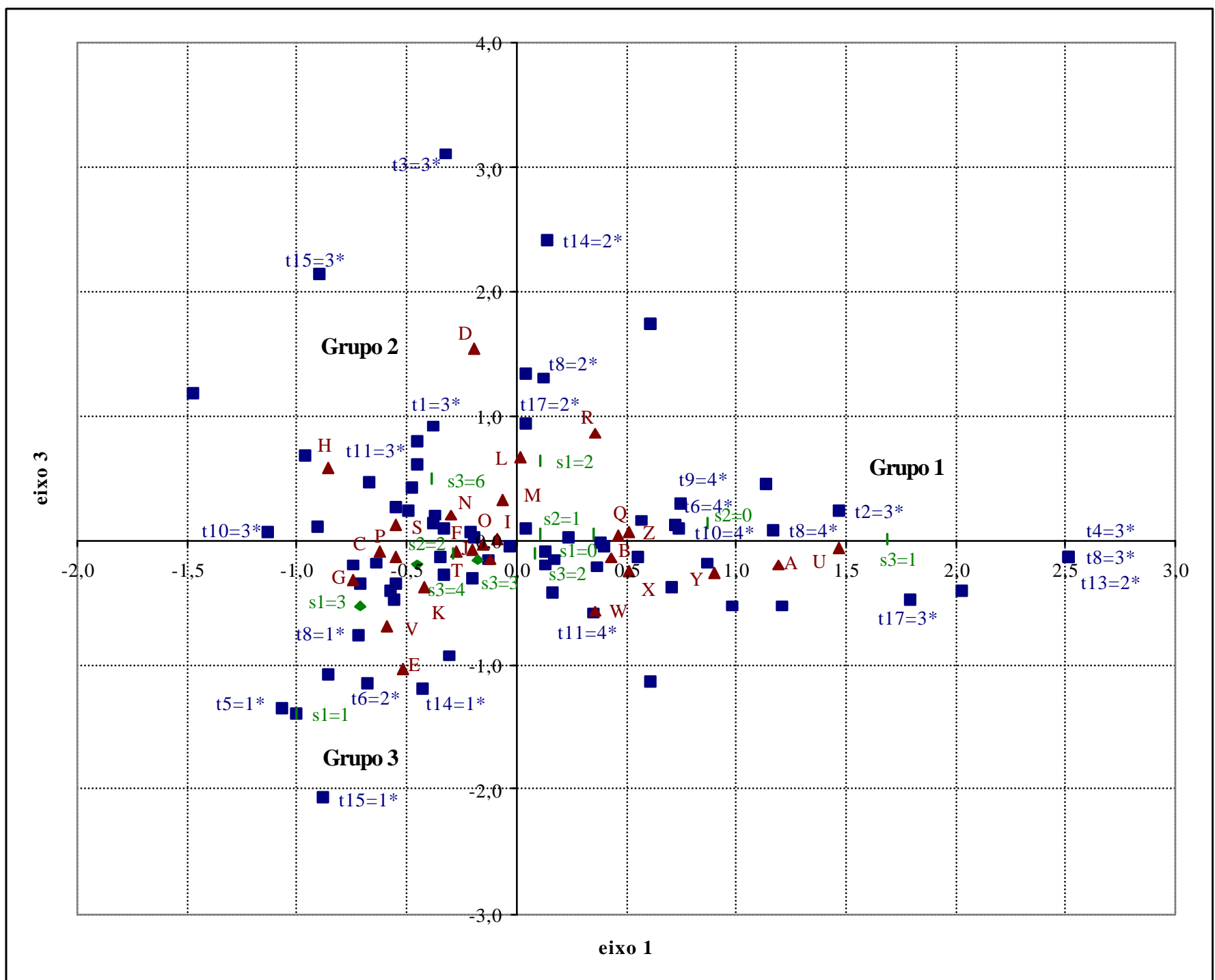


Apêndice 19

Terceiro Plano Fatorial Relacionando as Variáveis da Questão 6

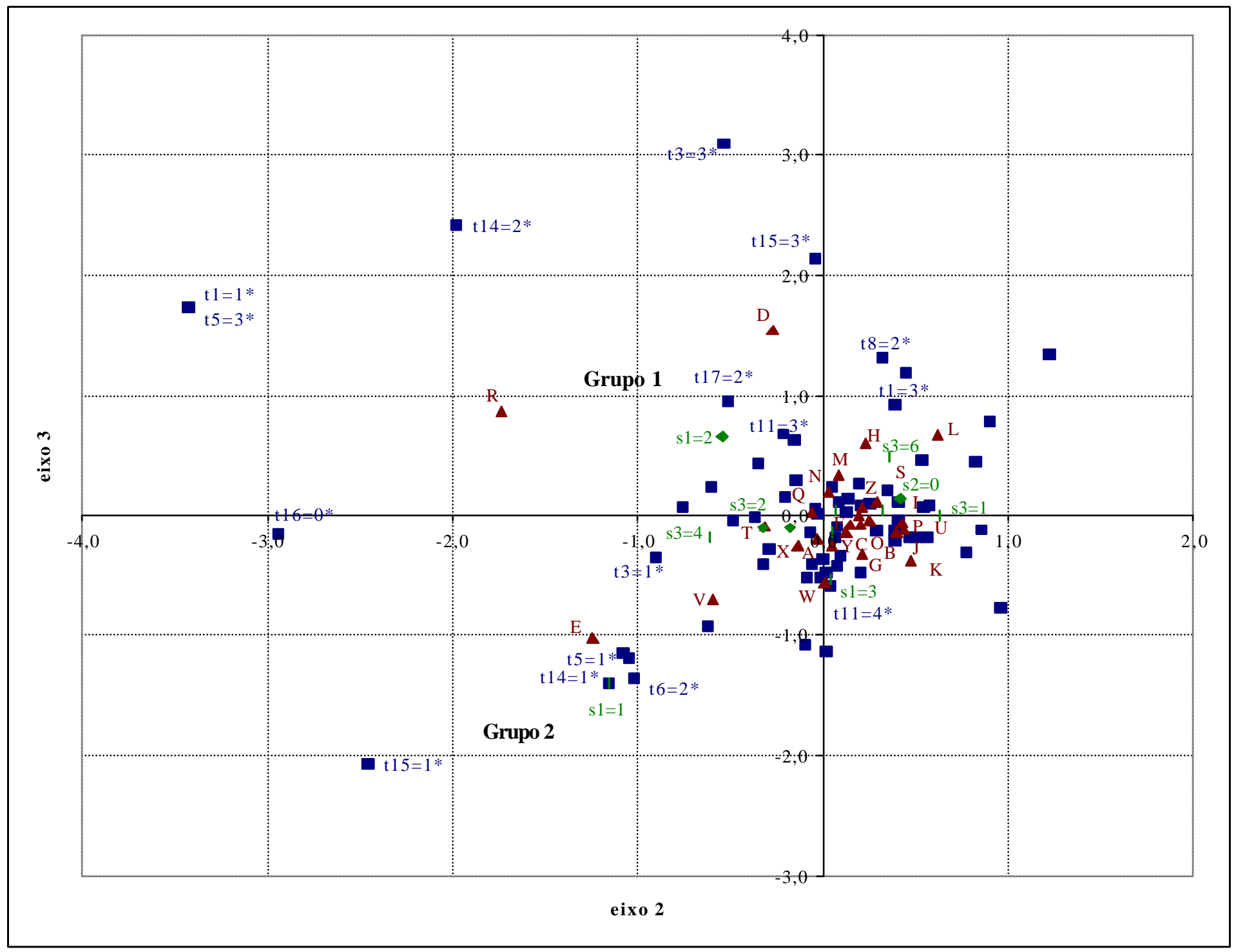


Apêndice 20

Quarto Plano Fatorial Relacionando as Variáveis da Questão 6

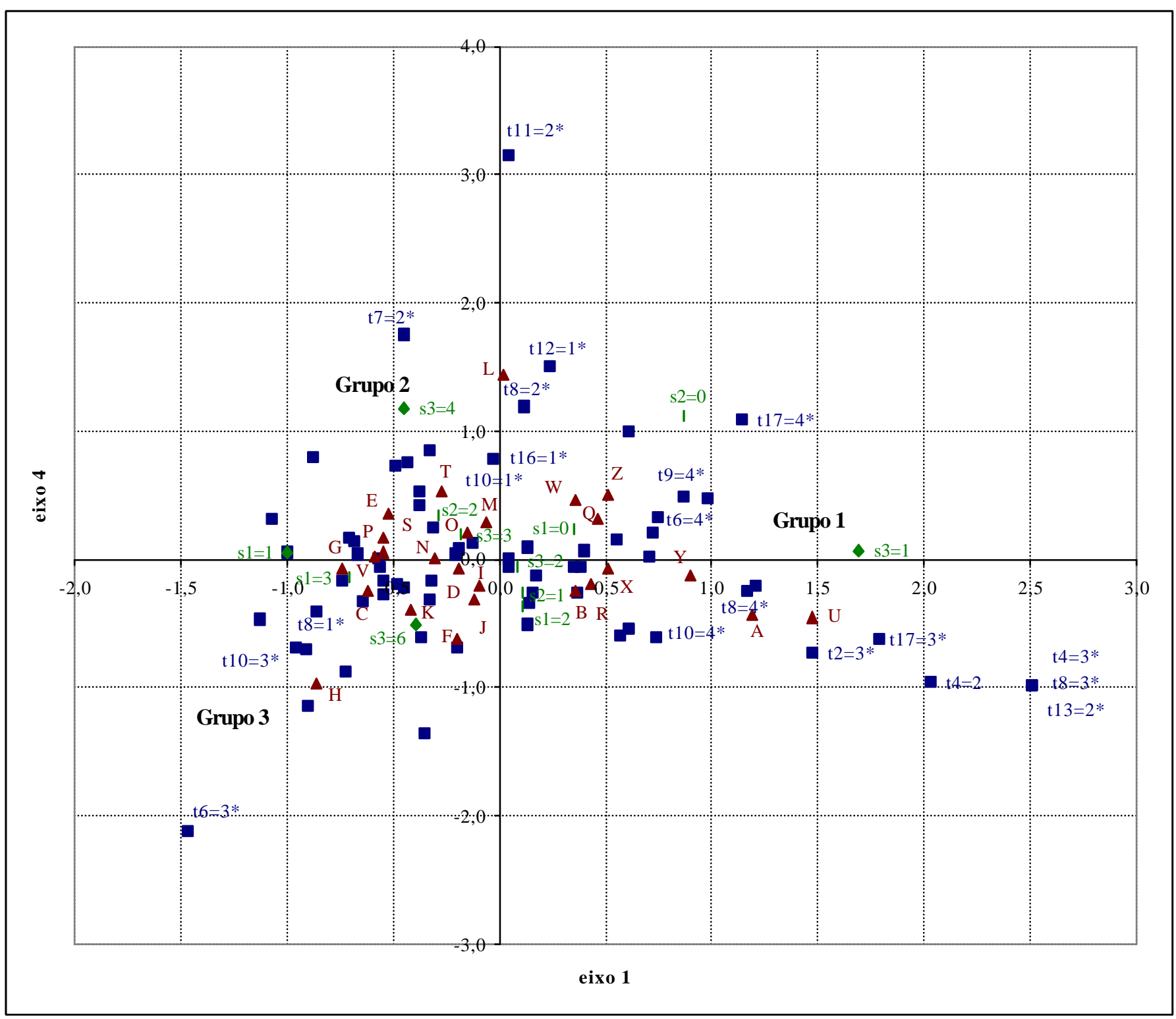


Apêndice 21

Quinto Plano Fatorial Relacionando as Variáveis da Questão 6

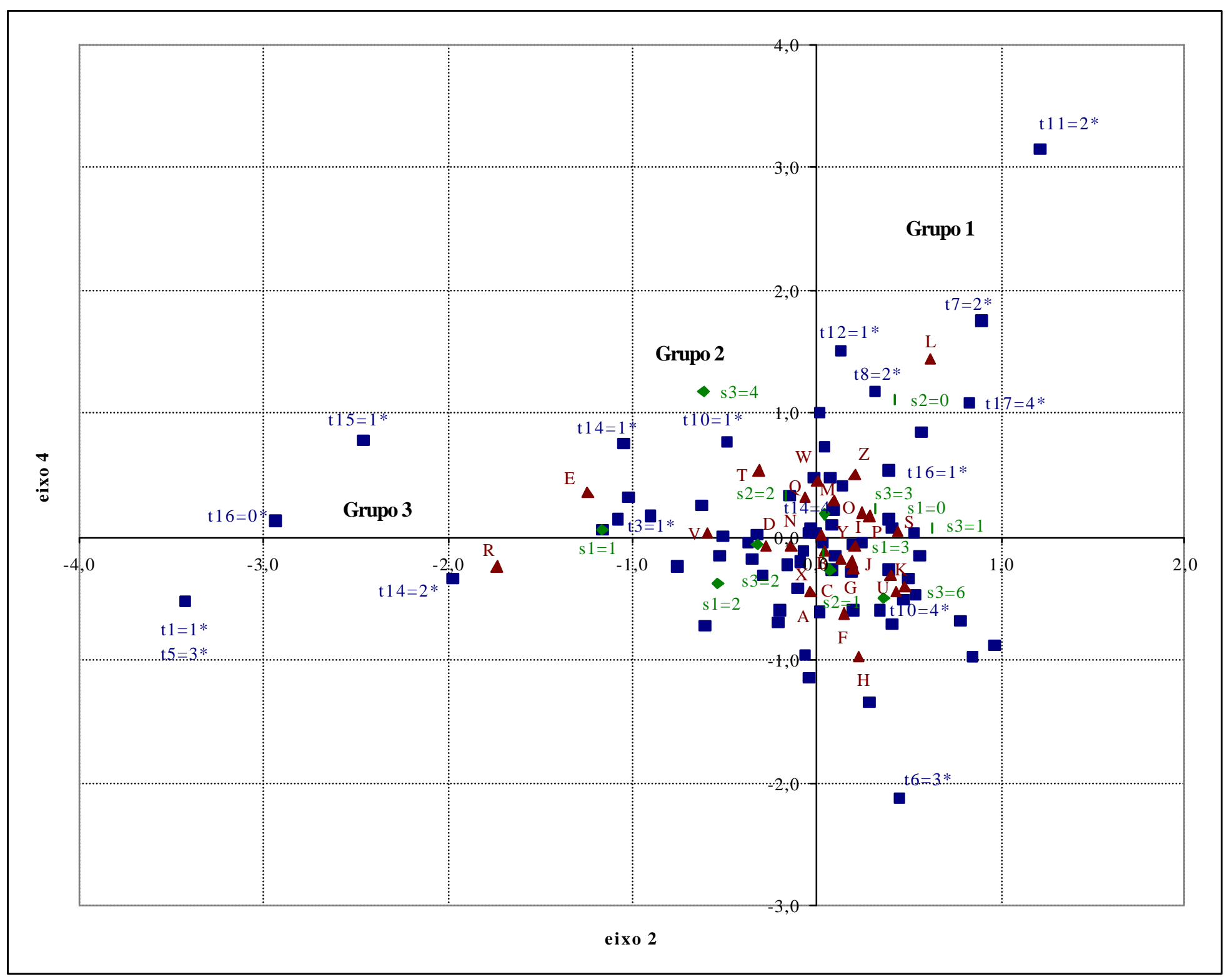


Apêndice 22

Sexto Plano Fatorial Relacionando as Variáveis da Questão 6

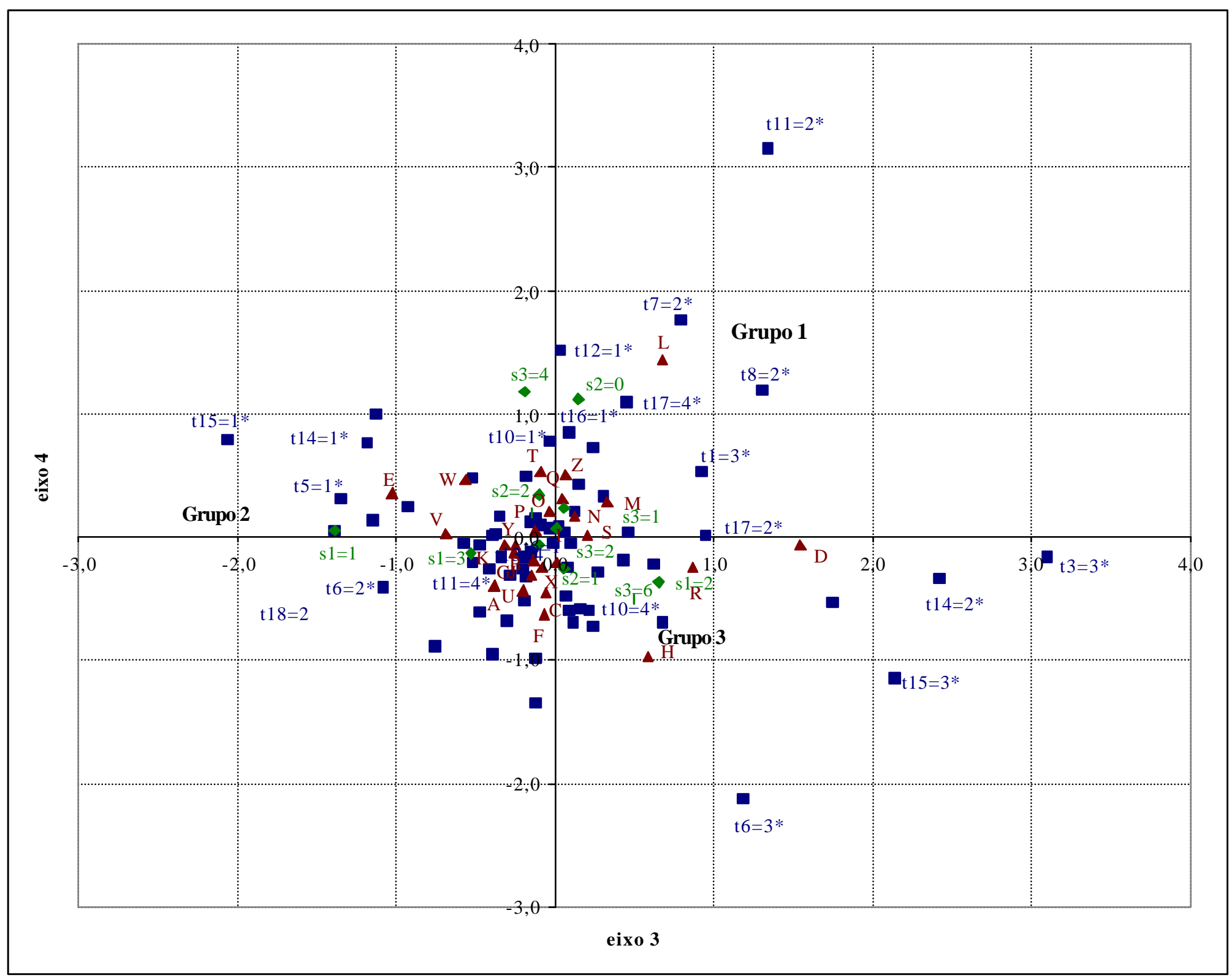




\section{Apêndice 23}

Número de classes obtidas pelo Método de Ward

\begin{tabular}{|c|c|c|c|c|c|c|}
\hline $\begin{array}{c}\text { Número } \\
\text { de } \\
\text { classes }\end{array}$ & \multicolumn{2}{|c|}{$\begin{array}{l}\text { Junção de } \\
\text { sistemas } \\
\text { (empresas) }\end{array}$} & $\begin{array}{l}\text { Freqüên- } \\
\text { cia }\end{array}$ & $\begin{array}{l}\text { Homogeneidade do } \\
\text { novo cluster } \\
\text { (RMSSTD) }\end{array}$ & $\begin{array}{c}\text { Perda de } \\
\text { homogeneidade } \\
\text { (SPR) }\end{array}$ & $\begin{array}{l}\text { Heterogeneidade } \\
\text { dos clusters } \\
\text { (RS) }\end{array}$ \\
\hline 25 & $\mathrm{~F}$ & $\mathrm{R}$ & 2 & 0,05160 & 0,00022 & 0,99979 \\
\hline 24 & $\mathrm{~K}$ & $\mathrm{M}$ & 2 & 0,11231 & 0,00102 & 0,99877 \\
\hline 23 & $\mathrm{G}$ & $\mathrm{T}$ & 2 & 0,11984 & 0,00116 & 0,99761 \\
\hline 22 & $\mathrm{H}$ & Q & 2 & 0,12088 & 0,00118 & 0,99643 \\
\hline 21 & $\mathrm{C}$ & $\mathrm{J}$ & 2 & 0,12748 & 0,00131 & 0,99512 \\
\hline 20 & A & CL24 & 3 & 0,12062 & 0,00133 & 0,99378 \\
\hline 19 & $\mathrm{E}$ & $\mathrm{N}$ & 2 & 0,14582 & 0,00172 & 0,99207 \\
\hline 18 & CL22 & Y & 3 & 0,13730 & 0,00186 & 0,99020 \\
\hline 17 & CL23 & V & 3 & 0,15058 & 0,00250 & 0,98770 \\
\hline 16 & CL21 & I & 3 & 0,17321 & 0,00353 & 0,98417 \\
\hline 15 & $\mathrm{O}$ & $\mathrm{Z}$ & 2 & 0,24047 & 0,00467 & 0,97950 \\
\hline 14 & B & $S$ & 2 & 0,25120 & 0,00510 & 0,97440 \\
\hline 13 & D & CL25 & 3 & 0,21708 & 0,00740 & 0,96701 \\
\hline 12 & CL18 & W & 4 & 0,21196 & 0,00784 & 0,95917 \\
\hline 11 & $\mathrm{~L}$ & $X$ & 2 & 0,34275 & 0,00949 & 0,94969 \\
\hline 10 & CL20 & CL16 & 6 & 0,21246 & 0,01103 & 0,93866 \\
\hline 9 & CL10 & CL11 & 8 & 0,27201 & 0,01411 & 0,92455 \\
\hline 8 & CL13 & CL15 & 5 & 0,28796 & 0,01450 & 0,91004 \\
\hline 7 & CL19 & CL17 & 5 & 0,27222 & 0,01856 & 0,89149 \\
\hline 6 & CL8 & $\mathrm{P}$ & 6 & 0,34485 & 0,02123 & 0,87026 \\
\hline 5 & CL9 & CL7 & 13 & 0,34026 & 0,04643 & 0,82383 \\
\hline 4 & CL14 & CL6 & 8 & 0,42227 & 0,04768 & 0,77616 \\
\hline 3 & CL4 & CL12 & 12 & 0,55276 & 0,15971 & 0,61645 \\
\hline 2 & CL5 & CL3 & 25 & 0,56123 & 0,22682 & 0,38962 \\
\hline 1 & CL2 & $\mathrm{U}$ & 26 & 0,70385 & 0,38962 & 0,00000 \\
\hline
\end{tabular}

Fonte: Dados da pesquisa 